\title{
The design of R\&D alliance contracts
}

Citation for published version (APA):

Dormans, B. L. E. (2013). The design of R\&D alliance contracts. [Doctoral Thesis, Maastricht University]. Datawyse / Universitaire Pers Maastricht. https://doi.org/10.26481/dis.20131121bd

Document status and date:

Published: 01/01/2013

DOI:

10.26481/dis.20131121bd

Document Version:

Publisher's PDF, also known as Version of record

\section{Please check the document version of this publication:}

- A submitted manuscript is the version of the article upon submission and before peer-review. There can be important differences between the submitted version and the official published version of record.

People interested in the research are advised to contact the author for the final version of the publication, or visit the DOI to the publisher's website.

- The final author version and the galley proof are versions of the publication after peer review.

- The final published version features the final layout of the paper including the volume, issue and page numbers.

Link to publication

\footnotetext{
General rights rights.

- You may freely distribute the URL identifying the publication in the public portal. please follow below link for the End User Agreement:

www.umlib.nl/taverne-license

Take down policy

If you believe that this document breaches copyright please contact us at:

repository@maastrichtuniversity.nl

providing details and we will investigate your claim.
}

Copyright and moral rights for the publications made accessible in the public portal are retained by the authors and/or other copyright owners and it is a condition of accessing publications that users recognise and abide by the legal requirements associated with these

- Users may download and print one copy of any publication from the public portal for the purpose of private study or research.

- You may not further distribute the material or use it for any profit-making activity or commercial gain

If the publication is distributed under the terms of Article $25 \mathrm{fa}$ of the Dutch Copyright Act, indicated by the "Taverne" license above, 
The design of $R \& D$ alliance contracts 
The design of R\&D alliance contracts

(C) Bart Dormans, Maastricht 2013

ISBN 9789461592651

Printed by: Datawyse/Universitaire Pers Maastricht 


\title{
The design of $R \& D$ alliance contracts
}

\author{
Proefschrift
}

ter verkrijging van de graad van doctor aan de Universiteit Maastricht, op gezag van de Rector Magnificus, Prof. dr. L.L.G. Soete volgens het besluit van het College van Decanen, in het openbaar te verdedigen op donderdag 21 november 2013, om 10.00 uur

door

Bart Leonardus Elisabeth Dormans

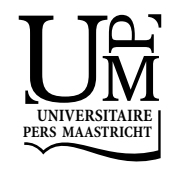




\section{Promotor}

Prof. dr. J. Hagedoorn

\section{Beoordelingscommissie}

Prof. dr. M.A. Carree (voorzitter)

Prof. dr. G. Duysters (Universiteit Tilburg)

Prof. dr. F. Moers 


\section{Acknowledgments}

I am not a fan of extensive acknowledgments bereft of purpose. Yet, I would like to mention a few individuals without whom writing this dissertation would have not been possible:

John Hagedoorn as my promotor;

Martin Carree, Geert Duysters and Frank Moers as my assessment committee;

Geerte Hesen for sharing her data with me and advice on law-related matters;

Hans Frankort, Katrin Hussinger and Wilko Letterie for constructive feedback;

The Department of Organization and Strategy at Maastricht University and The Graduate School of Arts and Sciences at Harvard University;

Ranjay Gulati for sponsoring my stay at Harvard University;

My mother, father, Roel, family, friends and colleagues;

My girlfriend Emel;

Pierre Bovens as my late grandfather and for standing behind my decisions no matter what.

Thank you. 



\section{Table of Contents}

List of Tables, Figures, and Appendices …......................................................................

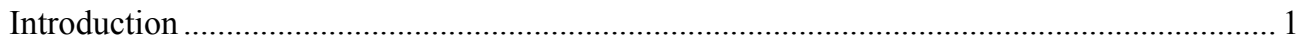

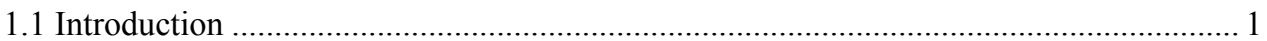

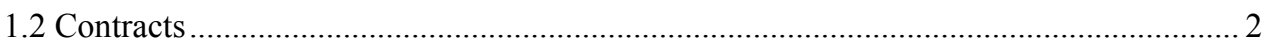

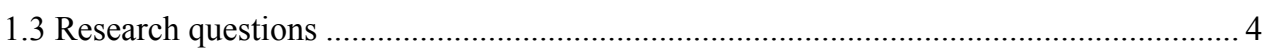

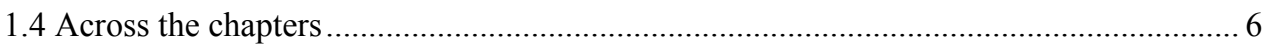

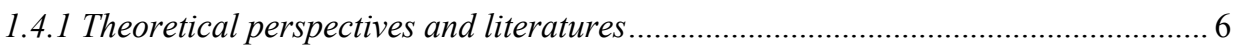

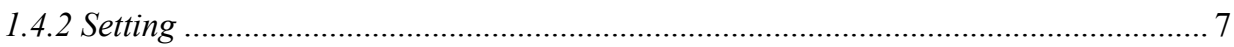

1.4.3 Alliance types and conditional sampling ............................................................. 8

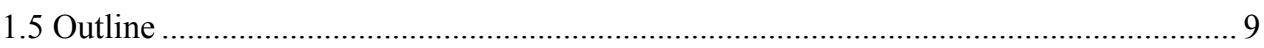

The Allocation of Intellectual Property Control Rights in R\&D Alliances: the Bargaining Power of Primary Technology Supplying Firms................................................................ 11

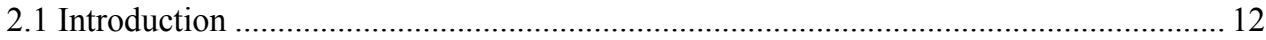

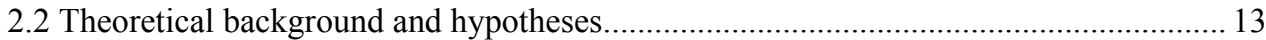

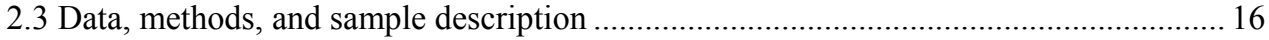

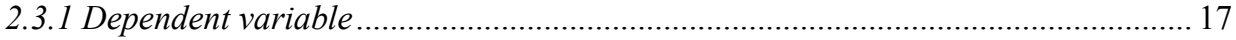

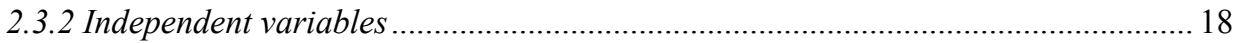

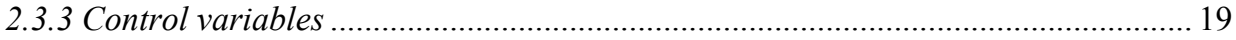

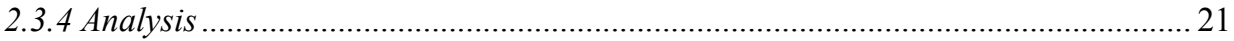

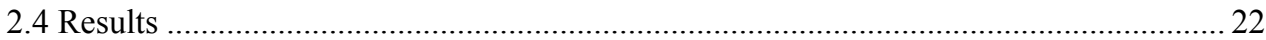

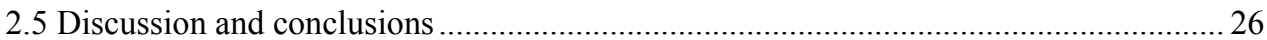

R\&D Alliance Contracts in the Biopharmaceutical Industry: the Stipulation of Contractual

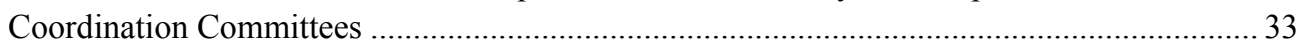

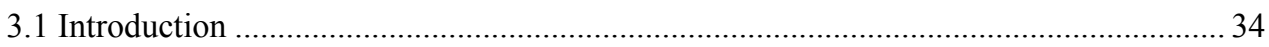

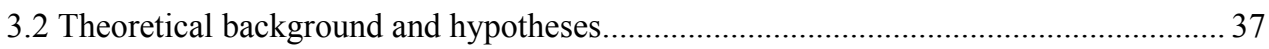

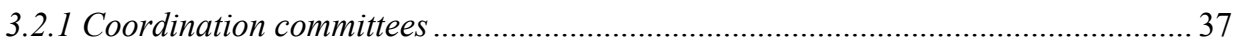

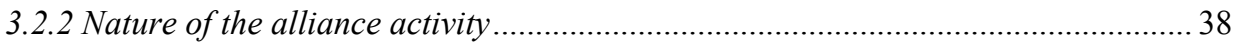

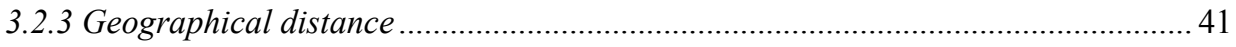

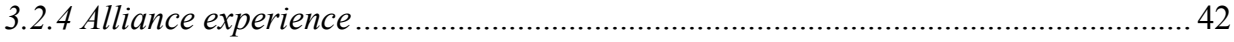

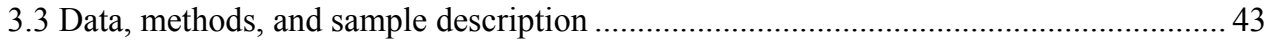

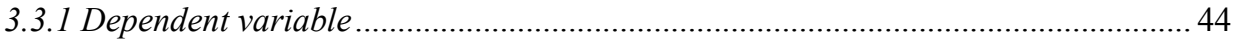

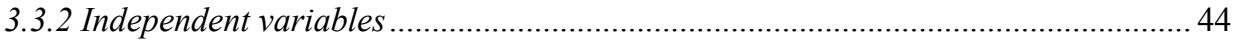

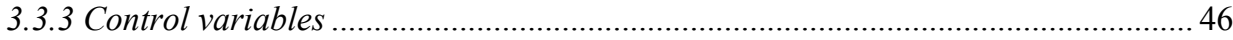




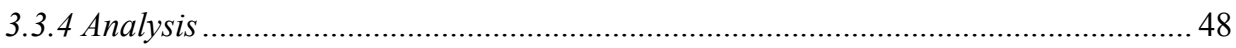

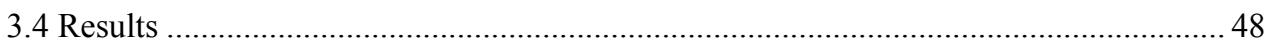

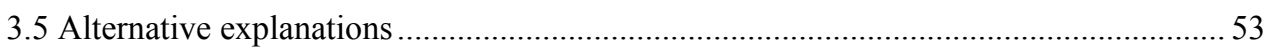

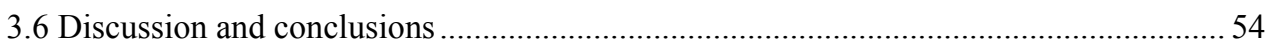

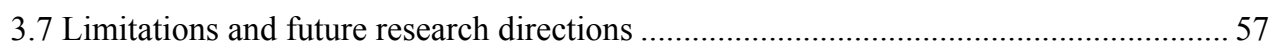

The Contractual Governance of Disputes in Biopharmaceutical Alliances ..............................5 59

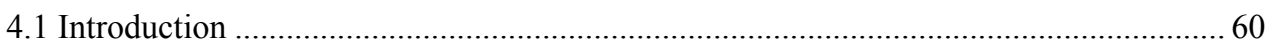

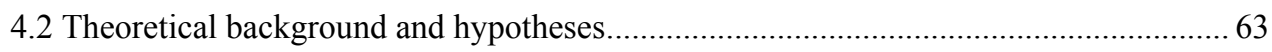

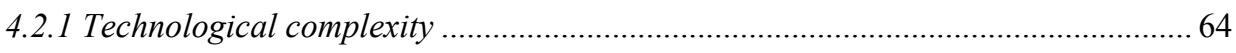

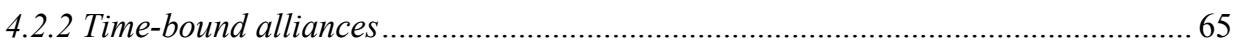

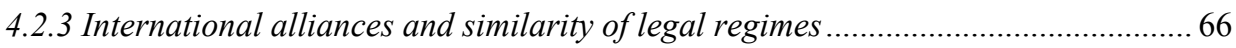

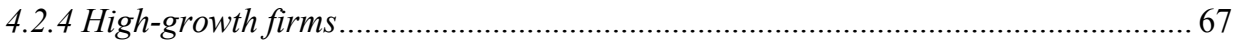

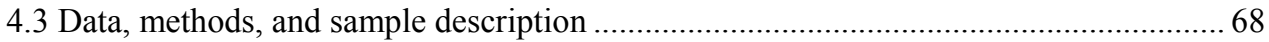

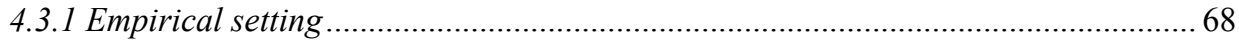

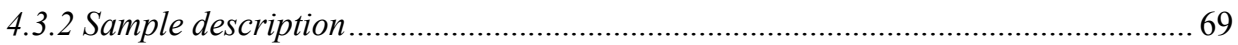

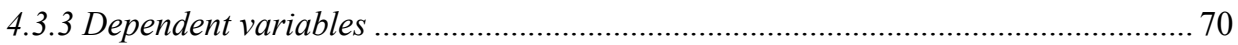

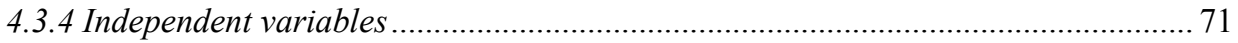

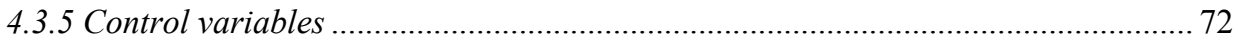

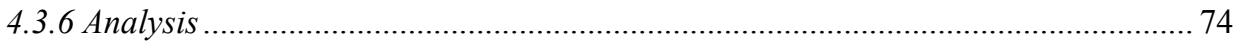

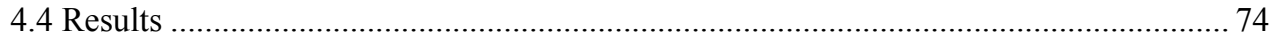

4.5 Alternative explanations and robustness checks ...................................................... 79

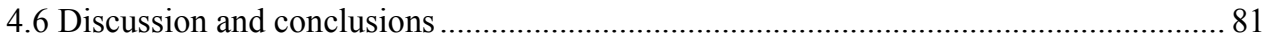

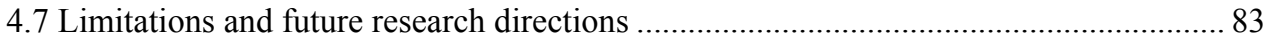

Current Employee, Future Competitor? Limiting the Outflow of Human Capital to

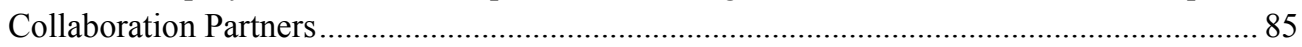

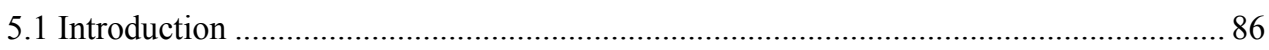

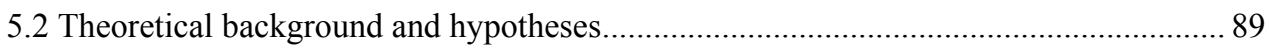

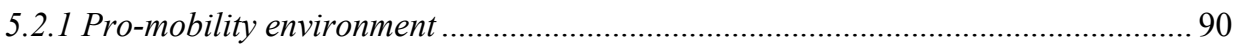

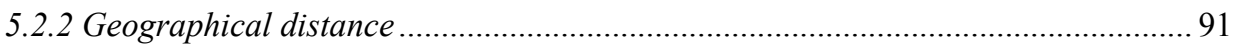

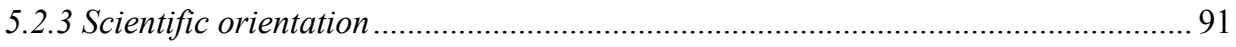

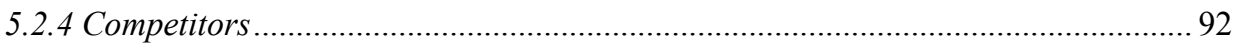

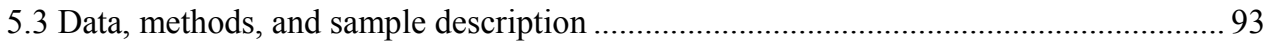

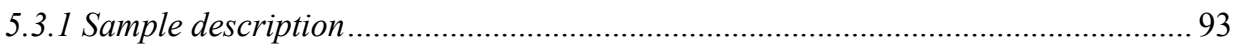

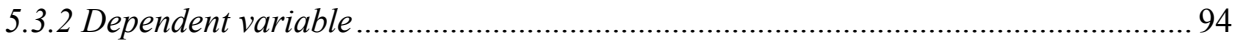

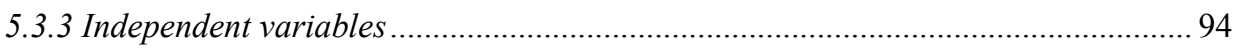




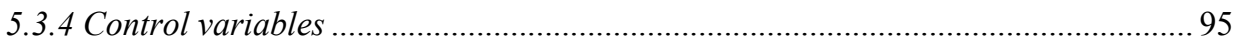

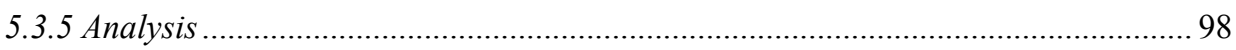

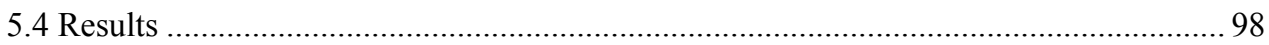

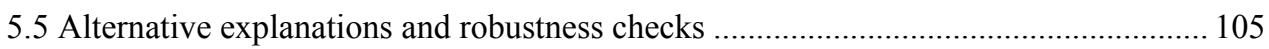

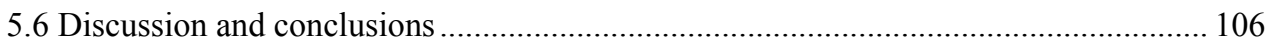

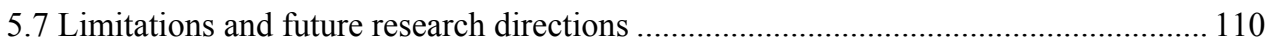

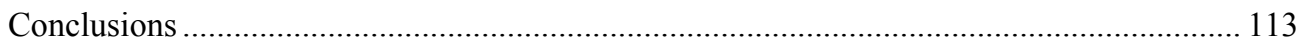

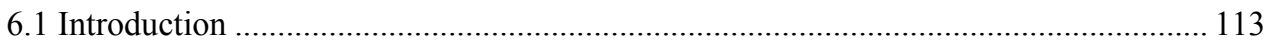

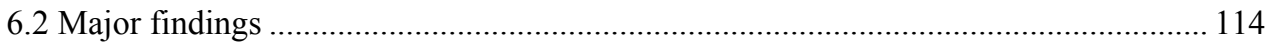

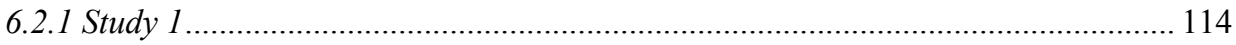

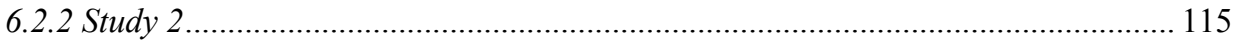

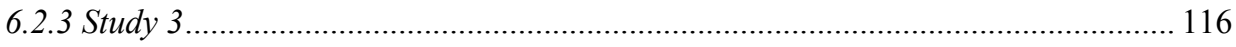

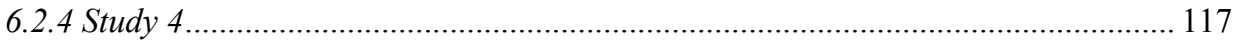

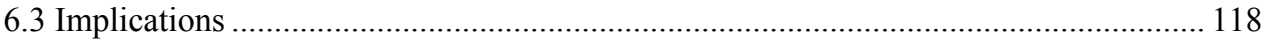

6.4 Limitations and suggestions for further research ................................................. 120

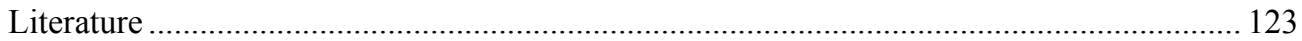

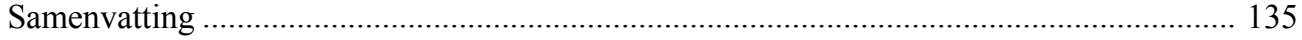

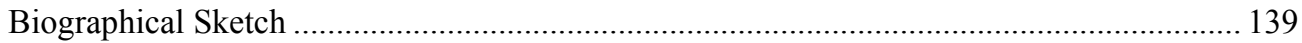





\section{List of Tables, Figures, and Appendices}

\section{Tables}

Table $2.1 \quad$ Descriptive statistics rights

Table 3.1

Descriptive statistics

Table 3.2

Poisson model estimation results of coordination committees

Table 4.1 Descriptive statistics Probit or Bivariate Probit model estimation results of internal dispute 78

Table 4.3 resolution and/or arbitration

Table 5.1 Internal dispute resolution and arbitration Design of contractual employee mobility restrictions $\quad 100$

Table 5.2 Descriptive statistics

Table 5.3 Probit model estimation results of employee mobility restrictions

\section{Figures}

Figure 1.

$$
\text { New molecular entity (NME) approvals }
$$

\section{Appendices}

$\begin{array}{lll}\text { Appendix 2.1 Intellectual property control rights } & 30\end{array}$

Appendix 2.2 Summary statistics of the sample 31

Appendix 2.3 Innovative capabilities asymmetry based on patenting intensity 32 



\section{Introduction}

\subsection{Introduction}

This dissertation encompasses four studies on the design of $R \& D$ alliance contracts. My research question can be stated as follows: what factors influence, or are associated with, the design of R\&D alliance contracts in the biopharmaceutical industry? In order to address this general research question, I later spell out four more specific research questions.

An interfirm alliance is an arrangement through which partners share resources and assets, which can take a variety of organizational forms and refer to a wide range of motives and goals (Hagedoorn, 1993; Gulati and Singh, 1998). One specific example of interfirm collaborations are R\&D alliances (Hagedoorn, 1993). Over the last few decades, R\&D alliances have become a prominent mechanism by which firms reach beyond organizational boundaries. Throughout the 1960s the number of yearly established R\&D alliances fluctuated between (nearly) 0 and 10, rising to around 700 in the year 1995 (Hagedoorn, 2002). Interestingly, the increase in the absolute number of yearly established R\&D alliances in the period 1960-1998 is accompanied by a relative decrease in the share of joint ventures, i.e., the increase in the absolute number of R\&D partnerships in the period 1960-1998 can be mainly attributed to an increase in the absolute number of contractual partnerships (Hagedoorn, 2002). Given the proliferation of contractual R\&D partnerships over the last decades, research in this field has the potential to contribute to an increased understanding of an especially salient aspect of firms' strategies in the high-technology sector.

The increased propensity of firms to participate in R\&D alliances over the last years did not go unnoticed by the academic community (Frankort, 2010). A burgeoning stream of literature on alliances developed that covers areas such as the choice of parties to opt for particular governance structures (Gulati, 1995; Gulati and Singh, 1998, Oxley, 1997), the tension between cooperation and competition (Hamel, 1991), firm performance effects (Baum, Calabrese and Silverman, 2000; Hagedoorn and Schakenraad, 1994), and more. Only recently strategy scholars have started to advance research on alliance governance structures by paying specific attention to the actual contracts that govern the relationship between alliance partners (Adegbesan and Higgins, 2011; Argyres, Bercovitz and Mayer, 2007; Argyres and Mayer, 2007; Ariño and Reuer, 2004; Furlotti, 2007; Hagedoorn and Hesen, 2007; Lerner and Merges, 1998; Lerner and Malmendier, 2010; Panico, 2011; Reuer and Ariño, 2007; Reuer, Ariño and Mellewigt, 2006; Ryall and Sampson, 2009). This dissertation aligns with research on alliance governance structures, and more in particular, with research that investigates the design of (R\&D) alliance contracts. Given the plethora of different contractual clauses that firms can implement in their contracts, cruder measures to distinguish 
between different governance structures might provide a somewhat blurred, i.e., disaggregated from reality, picture of the actual contracts underlying alliances. As such, this dissertation seeks to provide a more fine-grained perspective on the governance of alliances by specifically investigating R\&D alliance contracts. To do so, I first need to define the notion of a 'contract', especially in the context of R\&D alliances.

\subsection{Contracts}

As already stated by Adam Smith; "[the propensity to truck, barter, and exchange one thing for another] is common to all men, and to be found in no other race of animals, which seem to know neither this nor any other species of contracts" (Smith, 1979; p. 12). For instance, consider the following exchange of goods:

Illustration: Seller agrees to deliver books to Buyer. In return for this delivery of books, Buyer agrees to pay Seller $\$ 400$ within 14 days.

Such voluntary commitment is essentially a contract whereby Buyer promises to exchange cash for books, delivered by Seller (Farnsworth, 1969). A fairly common, legal, definition of 'contract' is specified in the Restatement of Contracts: "A contract is a promise or set of promises for the breach of which the law gives a remedy, or the performance of which the law in some way recognizes as a duty" (Cited in Goldberg, 1976; p. 46 and Macneil, 1974; p. 693). Economists somewhat diverge from this definition by defining a contract as "an agreement under which two parties make reciprocal commitments in terms of their behaviora bilateral coordination arrangement" (Brousseau and Glachant, 2002; p. 3). Over the years, legal scholars have proposed alternative views on the notion of contract (law) (Hesen, 2010). By and large, legal scholars distinguish between classical, neoclassical, and relational contract law (Macneil, 1978). ${ }^{1}$ An important role in distinguishing between different perspectives on contract law is reserved for the concept of 'discrete transactions'. Macneil (1978; p. 856) describes a discrete transaction as follows:

"A truly discrete exchange transaction would be entirely separate not only from all other present relations but from all past and future relations as well. In short, it could occur, it at all, only between total strangers, brought together by chance (not by any common social structure, since that link constitutes at least the rudiments of a relation outside the transaction). Moreover, each party would have to be completely sure of never again seeing or having anything else to do with the other. (...) Moreover, everything must happen quickly lest the parties should develop some kind of a relation impacting on the transaction so as to deprive it of discreteness. For example, bargaining about quantities or other aspects of the transaction can erode discreteness, as certainly does any effort to project the transaction into the future through promises."

\footnotetext{
${ }^{1}$ The objective here is not to fully specify all differences between classical, neoclassical and relational contract law. Rather, I point towards differences between classical and neoclassical contract law relevant for introducing my four studies. It suffices to state here that a particularly salient difference between neoclassical and relational contract law is that under the former the contract still maintains its function as a reference point.
} 
One example that comes close to being characterized as a truly discrete exchange transaction would be a foreign traveler purchasing an apple at a local grocery store. Classical contract law supports such discrete transactions (Ring and van de Ven, 1992), and offers, as stated by Hagedoorn and Hesen (2007; p. 344), some specific legal recommendations:

"The classical contracting perspective can also be characterized by the following legal recommendations: account for as much of the subject matter of the contract as possible; avoid open-ended agreements; restrict the sources used to define the content of the agreement, i.e., formal documents are preferred over informal communication; limit the amount of contractual remedies available to parties; and court enforcement is the preferred method of dispute resolution."

Although the above adequately describes a plethora of simple day-to-day transactions, for many transactions classical contract law falls short (Goldberg, 1976). A large number of transactions take place over a somewhat longer period of time, where parties frequently exchange goods and engage in complex and uncertain activities where transaction costs inhibit the drafting of complete contracts (Goldberg, 1976; Hagedoorn and Hesen, 2007; Macneil, 1978; Ring and van de Ven, 1992; Williamson, 1979; 1985). One example of the foregoing are R\&D alliance agreements that describe collaborations between firms that take place over several years, include complex technologies, and where the ultimate pay-off is inherently uncertain. It is conceivable that in such a complex and uncertain setting contracts are inevitably incomplete, i.e., it would strain credulity to assume that R\&D alliance parties are able to ex-ante specify all contingencies and contractual responses and not able to make ex-post efficiency alterations (Furlotti, 2007). It is indeed very likely that practitioners, even when assuming 'farsighted contracting' (Williamson, 1996), cannot draft complete contracts (Mellewigt, Decker and Eckhard, 2012). Incomplete contracts are especially problematic if we assume that alliance parties are given to opportunism (Williamson, 1981). Neoclassical contract law recognizes that contracts in many real-world settings are incomplete, and that an abrupt ending of an alliance entails severe economic costs for one or both parties involved, as is common when joint R\&D is involved (Pisano, 1989). A contract is therefore not to be seen as a mere summation of legal rules, but also as a guiding mechanism for interfirm collaboration. Following amongst others Llewellyn (1931), Macneil (1978; 2000) and Williamson (1979; 1996), a contract can serve as a framework that governs the relationship between organizations. Assuming contracts are inevitably incomplete (Williamson, 1996), certain important contract design decisions emerge relating to control (Adegbesan and Higgins, 2011; Elfenbein and Lerner, 2012; Grossman and Hart, 1986; Haeussler and Higgins, 2009; Lerner and Merges, 1998), coordination in a broad sense (Adler, 1995; Grandori, 1997; Gulati and Singh, 1998; Reuer and Ariño, 2007; Salbu, 1997; van de Ven, Delbecq and Koenig; 1976), dispute resolution (Allison, 1990; Bernstein, 1992; Bonn, 1972; Eisenberg and Miller, 2007; Johnson, McMillan and Woodruff, 2002; Lumineau and Oxley, 2012; Rubinstein, 2004; Williamson, 1991), and particular contractual safeguards such as limitations on parties' hiring behavior (Hamel, 1991; Hyde, 2012; Reuer and Ariño, 2007; De Rond and Bouchikhi, 2004; Somaya, Williamson and Lorinkova, 2008). These four elements of contract design guide the four empirical chapters incorporated in this dissertation. 


\subsection{Research questions}

In broad terms, the four studies reported here seek to answer which factors influence, or are associated with, the design of R\&D alliance contracts. Recently, several studies have attempted to shed a light on the design of alliance contracts (e.g. Hagedoorn and Hesen, 2007; Poppo and Zenger, 2002; Reuer and Ariño, 2007), thereby moving beyond a traditional view on contracts as mere legal safeguarding mechanisms and recognizing their role in controlling alliance partners' behavior and promoting interfirm coordination (Mellewigt, Decker and Eckhard, 2012). By and large, the bulk of studies on alliance contract design have focused on the notion of contractual complexity (Anderson and Dekker, 2005; Barthélemy and Quélin, 2006; Luo, 2002; Poppo and Zenger, 2002; Reuer and Ariño, 2007; Ryall and Sampson, 2009; Sobrero and Roberts, 2002), largely inspired by Parkhe's (1993) measure for ex-post deterrents. By now, several studies have investigated the antecedents of contractual complexity of alliance contracts (e.g. Anderson and Dekker, 2005; Barthélemy and Quélin, 2006; Poppo and Zenger, 2002, Sobrero and Roberts, 2002), and the consequences of contractual complexity (Ariño, Ragozzino and Reuer, 2008; Luo, 2002; Poppo and Zenger, 2002; Helm and Kloyer, 2004). Although these contributions have provided valuable insights in the design of alliance contracts, many suffer from an inherent weakness, i.e., contractual complexity is an aggregate measure that subsumes many different contractual functions. Reuer and Ariño (2007) brought attention to the multidimensional nature of alliance complexity, and contracts in general, by dividing Parkhe's (1993) measure in enforcement provisions and coordination provisions. Although it would strain credulity to claim that all individual contractual provisions fall neatly within a predefined categorization of contract functions, the main idea is that a general measure of contractual complexity oversees many of the idiosyncrasies of individual contracts, and that one needs to examine contracts more in detail to get a well-balanced grasp of alliance contract design (Poppo and Zenger, 2002).

The studies reported here examine the multifaceted nature of $R \& D$ alliance contracts. In that sense, I seek to answer the call by Coase (1992) who encourages more research that studies the process of contracting between companies in a 'real-world setting'. In order to answer my overall research question, I seek to answer four sub questions that recognize distinct functions of R\&D alliance contracts. Because of the more exploratory nature of many of the studies incorporated in this dissertation, three out of the four sub questions are formulated quite generally. First, previous literature signals the importance of 'control' when contracts are inevitably incomplete (Grossman and Hart, 1986), and several contributions consequently study the allocation of control rights in interfirm arrangements (e.g. Adegbesan and Higgins, 2011; Higgins, 2007; Lerner and Merges, 1998). Given that contracts are inevitably incomplete, control, whether through asset ownership or specific decision making rights, is important as it delineates which (alliance) contract party can make certain decisions when contingencies arise (Hart, 1989). Most previous work on control rights studies the allocation of control rights in a 'small biotechnology - large pharmaceutical' setting, based on a set of control rights identified by Lerner and Merges (1998). Based on the argument that the market structure since the late 1990s has changed, I divert from previous contributions by studying the allocation of intellectual property control rights to the primary, initial technology supplying firm, irrespective of its size and its industry background. More specifically, I ask: 
How is the bargaining power of initial, primary technology supplying firms associated with the number of intellectual property control rights allocated to these firms in $R \& D$ alliance contracts?

Essentially, chapter 2 investigates a more narrow set of control rights, i.e. intellectual property control rights, compared to most of the previous literature (e.g. Lerner and Merges, 1998), while incorporating a broader set of conditions that might influence the bargaining position of the initial, primary technology supplying firm.

Second, in chapter 3 I aim to highlight the coordination aspect of contracts by focusing on coordination committees. Prior work indicates that when contracts are incomplete, i.e., when it is prohibitively costly to incorporate responses to all possible contingencies in a contract, the contract serves an important function as a framework that promotes social order and cooperation (Llewellyn, 1931; Macneil, 1978; 2000; Williamson, 1979; 1996). Although coordination within firms has received substantial attention in previous literature (e.g. Adler, 1995; van de Ven, Delbecq and Koenig, 1976), the coordination aspect of R\&D alliance contracts has received only scant attention in literature. Therefore I ask:

What factors are associated with the stipulation of more or less interfirm coordination provisions in $R \& D$ alliance contracts?

This second research question takes a more supportive and cooperative perspective on $R \& D$ alliance contracts compared to many previous contributions that (Furlotti, 2007), for instance, study the allocation of unilateral control rights. Moreover, chapter 3 moves beyond equating contractual complexity with interfirm coordination, by specifically investigating contractual mechanisms aimed at facilitating interfirm coordination. Studying interfirm coordination is important, as several previous contributions hint at the proposition that alliances lacking a certain level of interfirm coordination are more likely to fail (Doz, 1996; Park and Ungson, 2001).

Third, in chapter 4 I seek to explore contractual mechanisms that determine how alliance parties will resolve any future disputes. In complex and uncertain environments it is inevitable that alliance parties will have to deal with disputes during their collaboration (Mayer and Teece, 2008), i.e., around two thirds of all alliances run into serious disputes within the first two years of collaboration (Das and Teng; 2000a; Koza and Lewin, 2000). It is therefore not surprising that alliance parties foresee the possibility of their collaboration ending in a dispute and design contracts accordingly. Previous contributions that touch upon dispute resolution highlight that over time alliance parties more clearly stipulate roles and responsibilities to avoid future disputes (Argyres and Mayer, 2007; Argyres, Bercovitz and Mayer, 2007), or aggregate dispute resolution clauses in more general measures of contractual complexity (Lumineau and Quélin, 2012; Parkhe, 1993; Reuer and Arińo, 2007). Nevertheless, the literature on alliance contracts seems conspicuously bereft of any empirical evidence regarding dispute resolution clauses. I intend to contribute to existing literature by asking:

What factors are associated with the stipulation of particular dispute resolution clauses in $R \& D$ alliance contracts? 
In broad terms, this third research question contributes to a burgeoning stream of literature on non-traditional dispute resolution mechanisms (e.g. Bonn, 1972; Bernstein, 1992; Mattli, 2001). Studying these non-traditional dispute resolution mechanisms is important, as it can point towards inefficiencies of the traditional legal system. Moreover, chapter 4 highlights that different contractual dispute resolution mechanisms are associated with different factors.

Fourth, in chapter $5 \mathrm{I}$ investigate contractual limitations on the hiring behavior of collaborating firms. Prior work indicates that over time alliance parties get a good feel for each other's resources and capabilities (Das and Teng, 2000b; Hamel, 1991), such as key employees. Absent an R\&D collaboration, specific contributions of individual employees to the overall success of 'Firm A' are, to a large extent, unobservable to 'Firm B'. It is reasonable to suspect that firms are concerned about employee poaching during or after a collaboration. Recent contributions illustrate that within collaborative endeavors it indeed occurs that one firm entices employees of the other firm to cancel their employment in response to a job offer (see De Rond and Bouchikhi, 2004). Although the literatures on alliances, employee mobility, and employee poaching are generally well-developed, our knowledge about contractual limitations on the hiring behavior of firms participating in an $\mathrm{R} \& \mathrm{D}$ alliance is limited. Reducing the risk of employee poaching is important for firms, as it diminishes the chance of information leakage as a negative byproduct of an alliance (Oxley and Wada, 2009). Therefore I ask:

What factors are associated with the stipulation of employee mobility restrictions in $R \& D$ alliance contracts?

This fourth research question combines literatures on alliances, employee mobility, and employee poaching. It that sense, it moves beyond general measures of contractual safeguards (Parkhe, 1993), and specifically investigates those cases in which parties voluntarily limit their hiring behavior. Chapter 5 complements a study by Reuer and Ariño (2007), who highlight that alliance parties can limit each other's hiring behavior via contract, but leave further examination of these clauses to future research. In addition, chapter 5 speaks to a recent stream of literature on competitor recruitment that highlights the frequent use of employee poaching by firms to gain a competitive advantage (e.g. Horn, 2011), especially in more research-intensive industries.

\subsection{Across the chapters}

Each chapter in this dissertation revolves around a distinct element of contract design. Across the chapters some key similarities emerge along with restrictions on the scope of this dissertation.

\subsubsection{Theoretical perspectives and literatures}

Across and within each chapter I employ a range of different theoretical perspectives and literatures. For instance, in chapter 2, where I study the allocation of intellectual property control rights to the primary technology supplying firm, I take a bargaining view on R\&D alliance contracts in which more dominant firms are assumed to be able to extract more favorable contracting terms. By comparison, in chapter 3, drawing from more general 
organizational economics, strategy, and organization literatures on the design of contracts, I postulate relationships between the degree of interfirm coordination as suggested by the actual contracts, and the nature of alliance activities, geographical distance, and a more dynamic element relating to previous alliance experience. Then, in chapter 4, I couple elements of Transaction Cost Economics (TCE) theory with literature on alternative dispute resolution mechanisms to derive predictions regarding the use of certain contractual dispute resolution mechanisms in R\&D alliances. Last, in chapter 5, I rely on parts of TCE theory to form predictions regarding the use of contractual employee mobility restrictions while simultaneously acknowledging the role of the institutional environment in which firms reside. The use of different theoretical perspectives and literatures epitomizes my conviction that, based on empirical findings by Reuer and Ariño (2007), contract design is multidimensional. As such, lest I am to provide but a partial picture of contract design, I cannot solely rely on one theoretical perspective or stream of literature to explain the use of various contractual provisions by parties.

\subsubsection{Setting}

All studies in this dissertation focus on $R \& D$ alliances within the biopharmaceutical industry in the period 1996-2005. The biopharmaceutical industry is a well-suited arena to test my theoretical predictions for three reasons.

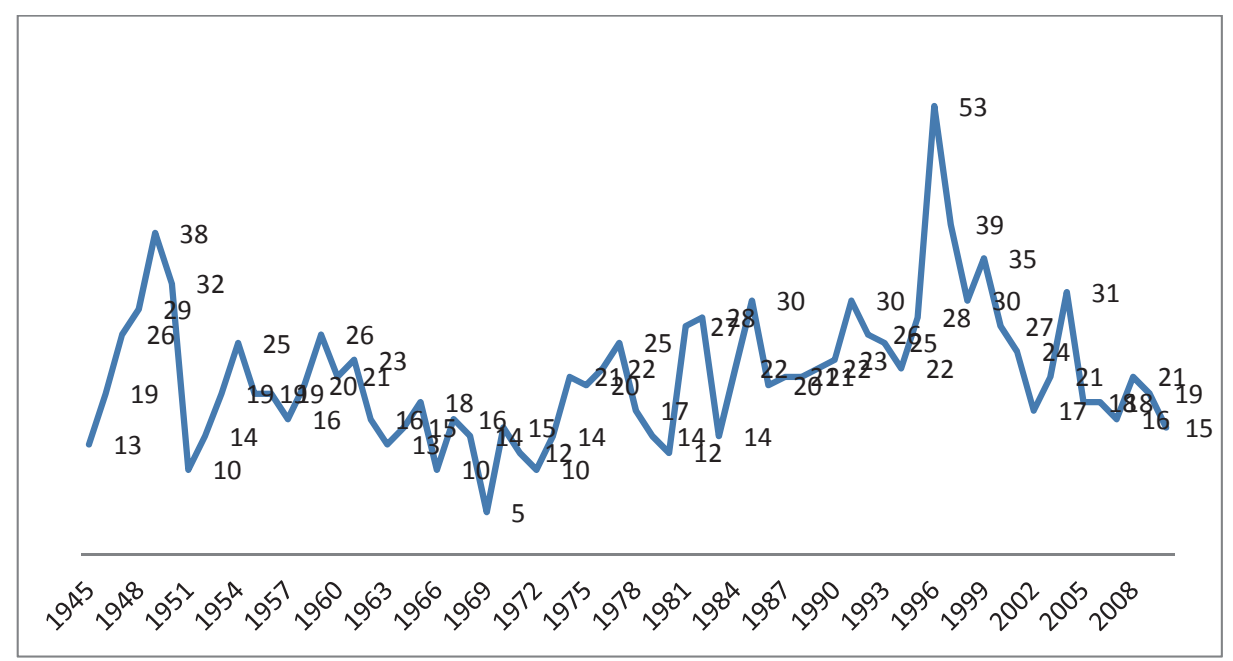

Figure 1.1: New molecular entity (NME) approvals.

Notes: Data retrieved from the FDA. Adjusted after 2004 because of inclusion Biologic License Applications.

First, biopharmaceutical alliances closely match the setting depicted in literature as they are inherently complex, uncertain, and costly (Lerner and Merges, 1998). Therefore, by and large, biopharmaceutical alliance contracts will be inevitably incomplete giving rise to, for instance, control and enforcement issues (Grossman and Hart, 1986; Lerner and Merges, 1998). Moreover, since biopharmaceutical alliances are costly and risky - figure 1.1 shows that only a limited number of NME's (substances that have never, in any form, been approved for marketing before) get approved each year by the FDA - parties will diligently design the 
associated contracts, i.e., contracts in the biopharmaceutical industry are unlikely to be characterized by a haphazard collection of clauses. Second, the potential pay-off of biopharmaceutical projects. i.e., alliances, is substantial which leads to strong competitive pressures between firms (Shan, Walker and Kogut, 1994). While the number of NME approvals seem to fluctuate around 20 per year (see figure 1.1), industry R\&D expenses appear to be increasing. In terms of the design of $R \& D$ alliance contracts, these competitive pressures can cause friction between parties as they seek to balance cooperation - for instance, by stipulating contractual coordination committees - with competition - for instance, by implementing contractual restrictions on hiring behavior - in the design of their collaboration agreements (Das and Teng, 2000a). Third, firms in the biopharmaceutical industry are responsible for a large share of the total alliance activity in the high-technology sector. More specifically, Roijakkers and Hagedoorn (2006) show that in the year 1999 out of approximately 500 newly established R\&D partnerships, around 150 newly established R\&D partnerships were formed in the biopharmaceutical industry, i.e., roughly $30 \%$. As such, given the potential generalizability to the realm of high-technology alliances, R\&D alliances in the biopharmaceutical industry are suitable subjects for this dissertation as they represent a large share of all R\&D alliances. Nevertheless, for the sake of completeness and with regards to the scope of the current dissertation, I note that particular findings of this dissertation might be idiosyncratic to the biopharmaceutical industry and should be extrapolated with care, especially to non-high-technology alliances.

\subsubsection{Alliance types and conditional sampling}

I focus on collaborative R\&D alliances in the biopharmaceutical industry for which an actual contract was drawn up. These contracts were obtained from the U.S. Securities and Exchange Commission (SEC) and Pharmaventures' clients. In addition, alliances were excluded in case (1) one of the parties is a government agency or university or (2) an alliance is a renegotiation or restatement of a previous alliance between firms or (3) one firm has a controlling interest in the other firm or (4) more than two parties are involved. In that sense, I created a population free of undesirable heterogeneity akin to the procedure followed by Lerner and Merges (1998). The aforementioned directly implies that certain interfirm arrangements (e.g. multiparty alliances) fall outside the scope of the current dissertation.

By and large, I examine the inclusion of certain clauses in R\&D alliance contracts, and therefore take these contracts as a given. Implicit in my analyses is that, per observation, two firms engage in a collaborative $R \& D$ alliance in the biopharmaceutical industry and that a contract is drawn up to guide their collaborative endeavor. As already mentioned by Frankort (2010), this form of selective sampling is quite common, but poses limitations on the extent to which I can generalize findings to, for instance, all firms. Previous research suggests that firms that engage in R\&D alliances are likely to differ systematically from firms that do not (Frankort, 2010). For instance, compared to firms that do not engage in alliances, firms that engage in $R \& D$ alliances may be in a better position to evaluate external opportunities (Cohen and Levinthal, 1990), be characterized by their strategic vulnerability (Eisenhardt and Schoonhoven, 1996), pursue different strategies (Koza and Lewin, 1998), or have more complementary assets to offer (Hagedoorn, 1993). Referring to the stipulation of contracts, previous research hints at the proposition that formalized transactions differ from nonformalized transactions in a number of aspects (Mellewigt, Decker and Eckhard, 2012). By 
merely focusing on alliances for which an actual contract is created, this dissertation might underrepresent trusting relationships (Macaulay, 1963), or overly represent those alliances characterized by substantial exchange hazards (Poppo and Zenger, 2002). One should take care when extrapolating findings in this dissertation to those firms that do not engage in $R \& D$ alliances or to interfirm arrangements for which no formal contract is stipulated.

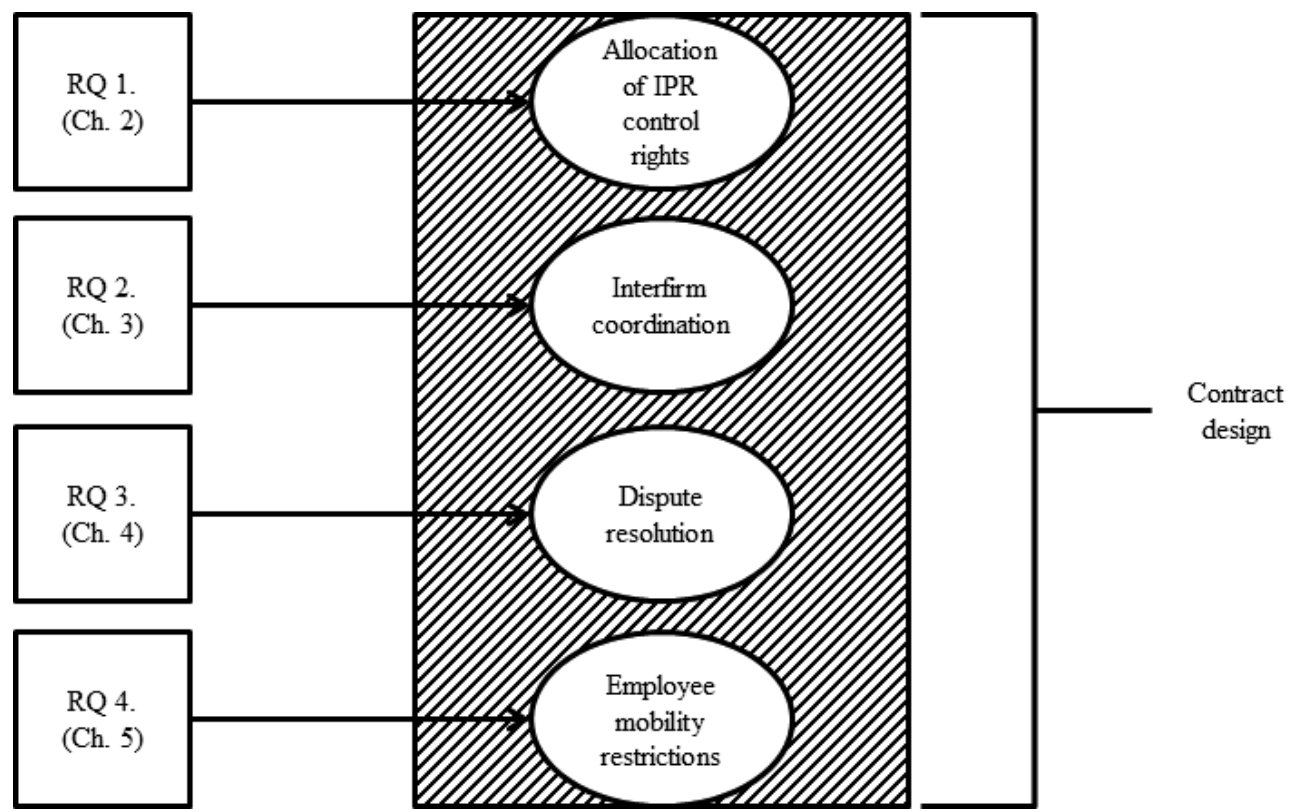

Figure 1.2: Overview of the dissertation and the specific research questions.

\subsection{Outline}

In figure 1.2 an overview of the dissertation and the specific research questions is given. Each of the following four chapters addresses one of the research questions described in section 1.3 and shown in figure 1.2. Chapter 2 will investigate how the bargaining power of the initial, primary technology supplying firm is associated with the number of intellectual property control rights allocated to this firm. As the alliance process is often more cooperative than envisioned in much of the literature (Grandori, 1997), chapter 3 will move away from a focus on control and highlight another function of contracts as devices to promote interfirm coordination. Then, chapter 4 will revolve around the contractual stipulation of particular dispute resolution clauses. The chapter responds to the emerging role of alternative dispute resolution mechanisms (Bernstein, 1992), by investigating the use of specific dispute resolution clauses in $\mathrm{R} \& \mathrm{D}$ alliance contracts. Chapter 5 will seek to answer how parties design contractual limitations on hiring behavior, and when these clauses are most likely to be implemented by contract parties. All four chapters that revolve around answering each individual research question postulated in section 1.3 are fully self-contained and can be read separately. Chapter 6 summarizes the findings of this dissertation, highlights its implications, and gives some possible research directions for future contributions to the field of alliance contract design using the shaded area in figure 1.2 as a starting point. 



\title{
The Allocation of Intellectual Property Control Rights in R\&D Alliances: The Bargaining Power of Primary Technology Supplying Firms ${ }^{2}$
}

\begin{abstract}
This study examines intellectual property control rights that refer to contractual obligations regarding the ownership and decision making on the use of inventions, technology, and technology transfer, allocated to $\mathrm{R} \& \mathrm{D}$ alliance contract partners. The empirical setting is found in the biopharmaceutical industry. In recent decades the biopharmaceutical industry has developed beyond the stereotype large pharma - small biotech dichotomy in R\&D alliances. In that context, it appears relevant to pay special attention to the role of the alliance partner that can be characterized as the primary, initial technology supplying firm, irrespective of its size and its industry background. More in particular, I take a closer look at the allocation of intellectual property control rights to the primary technology supplying firm. The findings show that the stronger the bargaining power of the primary technology supplying firm vis-àvis its partner in terms of its innovative capabilities asymmetry, rather than a firm size basedasymmetry, the more intellectual property control rights are allocated to that firm. Also, the technological breadth of an R\&D alliance, based on the initial technology input from the primary technology supplying firm, generates a larger number of intellectual property control rights assigned to that firm.
\end{abstract}

\footnotetext{
${ }^{2}$ This chapter is based on collaborative work with John Hagedoorn. I thank Hans Frankort, Carolin Haeussler, Geerte Hesen, Matt Higgins, Aija Leiponen, Ammon Salter, participants at seminars at Grenoble Graduate School of Business, Imperial College London, Maastricht University, and the Sorbonne Graduate Business School, and participants at the Society for Empirical Legal Studies conference at Yale University and the American Law and Economics Association conference at Columbia University for helpful suggestions and comments on earlier versions of this paper.
} 


\subsection{Introduction}

In recent years there is a gradual increase in the number of empirical studies on contract design, including studies that focus on interfirm alliances and the allocation of control rights to alliance partners. These control rights refer to provisions in alliance contracts that give a contract party, i.e., an alliance partner, certain rights with regard to ownership and decision making. In the current contribution I study control rights allocated to the firm that is the initial source of the technology that is developed further or used within an R\&D alliance in the biopharmaceutical industry. Control rights are critical to any sort of interfirm alliance but, compared to other alliances, for instance manufacturing or marketing alliances, even more so in case of $R \& D$ alliances. In particular with $R \& D$ alliances it is difficult for firms to ex-ante calculate future innovation rents created by their joint R\&D and to decide about the actual distribution of these rents among partners. Hence, it is reasonable to expect that the allocation of control rights plays an important role in the negotiation of alliances and the design of alliance contracts.

The empirical setting for this study is the biopharmaceutical industry, which has become one of the main fields, if not the main field, of R\&D partnering and as such it is very representative for the high-tech setting of R\&D alliances (Hagedoorn, 2002). In that context, my paper differs from the existing body of empirical literature with respect to a number of crucial elements. Most previous studies (Adegbesan and Higgins, 2011; Bosse and Alvarez, 2010; Haeussler and Higgins, 2009; Higgins, 2007; Lerner and Merges, 1998; Lerner, Shane and Tsai, 2003; Panico, 2011) consider a typical 'large pharma - small biotech' alliance setting that appears to have been most relevant for understanding the market structure of the biopharmaceutical industry during the 1980s and early 1990s. However, since the 1990s the biopharmaceutical industry has developed towards an industry that is less characterized by a dual market structure. As explained in both the academic and the practitioner's literature (Chiaroni, Chiesa and Frattini, 2008; Cooper, 2007; Ohba and Figueiredo, 2007; Roijakkers and Hagedoorn, 2006), in recent decades many small biotech firms, that were not acquired, have developed to medium sized firms and some have even developed into 'regular' pharmaceutical firms. Such developments have led to a market structure where interfirm alliances are established by a range of firms, from large and medium sized pharmaceutical and chemical firms, to medium sized product biotech firms, and small and medium sized specialist biotech firms. The academic and practitioner's literature also reveals that with these changes, small dedicated biotechnology firms are no longer the primary source of innovation that led to the prevalence of small biotech - large pharma alliances as the innovation and alliance process is currently distributed over a broader range of firms (see also CATI, 2012). In line with both this new market structure and parallel pattern in $R \& D$ alliances in the biopharmaceutical industry, this paper covers a wider range of collaborative R\&D efforts, with various combinations of different categories of firms, such as small, medium-size and larger biotech firms, medium-size and large pharmaceutical firms, and large diversified chemical firms (see also Appendix 2.2, panel B).

In the current analysis, given its broader perspective, the allocation of control rights is viewed from the perspective of the firm that, irrespective of its size, is the initial source of the technology that is developed further or used within the alliance. I label that firm as the primary technology supplying partner of an alliance where partners jointly undertake $R \& D$ with various degrees of R\&D input, while building on the initial technology input from one 
partner. For this primary technology supplying partner of an R\&D alliance, one can expect that, given its critical technological input, it is vital to negotiate a range of intellectual property control rights for its $R \& D$ alliance contract as a claim on future innovation rents. Most prior research, based on property rights theory (see below), assumes that the primary technology supplying firm, in those studies the small biotech firm, should, given its bargaining power, retain control rights when research is non-contractible although it might have to sacrifice some rights if its resources are constrained. In this study, I focus on an extended set of dimensions of this bargaining power, both at the level of firms and the level of transactions (alliances), that are expected to affect the number of intellectual property control rights the primary technology supplying firm retains.

As such my approach extends a number of interesting directions for empirical research on contract design (see Adegbesan and Higgins, 2011; Aghion and Tirole, 1994; Elfenbein and Lerner, 2012; Higgins, 2007; Lerner and Merges, 1998; Lerner, Shane and Tsai, 2003). I concentrate my analysis on four dimensions of bargaining power that are expected to affect the allocation of control rights from the perspective of the primary technology supplying firm. At the firm level, I develop hypotheses on the bargaining power of firms in terms of their size asymmetries and the asymmetry in the innovative capabilities of partners that are both expected to impact the allocation of intellectual property control rights. At the transaction (alliance) level, I formulate hypotheses that guide my understanding of the bargaining power of the primary technology supplying firm in the context of the scope of alliances. This scope of alliances is understood in terms of both the focus on different stages of the innovation process where the primary technology supplying firm is expected to play a crucial role in the early research phase of an alliance, and the breadth of an alliance as indicated by the number of potential technology applications that originate from the initial input by the primary technology supplying partner.

Finally, although previous work has taken a look at intellectual property as a sub-category of control rights, the main focus of these studies is on the allocation of control rights in general. These more general control rights refer to the combined management, governance, planning, and property aspects of alliances (Adegbesan and Higgins, 2011; Higgins, 2007; Lerner and Merges, 1998). In the following, I study the allocation of intellectual property control rights, that refer to ownership and decision making rights regarding the use of inventions, technology, and technology transfer, as a specific category of control rights sui generis. Given the nature of $R \& D$ alliances where firms jointly perform $R \& D$ or this $R \& D$ is shared between partners, intellectual property control rights are a crucial element in the contract design for this specific group of alliances (Hagedoorn and Hesen, 2007).

\subsection{Theoretical background and hypotheses}

Inspired by the Aghion and Tirole (1994) qualification of the classical Grossman-Hart-Moore (GHM) approach to property rights (Grossman and Hart, 1986; Hart and Moore, 1990), I take the relative bargaining power of alliance partners as an important condition associated with the allocation of control rights (Adegbesan and Higgins, 2011). The original Aghion and Tirole (1994) framework envisioned an alliance as a collaboration between a small research firm (e.g. a dedicated biotechnology firm) and a large contracting firm (e.g. a pharmaceutical firm), see also Higgins (2007) and Lerner and Merges (1998). In that framework, the small research firm has the technical know-how but it lacks certain resources, related to its 
relatively small size, that are in abundance with the large contracting firm and that do provide more bargaining power to the larger partner and less bargaining power to the small firm. Aforementioned literatures consider these biotech firms as the main suppliers of R\&D input into alliances, somewhat similar to what I label as the role of primary technology supplying partners.

Earlier industrial organization contributions to the alliance literature had already indicated that the size of firms and in particular size asymmetry of alliance partners can play a role in the relative bargaining position that firms attain during the alliance formation process (for instance Berg, Duncan and Friedman, 1982; Mytelka, 1991). This literature suggests that the size asymmetry of partners, that also indicates market power asymmetry, generates a higher appropriability hazard for the smaller firm due to the potentially opportunistic behavior of its larger partner. For instance, the literature on interfirm cooperation through licensing indicates that when firms of different sizes engage in technology collaboration, larger firms attempt to dominate the agreement based on size-related bargaining asymmetries that affect the terms of the agreement (Bessy and Brousseau, 1998; Caves, Crookell and Killing, 1983). In other words, the relative size of firms participating in an alliance appears to affect their relative bargaining position.

Recent property rights literatures on bargaining power asymmetries in terms of size differences between alliance partners reveal that these asymmetries affect the actual control rights assigned to alliance partners (Aghion and Tirole, 1994; Leiponen, 2008; Lerner and Merges, 1998). I expect these size and market power asymmetries, or lack thereof, to also affect the allocation of intellectual property control rights in the context of R\&D alliances. The less the primary technology supplying firm is subject to size asymmetry vis-à-vis its partner, as it is either larger or relatively close to its partner's size, the stronger I expect its bargaining power for negotiating more intellectual property control rights. Hence:

Hypothesis 1. The less a primary technology supplying firm is subject to size asymmetry vis-à-vis its partner, the more intellectual property control rights are allocated to that firm.

I see the technological strength of the primary technology supplying partner, reflecting its innovative capabilities, as an important, but often neglected, element of the bargaining power of that firm (for an exception, see Das and Kumar, 2007). As the primary technology supplying partner is the initial source of the technology used or developed further through the alliance, I expect that the greater the technological strength of the primary technology supplying partner, based on its long-term innovative capabilities, the more instrumental that firm is to the success of the alliance. The greater the technological strength of the primary technology supplying firm vis-à-vis its partner, i.e., the higher its positive innovative capabilities asymmetry with its partner, the more crucial its role in the R\&D alliance.

As efforts made by the primary technology supplying firm are expected to be crucial to the technological success of the alliance, this firm may demand allocation of more intellectual property control rights than it would retain otherwise. The partner firm might relinquish these control rights to the primary technology supplying firm to generate adequate incentives for the latter. As such, the bargaining power of the primary technology supplying firm in terms of its relative technological strength vis-à-vis its partner is expected to condition the allocation of intellectual property control rights to the primary technology supplying firm. Hence: 
Hypothesis 2. The larger the positive innovative capabilities asymmetry in an $R \& D$ alliance, from the perspective of the primary technology supplying firm, the more intellectual property control rights are allocated to that firm.

So far I considered the bargaining position of primary technology supplying firms in terms of their relative (asymmetric) bargaining power in an R\&D alliance at the firm level. However, the bargaining power of firms can also be seen at the transactional level, the alliance itself. In that context, I look at the bargaining position of the primary technology supplying firm in terms of its specific contribution within the scope of the alliance. I understand this scope of an alliance to refer to both its focus and breadth. The focus of an R\&D alliance concerns the different R\&D activities undertaken within the alliance, i.e., the stage of development at which the R\&D alliance finds itself, while its breadth refers to the number of (potential) technology applications.

Following previous research (Adegbesan and Higgins, 2011; Haeussler and Higgins, 2009; Higgins, 2007; Lerner, Shane and Tsai, 2003), I posit that an R\&D alliance may focus on either an early research phase or a later development phase. A major characteristic of the first phase is that research, be it basic or applied, is experimental and full of uncertainties. At this stage, collaborating firms face a range of research options and, therefore, potentially a variety of directions for their joint research projects (Freeman and Soete, 1997; Nelson, 1961; 1982). In general, the open nature of the range of options that firms still have at this early stage indicates that there is little or no information on the concrete new products and processes that will eventually be developed. In this early research stage, research efforts of the primary technology supplying partner are expected to be paramount to alliance success. However, technological uncertainty prevents ex-ante contractual specification of all efforts to be made by the primary technology supplying firm during alliance execution. Therefore, as the success of an alliance that focuses on an early research stage rests to a large extent on the non-contractible efforts of the party that introduces the technology to the alliance, i.e. the primary technology supplying firm, this firm is likely to have a strong bargaining position to negotiate a larger number of intellectual property control rights.

On the other hand, development projects are far less uncertain in technological and economic terms because they usually start from a predetermined set of technologies that will be developed further into commercial applications (Freeman and Soete, 1997). During this later phase, firms increasingly focus on the implementation of innovations and the actual introduction of new products and processes. In this later development stage, because of reduced technological uncertainty, efforts of the primary technology supplying firm are more easily contractually specified and less critical to alliance success as commercial application of the innovative effort becomes of the essence.

The above illustrates that, for an early research stage, the non-contractible efforts of the primary technology supplying firm are a critical contribution to the success of the alliance. Therefore, given its crucial role in the early research phase, I expect the initial technology supplying firm to obtain a relatively strong bargaining position and to retain a larger share of intellectual property control rights in the earlier stages of an R\&D alliance. Hence:

Hypothesis 3. The earlier the innovation process stage of an $R \& D$ alliance, the more intellectual property control rights are allocated to the primary technology supplying partner. 
Previous research (e.g. Kalaignanam, Shankar, and Varadarajan, 2007) has considered the breadth of alliance scope in terms of functional activities that partly overlaps with alliance focus as referred to in my previous hypothesis. As suggested by Hansen and Higgins (2008), I, however, understand the breadth of the scope of R\&D alliances in terms of the number of application areas that could be affected by the technology stipulated in the alliance contract. I take the number of potential applications of a technology as an ex-ante indication of the expected demand for this technology and its products (see also McGrath, 1997).

Higher expected demand for a technology that is developed further in an R\&D alliance puts the initial provider of that technology in a stronger bargaining position vis-à-vis its partner firm. Higher expected demand for a technology and its products developed through an R\&D alliance can potentially create higher innovation rents. If realized, both partners can benefit from these innovation rents but the primary technology supplying partner plays a crucial role through its initial technology input in the R\&D alliance. Thus, given this crucial input for reaching the potential of these technology applications, we anticipate the primary technology supplying firm to retain a larger number of intellectual property control rights. Hence:

Hypothesis 4. The higher the number of potential technology applications for an $R \& D$ alliance, the more intellectual property control rights are allocated to the primary technology supplying partner.

\subsection{Data, methods, and sample description}

My sample covers a set of nearly 300 R\&D alliance contracts in the US biopharmaceutical industry obtained from Pharmaventures, a UK-based information and consulting firm. Pharmaventures has identified thousands of alliances in the healthcare and biopharmaceutical sector in their PharmaDeals database. The collected deals are grouped into a number of categories, such as collaborative R\&D, distribution/marketing, manufacturing/supply, and business acquisition. For each agreement, the PharmaDeals database provides information on the names of the partners, type of contractual relationship, date deal signed, equity investment, relevant product areas and technology fields, press releases and, where available, the actual contracts. These actual contracts were obtained from the U.S. Securities and Exchange Commission (SEC) filings and Pharmaventures' clients. ${ }^{3}$

My dataset covers R\&D alliance contracts and additional information for the period 1996 through 2005. I collected information on alliances where the main focus is on R\&D and for which PharmaDeals includes an actual legal document (contract). Using this sample I am able to generate a set of contracts in a homogeneous contracting space, which facilitates the comparison of key contract features across alliances. In this manner, I can be assured that variation in contracting terms and control rights does not come from a variation in the underlying industrial contracting environment.

The preliminary sample comprised 587 deals for the period 1996-2005. To avoid further unnecessary heterogeneity I excluded all the agreements where:

\footnotetext{
${ }^{3}$ Publicly traded firms are required by the SEC to file material documents. Firms tend to interpret this requirement conservatively and often file contracts specifying alliances as amendments to $10-\mathrm{K}, 10-\mathrm{Q}, \mathrm{S}-1$ or 8 $\mathrm{K}$ statements. In addition, a number of state governments in the USA require privately held firms with employee stock options to file material documents, which are then made available to the public.
} 
- one of the parties is a government agency or university

- the alliance is, as stated in the contract, a renegotiation or restatement of a previous alliance between the firms

- there is no R\&D component to the alliance

- one firm has a controlling interest in the other firm (greater than 50\%)

- contracts involve more than two parties.

The final contract database contains a set of 304 contracts which was reduced to 289 contracts due to various missing values. These contracts represent the first interaction between the firms as found in the PharmaDeals dataset for the period 1996-2005. Consequently, an alliance between firms A and B appears only once in the final dataset.

The agreements include both US (domestic) contracts, i.e. the contracting parties are both US-based firms (170 alliances), and international contracts, i.e. a US-based firm collaborates with a non-US based firm (119 alliances). About 45\% of the agreements were concluded between a biotech firm acting as a primary technology supplying firm and a pharmaceutical or a chemical firm acting as a partner firm. ${ }^{4}$

I collected additional information on for instance the size of firms, their R\&D expenditures, their US patents, and alliance experience for the firms participating in these 289 deals. My complete dataset combines information from PharmaDeals with data retrieved from firm annual reports, Cooperative Agreements and Technology Indicators (CATI), Datastream, Compustat, Corptech, Deloitte Recap, Thomson One Banker, Thomson Platinum SDC alliances, and the USPTO.

\subsubsection{Dependent variable}

Control rights. In previous studies, a variety of control rights allocated to either pharmaceutical firms or their biotech partners have been used as a dependent variable (Adegbesan and Higgins, 2011; Higgins, 2007; Hansen and Higgins, 2008; Haeussler and Higgins, 2009; Lerner, Shane and Tsai, 2003; Lerner and Merges, 1998). My dependent variable differs from these previous studies in two dimensions. First, the sample covers a broader set of alliances than those between large pharmaceutical firms and small biotech firms and hence, regardless of the size of firms, I view the allocation of control rights from the perspective of the firm that, according to information provided by Pharmadeals, acts as the primary, initial technology supplier within the alliance (see Appendix 2.2, panel B, for an overview of the different size combinations). Second, given the R\&D nature of the alliances in my sample, I consider intellectual property control rights as the main focus of my study. As a concrete measure of the allocation of control rights I take the actual fraction of a total number of six intellectual property control rights allocated to the primary technology supplying firm within an alliance as the dependent variable. These six intellectual property control rights are derived from a combination of categorizations of relevant control rights as found in Adegbesan and Higgins (2011), Higgins (2007), and Lerner and Merges (1998). See Appendix 2.1 for a list of intellectual property control rights in these contracts.

\footnotetext{
${ }^{4}$ A biotech firm is categorized as such, regardless of its size. The remaining $55 \%$ of these alliances refer to the other possible combinations, as pictured in the introduction and in Appendix 2.2.
} 


\subsubsection{Independent variables}

Size asymmetry. To proxy size asymmetry, I use a variable based on the number of employees of the firms participating in an alliance. This variable is defined as the logarithmic value of the number of employees of the principal technology supplying firm, minus the logarithmic value of the number of employees of its partner firm.

Innovative capabilities asymmetry. Given the importance of $\mathrm{R} \& \mathrm{D}$ as an input indicator of innovative capabilities and patents as an output indicator of these capabilities in an R\&D and patenting intensive, high-tech industry, such as the biopharmaceutical sector, I measure innovative capabilities asymmetry in terms of both R\&D intensity and patenting intensity.

$R \& D$ intensity indicates the degree to which a firm invests in its $R \& D$ as a major source of its future innovativeness. R\&D intensity asymmetry indicates the difference between a primary technology supplying firm and its alliance partner in terms of the degree to which firms devote resources to develop their innovative capabilities. For each firm I collected data on its R\&D expenses in millions of US dollars. Average R\&D expenses are calculated based on the $R \& D$ expenditures during the year of deal conclusion and the previous year. Assume $A$ is the primary, initial technology supplying firm and B its partner, this variable is defined as follows:

$R \& D$ Intensity Asymmetry $=\frac{\left(R \& D \text { Intensity }_{A}\right)-\left(R \& \text { Intensity }_{B}\right)}{\left(R \& \text { Intensity }_{A}\right)+\left(R \& \text { Intensity }_{B}\right)}$

Where R\&D Intensity is defined as follows:

$R \& D$ Intensity $=\frac{R \text { \& expenses }}{\text { Net sales }}$

If one would consider R\&D asymmetry from the perspective of the larger firm in an alliance, a mere division of $R \& D$ expenses could be used to identify the R\&D asymmetry between partners. However, as I take the perspective of the primary technology supplying firm, whether this firm is larger or smaller than its partner, such a division could prove to be statistically problematic. ${ }^{5}$ Hence, I propose the variable given above, which generates a value between -1 and $+1 .^{6}$

As a second indicator, I apply patenting intensity asymmetry as an output indicator of innovative capabilities asymmetry, measured in a similar way as R\&D intensity asymmetry. See Appendix 2.3 for further details about this second indicator.

\footnotetext{
${ }^{5}$ If the R\&D expenses of the partner firm equal or exceed those of the primary technology supplying firm, such division would generate a value between $[0,1)$. In the opposite case, when the R\&D expenses of the primary technology supplying firm exceed those of the partner firm, such division would fall in the domain $[1, \rightarrow)$.

${ }^{6}$ For some R\&D alliances, one firm has an extremely high R\&D intensity close or even higher than 1 whereas its partner has a more moderate R\&D intensity. Well-known examples of this are found in the cooperation between small biotech research firms and large pharmaceutical firms. Depending on the number of cases in my sample, this very large asymmetry might drive the results of the analysis. In an additional unreported analysis, I exclude those observations in which the R\&D intensity asymmetry is either very low (5\% lowest), or very high $(5 \%$ highest). Results remain consistent with those reported here.
} 
Innovation process stage. The PharmaDeals database provides information on the stages of the innovation process underlying each deal. These stages refer to an early stage of collaborative research and a later stage of co-development of new products. I use a dummy variable which equals 0 if the alliance contract concerns collaborative research and 1 if it refers to the co-development of products.

Potential technology applications. For each R\&D alliance, PharmaDeals lists the number of possible technological interest areas for the products and/or technologies developed through that alliance, with a maximum of eight interest areas. I interpret these interest areas for a product and/or a technology in terms of the number of potential technology applications. ${ }^{7}$

\subsubsection{Control variables}

Equity investment. For each $\mathrm{R} \& \mathrm{D}$ alliance contract, PharmaDeals reports whether or not equity is involved. Equity participation generates control in the alliance and this control might affect the allocation of intellectual property control rights (Hagedoorn, Cloodt and van Kranenburg, 2005; Oxley, 1997). A dummy variable was created which equals 1 if the contract involves an equity stake and 0 otherwise.

$R \& D$ Plus. Many alliances include additional activities such as marketing, distribution and/or manufacturing. These additional activities have been shown to increase the complexity of alliances (Ryall and Sampson, 2009; Sampson, 2004b). Although I expect no specific relationship between the variable R\&D Plus and the allocation of intellectual property control rights to the primary technology supplying firm, I do wish to control for any possible confounding effects. I therefore include a dummy variable that equals 1 if any additional activities are included besides R\&D and 0 otherwise.

Time-bound. There is considerable heterogeneity in the duration of alliances. Here, I include a dummy variable to indicate whether or not the alliance is time-bound, i.e., whether there is a predefined ending date of the alliance as stipulated in the contract. Previous research has shown that the contractual structure of time-bound alliances differs considerably from more open-ended alliances (e.g. Reuer and Ariño, 2007). This dummy variable takes a value of 1 if the contract has a pre-defined ending date, and 0 otherwise.

Financial strength asymmetry. As in previous research (for instance, Lerner and Malmendier, 2010) I take net income as an adequate proxy of financial strength of the primary technology supplying firm that is expected to impact the bargaining power and the allocation of control rights for that firm. I proxy financial strength as the ROA (Return On Assets) of the primary technology supplying firm, minus the ROA of its partner firm.

Prior ties. Previous literature highlights the role that repeated interactions between partner firms play in the choice for different contractual arrangements (Gulati, 1995) and the evolvement of contractual provisions (Argyres, Bercovitz and Mayer, 2007). Although this literature does not suggest a straightforward relationship between prior ties and the allocation of intellectual property control rights to the primary technology supplying firm, adequate

\footnotetext{
${ }^{7}$ It could be argued that instead of being a proxy for potential technology applications, the number of interest areas could in fact be a measure of uncertainty. Early stage molecules/candidates will often have multiple indications as a result of general uncertainty as to what might pan out in clinical trials. However, as shown in Table 2.1, the correlation between potential technology applications and the innovation process stage is only 0.131 .
} 
performance in a previous alliance could increase the bargaining power of that firm. As such, I choose to control for the number of prior ties between partner firms in a 5-year window before the focal alliance.

Competition. Contracts between competitors and between a supplier and a customer are expected to be different. Indeed, recent evidence suggests that partnerships between competitors can bring significant benefits to participants, while simultaneously increasing the efforts of these participants in limiting the chance of unintended knowledge leakage (Lhuillery and Pfister, 2009). In terms of the fraction of intellectual property control rights allocated to the primary technology supplying firm, this could mean that the level of competition between alliance partners has an impact on the degree to which intellectual property control rights are negotiated, and as a result, divided between alliance partners. As such, I control for the level of competition between alliance partners based on SIC codes (Mowery, Oxley and Silverman, 1996). Using data from Thomson ONE Banker, this variable takes on a value of 2 if both parties operate in the same primary 4-digit SIC code, 1 if both parties do not operate in the same primary 4-digit SIC code but do operate in the same 3-digit SIC code, and 0 otherwise.

Biotech firm. Dedicated biotech firms are known to have been major drivers of technological development in the biopharmaceutical industry (Adegbesan and Higgins, 2011; Higgins, 2007; Lerner and Merges, 1998). In that context, I control for the specific role that biotech firms, irrespective of their size, play as primary technology supplying firms in $R \& D$ alliances with other firms. If the primary technology supplying firm is a biotech firm and its partner is a non-biotech firm the dummy variable equals 1 and otherwise 0 .

Alliance portfolio. The number of alternative partners for a primary technology supplying firm's R\&D alliance, is expected to impact the number of intellectual property control rights assigned to that firm, as, given these alternative options, it has a stronger bargaining position. In theory, the maximum number of alternative options equals the number of qualified other firms in the industry that are interested in forming an R\&D alliance. As such, there are probably a considerable number of alternative options. In practice, however, firms are known to prefer forming alliances with earlier or existing partners (Gulati, 1995). I take the number of concurrent biopharmaceutical $R \& D$ alliance partners, with which the primary technology supplying firm is involved at the signing date of the focal alliance, as an indication of the number of alternative partnering options it has. The larger the number of concurrent other R\&D alliance partners, i.e., the larger the pool of alternative partners, the stronger the bargaining position of the primary technology supplying firm vis-à-vis its partner because of its decreased dependency on this partner. This stronger bargaining position of the primary technology supplying firm is expected to affect its ability to retain a larger number of intellectual property control rights (see also Adegbesan and Higgins, 2011). I measure this control variable as the number of alliance partners of the primary technology supplying firm, excluding its current contract partner, in a three year period prior to the year of deal conclusion. Using the CATI, Deloitte Recap, and Thomson Platinum SDC alliances databases, I obtained data on the prior R\&D alliance experience of the primary technology supplying firm, that is not reported in the PharmaDeals dataset, counting back three years from the year of deal conclusion.

US partners. I include a dummy variable which takes a value of 1 if the partnering firms are headquartered in the same country (the US) and a value of 0 if otherwise (international deal). Firms are expected to have less information about foreign firms than about domestic 
firms and trust tends to emerge more readily between firms that share a similar social background, for instance those that are domestic partners (Zucker, 1986). This also suggests that behavioral uncertainty and opportunistic behavior may be more likely to arise in crossborder alliances affecting the governance of alliances (see also Hagedoorn, Cloodt and van Kranenburg, 2005). This behavioral uncertainty might be compensated by a larger number of intellectual property control rights allocated to the primary technology supplying firm.

Value. For each R\&D alliance, PharmaDeals gives information about the (potential) deal value if available. In addition, I collected additional deal value data from the LexisNexis database. In line with my bargaining perspective, a larger (potential) deal value might influence the bargaining position of one or both firms. As such, I include the logarithmic value of the deal value in millions of dollars. If information for this variable is missing, the value is set to zero. ${ }^{8}$

Value dummy. I control for missing information concerning deal value. If information concerning the (potential) deal value of an alliance is missing, this dummy variable takes on a value of 1 and 0 otherwise.

Year fixed effects. As the propensity to engage in R\&D alliance contracts may vary during the period 1996-2005, I included year dummies. A year dummy equals 1 if the deal is concluded within that specific year and 0 otherwise.

\subsubsection{Analysis}

In the following, I present a Generalized Linear Model (GLM) with the fraction of intellectual property control rights allocated to the technology supplying firm as the dependent variable. I use GLM with a Bernoulli variance function and a logit link function utilizing maximum likelihood optimization with robust and clustered standard errors, as proposed by Papke and Wooldridge (1996) and applied amongst others by Adegbesan and Higgins (2011). Alternatively, in unreported regressions, I applied a basic Tobit model first without and then with robust and clustered standard errors. Results are similar to those presented below. ${ }^{9}$

The contracts that I analyze represent the 'first interactions' between firms in the PharmaDeals dataset for the period 1996-2005 but a small number of firms appear in the dataset more than once. This occurs when firm A contracts with firm B and firm C separately, in that case both the $\mathrm{AB}$ and $\mathrm{AC}$ contracts are in the sample. Since firm A's behavior in contract $\mathrm{AC}$ is probably not independent of firm A's behavior in contract $\mathrm{AB}$, error terms may not be independently distributed. Correlated error terms at the firm level might cause

\footnotetext{
${ }^{8}$ Although frequently used (see, for instance, Bastos (2010), Griliches (1976), Khorana, Servaes and Tufano (2009), Singh (2008); Smith and Huang (1995)), this method of dealing with missing values has its drawbacks, as do alternative methods. In unreported analyses, I use four other methods to deal with missing values to investigate whether or not results change depending on which method I use. First, I run a regression without controlling for value. Second, I run a regression in which I only control for whether or not information on value is missing. Third, I limit the sample to only those observations for which I was able to retrieve information on the value of alliances. Fourth and last, based on a host of observable variables, I estimate the value of an alliance if this information is missing, and use these estimates in the full model. Results do not materially change from those presented here.

${ }^{9}$ In Table 2.2, I report Wald $\chi^{2}$ tests instead of $\log$ likelihood ratio tests as GLM estimators with clustered and robust standard errors provide log pseudolikelihoods instead of log likelihoods. Using log likelihoods derived from Tobit estimators without robust and clustered standard errors provides similar results.
} 
underestimated standard errors for firm attributes that are constant over multiple contracts. As such, I clustered the standard errors by firm. ${ }^{10}$

\subsection{Results}

Table 2.1 provides the descriptive statistics and the correlation matrix. Additional information on the sample can be found in Appendix 2.2. I use R\&D and patent-based indicators of innovative capabilities asymmetry in separate regressions (see Table 2.2). Correlations between relevant variables are in general moderate to very low, except for the correlation between value and value dummy. I refer to footnote 8 for a more elaborate explanation of this issue. Additional VIF statistics with values between 1.18 and 8.69 indicate that multicollinearity does not play a role in the analyses.

Table 2.2 presents the results of the GLM regression analyses. Model 1 in Table 2.2 refers to the basic model with only control variables. In models 2 - 4 each hypothesis-related independent variable is added to the set of control variables, after which models 5 and 6 show regressions with all the independent variables included. An alternative procedure where hypothesis-related independent variables were added subsequently led to similar results.

\footnotetext{
${ }^{10}$ More specifically, I clustered the standard errors based on the ID-numbers of the partner firms, and not the primary technology supplying firms. The main argument for this clustering strategy is that, in my sample, partner firms tend to occur more frequently than primary technology supplying firms. Nevertheless, clustering by primary technology supplying firm ID produces identical results to those shown below. Alternatively, I ordered all firm ID's according to the frequency in which these firms show up in the sample, either as primary technology supplying firm or as partner firm. First, I included an additional control variable that equals 1 if an alliance includes a frequently occurring firm using various criteria to determine what constitutes 'frequently occurring'. The results presented below remain the same. Second, I included individual firm fixed effects for the 10 most frequently occurring firms. While some of these dummy variables significantly affect the fraction of intellectual property control rights allocated to the primary technology supplying firm, they have little impact on the other coefficients.

The inclusion of firm fixed effects also alleviates, to some extent, potential endogeneity issues (Lerner and Malmendier, 2010). More specifically, it relaxes the concern that unobserved firm characteristics actually drive the results.
} 


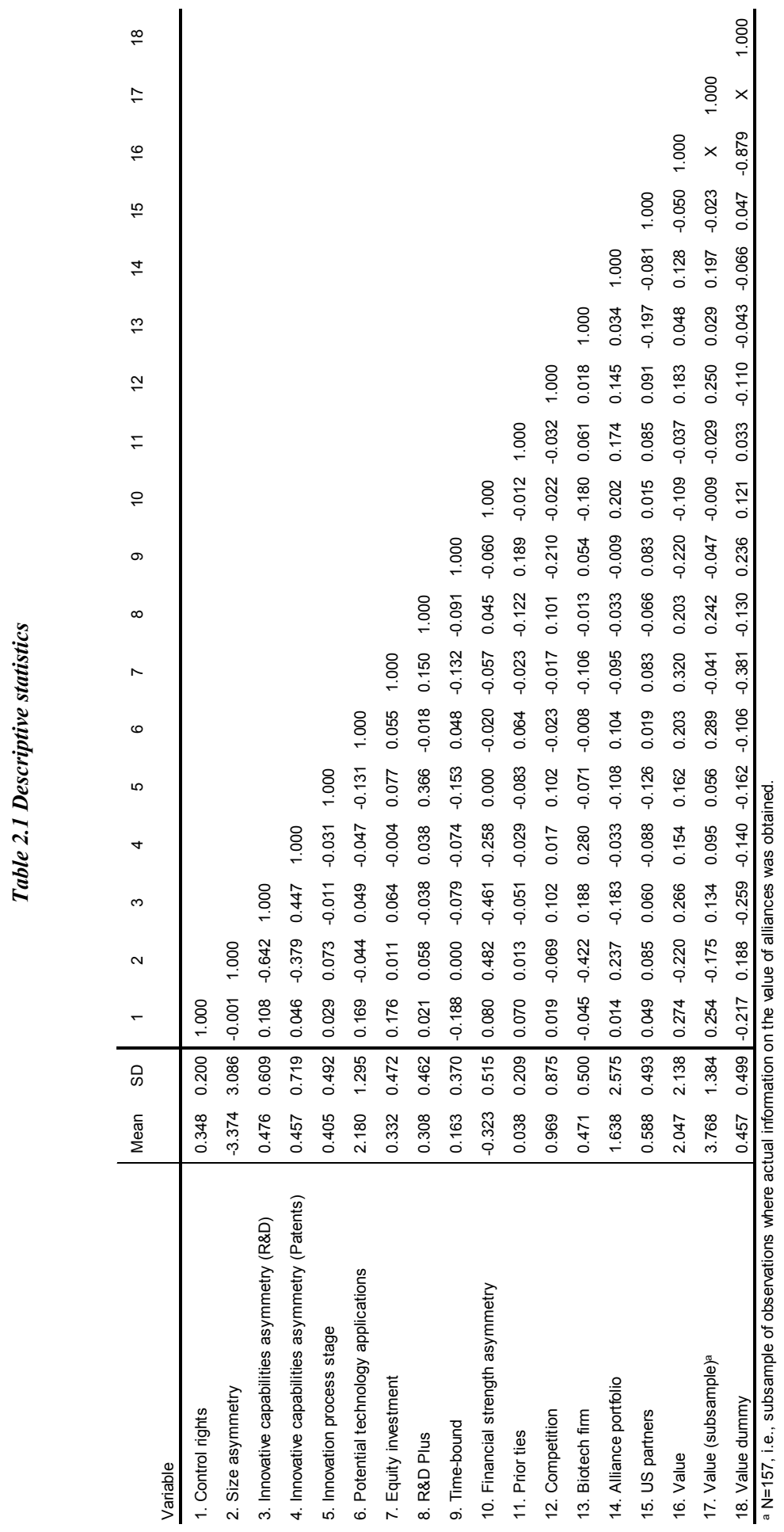


I find mixed support for the set of four hypotheses and the bargaining power perspective suggested in the above. The first hypothesis which states that the less the primary technology supplying firm is subject to size asymmetry vis-à-vis its partner, the more intellectual property control rights are allocated to that firm, is not supported. Additional, unreported, regressions where I considered the effect of the quartile where primary technology supplying firms were least affected by size asymmetry only generated a marginally significant effect. Hypothesis 2 predicts that the larger the positive innovative capabilities asymmetry in an R\&D alliance, seen from the perspective of the primary technology supplying firm, the more intellectual property control rights are allocated to that firm. This hypothesis is supported for the R\&Dbased input indicator, as I find the expected significant positive effect, but I find no support when using a patent-based output indicator, see models 3 and 6 in Table 2.2. As already mentioned in the previous section, in an additional, unreported, analysis I control for the effect of a very high R\&D intensity asymmetry between the technology supplying firm and the partner firm, as found in the cooperation between small extremely R\&D intensive biotech research firms and large pharmaceutical and chemical firms. The results for the regressions without such outliers are similar to those presented here. Hypothesis 3 states that, in terms of the focus of an R\&D alliance, the earlier the innovation process stage of an R\&D alliance, the more intellectual property control rights are expected to be allocated to the primary technology supplying firm. However, I find no support for this hypothesis in models $4-6$ in Table 2.2. I do find strong support for hypothesis 4 which predicts that the higher the number of potential technology applications for an $R \& D$ alliance, the more intellectual property control rights are allocated to the primary technology supplying firm. See models $4-6$ in Table 2.2, where I find the expected significant positive effect for the breadth of an R\&D alliance technology scope. 
Table 2.2 Generalized Linear Model (GLM) estimation results of IP control rights

\begin{tabular}{|c|c|c|c|c|c|c|c|c|c|c|c|c|}
\hline Variable & \multicolumn{2}{|l|}{ Model 1} & \multicolumn{2}{|l|}{ Model 2} & \multicolumn{2}{|l|}{ Model 3} & \multicolumn{2}{|l|}{ Model 4} & \multicolumn{2}{|l|}{ Model 5} & \multicolumn{2}{|l|}{ Model 6} \\
\hline Size asymmetry & & & $\begin{array}{c}0.030 \\
(0.025)\end{array}$ & & $\begin{array}{c}0.006 \\
(0.023)\end{array}$ & & & & $\begin{array}{c}0.032 \\
(0.024)\end{array}$ & & $\begin{array}{c}0.009 \\
(0.022)\end{array}$ & \\
\hline Innovative capabilities asymmetry (R\&D) & & & $\begin{array}{c}0.246 \\
(0.113)\end{array}$ & & & & & & $\begin{array}{c}0.247 \\
(0.111)\end{array}$ & & & \\
\hline Innovative capabilities asymmetry (Patents) & & & & & $\begin{array}{c}0.043 \\
(0.078)\end{array}$ & & & & & & $\begin{array}{c}0.056 \\
(0.074)\end{array}$ & \\
\hline Innovation process stage & & & & & & & $\begin{array}{l}-0.013 \\
(0.120)\end{array}$ & & $\begin{array}{l}-0.019 \\
(0.118)\end{array}$ & & $\begin{array}{c}-0.012 \\
(0.119)\end{array}$ & \\
\hline Potential technology applications & & & & & & & $\begin{array}{c}0.088 \\
(0.033)\end{array}$ & $* * *$ & $\begin{array}{c}0.088 \\
(0.033)\end{array}$ & $* * *$ & $\begin{array}{c}0.090 \\
(0.033)\end{array}$ & $* * *$ \\
\hline Equity investment & $\begin{array}{c}0.200 \\
(0.118)\end{array}$ & & $\begin{array}{c}0.203 \\
(0.118)\end{array}$ & * & $\begin{array}{c}0.201 \\
(0.118)\end{array}$ & * & $\begin{array}{c}0.189 \\
(0.116)\end{array}$ & & $\begin{array}{c}0.190 \\
(0.116)\end{array}$ & & $\begin{array}{c}0.189 \\
(0.116)\end{array}$ & \\
\hline R\&D Plus & $\begin{array}{l}-0.112 \\
(0.112)\end{array}$ & & $\begin{array}{l}-0.107 \\
(0.111)\end{array}$ & & $\begin{array}{l}-0.118 \\
(0.112)\end{array}$ & & $\begin{array}{l}-0.089 \\
(0.119)\end{array}$ & & $\begin{array}{l}-0.083 \\
(0.116)\end{array}$ & & $\begin{array}{l}-0.097 \\
(0.119)\end{array}$ & \\
\hline Time-bound & $\begin{array}{l}-0.397 \\
(0.184)\end{array}$ & ** & $\begin{array}{l}-0.374 \\
(0.184)\end{array}$ & ** & $\begin{array}{l}-0.392 \\
(0.185)\end{array}$ & ** & $\begin{array}{l}-0.415 \\
(0.187)\end{array}$ & ** & $\begin{array}{l}-0.393 \\
(0.187)\end{array}$ & ** & $\begin{array}{l}-0.408 \\
(0.187)\end{array}$ & ** \\
\hline Financial strength asymmetry & $\begin{array}{c}0.221 \\
(0.124)\end{array}$ & * & $\begin{array}{c}0.272 \\
(0.133)\end{array}$ & ** & $\begin{array}{c}0.220 \\
(0.132)\end{array}$ & * & $\begin{array}{c}0.225 \\
(0.123)\end{array}$ & * & $\begin{array}{c}0.272 \\
(0.134)\end{array}$ & ** & $\begin{array}{c}0.222 \\
(0.133)\end{array}$ & * \\
\hline Prior ties & $\begin{array}{c}0.478 \\
(0.261)\end{array}$ & * & $\begin{array}{c}0.510 \\
(0.249)\end{array}$ & ** & $\begin{array}{c}0.480 \\
(0.258)\end{array}$ & * & $\begin{array}{c}0.456 \\
(0.265)\end{array}$ & * & $\begin{array}{c}0.489 \\
(0.254)\end{array}$ & * & $\begin{array}{c}0.458 \\
(0.261)\end{array}$ & * \\
\hline Competition & $\begin{array}{l}-0.070 \\
(0.059)\end{array}$ & & $\begin{array}{l}-0.073 \\
(0.060)\end{array}$ & & $\begin{array}{l}-0.067 \\
(0.060)\end{array}$ & & $\begin{array}{l}-0.059 \\
(0.057)\end{array}$ & & $\begin{array}{c}-0.062 \\
(0.059)\end{array}$ & & $\begin{array}{l}-0.055 \\
(0.058)\end{array}$ & \\
\hline Biotech firm & $\begin{array}{c}0.000 \\
(0.100)\end{array}$ & & $\begin{array}{c}0.022 \\
(0.110)\end{array}$ & & $\begin{array}{c}-0.002 \\
(0.108)\end{array}$ & & $\begin{array}{c}0.006 \\
(0.100)\end{array}$ & & $\begin{array}{c}0.031 \\
(0.110)\end{array}$ & & $\begin{array}{c}0.005 \\
(0.108)\end{array}$ & \\
\hline Alliance portfolio & $\begin{array}{l}-0.016 \\
(0.018)\end{array}$ & & $\begin{array}{l}-0.015 \\
(0.018)\end{array}$ & & $\begin{array}{l}-0.018 \\
(0.018)\end{array}$ & & $\begin{array}{l}-0.020 \\
(0.019)\end{array}$ & & $\begin{array}{l}-0.019 \\
(0.019)\end{array}$ & & $\begin{array}{l}-0.021 \\
(0.019)\end{array}$ & \\
\hline US partners & $\begin{array}{c}0.129 \\
(0.115)\end{array}$ & & $\begin{array}{c}0.097 \\
(0.115)\end{array}$ & & $\begin{array}{c}0.127 \\
(0.115)\end{array}$ & & $\begin{array}{c}0.128 \\
(0.115)\end{array}$ & & $\begin{array}{c}0.095 \\
(0.115)\end{array}$ & & $\begin{array}{c}0.126 \\
(0.114)\end{array}$ & \\
\hline Value & $\begin{array}{c}0.160 \\
(0.040)\end{array}$ & $* * *$ & $\begin{array}{c}0.158 \\
(0.038)\end{array}$ & $* * *$ & $\begin{array}{c}0.162 \\
(0.038)\end{array}$ & $* * *$ & $\begin{array}{c}0.128 \\
(0.042)\end{array}$ & $* * *$ & $\begin{array}{c}0.127 \\
(0.041)\end{array}$ & $* * *$ & $\begin{array}{c}0.130 \\
(0.041)\end{array}$ & $* * *$ \\
\hline Value dummy & $\begin{array}{c}0.311 \\
(0.194)\end{array}$ & & $\begin{array}{c}0.340 \\
(0.189)\end{array}$ & * & $\begin{array}{c}0.319 \\
(0.192)\end{array}$ & * & $\begin{array}{c}0.212 \\
(0.196)\end{array}$ & & $\begin{array}{c}0.242 \\
(0.191)\end{array}$ & & $\begin{array}{c}0.220 \\
(0.194)\end{array}$ & \\
\hline Year fixed effects & $\mathrm{X}$ & & $\mathrm{X}$ & & X & & X & & X & & X & \\
\hline Constant & $\begin{array}{l}-0.988 \\
(0.201)\end{array}$ & $* * *$ & $\begin{array}{l}-0.997 \\
(0.215)\end{array}$ & $* * *$ & $\begin{array}{c}-0.982 \\
(0.210)\end{array}$ & *** & $\begin{array}{l}-1.070 \\
(0.204)\end{array}$ & $* * *$ & $\begin{array}{l}-1.073 \\
(0.217)\end{array}$ & $* * *$ & $\begin{array}{l}-1.064 \\
(0.211)\end{array}$ & $* * *$ \\
\hline Wald test $\left(X^{2}\right)$ & 79.82 & $* * *$ & 87.15 & *** & 83.01 & *** & 97.04 & $* * *$ & 105.49 & $* * *$ & 100.06 & $* * *$ \\
\hline Wald test versus model $1\left(X^{2}\right)$ & - & & 4.78 & * & 0.32 & & 7.27 & $* *$ & 12.66 & ** & 9.21 & * \\
\hline Observations & 289 & & 289 & & 289 & & 289 & & 289 & & 289 & \\
\hline
\end{tabular}

Notes: GLM model, logit link function, bernoulli variance function, robust and clustered standard errors in parentheses.

* significance at the $10 \%$ level; ${ }^{* *}$ significance at the $5 \%$ level; ${ }^{* *}$ significance at the $1 \%$ level. 
Turning to the control variables, a number of these variables have a significant influence on the fraction of intellectual property control rights allocated to the primary technology supplying firm and appear to provide some additional support to a bargaining power perspective on the role of that firm. In line with previous research (for instance Higgins, 2007; Lerner and Merges, 1998), I find a positive and significant value for the financial strength asymmetry measure in all models. This indicates that as the financial strength of the primary technology supplying partner increases, so might its bargaining power and ability to negotiate a larger share of intellectual property control rights. Prior ties that could indicate adequate performance by the primary technology supplying firm in previous alliances with the same partner and imply an increase of the bargaining power of the primary technology supplying firm are also associated with the allocation of more intellectual property control rights to that firm. Finally, in support of a bargaining power perspective on the primary technology supplying firm, the larger the (potential) deal value, the more intellectual property control rights are allocated to that firm. In addition, I find that in alliances that are time-bound, the primary technology supplying firm is allocated fewer intellectual property control rights.

I also considered whether the particular bundle of intellectual property control rights, used in the analyses, drives the current results (Higgins, 2007). I sequentially excluded individual control rights from my dependent variable to see if a particular control right drives the results. Although there are minor differences in the level of significance for individual variables, the main findings for these regressions are qualitatively consistent with the findings reported in Table 2.2.

\subsection{Discussion and conclusions}

In support of the Aghion and Tirole (1994) qualification of the GHM approach, this research finds that some elements of the relative bargaining position of a primary technology supplying firm play a decisive role in the allocation of intellectual property control rights to that firm. In the context of R\&D alliances, it turns out that this relative bargaining position when based on asymmetries in innovative capabilities is, as also suggested by Bosse and Alvarez (2010), more relevant than the general asymmetry in bargaining power based on firm size or market power differentials that was stressed in previous research (Aghion and Tirole, 1994; Leiponen, 2008; Lerner and Merges, 1998). However, this finding comes with a caveat. When using an innovative capabilities input measure (R\&D expenses), more innovative primary technology supplying firms, i.e. more innovative relative to their partner firms, retain a larger number of intellectual property control rights in all specifications. This effect is not found for innovative capabilities asymmetry based on an innovation output measure (patents).

Referring to the scope of alliances, the second condition that is found to impact the allocation of intellectual property control rights is based on the technology breadth of an R\&D alliance. The higher the number of potential technology applications, the higher the latent demand for this technology and the products based on this technology. Again this suggests that, following the Aghion and Tirole (1994) qualification of the GHM approach, under that condition the primary technology supplying partner has a strong bargaining position for the allocation of intellectual property control rights.

I also find some additional support for a bargaining power perspective on the allocation of intellectual property control rights. The relative financial strength of the primary technology supplying firm, the prior ties of partners, and the potential value of the alliance are related to 
the bargaining power of the primary technology supplying partner and these variables appear to affect the allocation of intellectual property control rights to this firm as well.

Interestingly, I find no effect of the scope of R\&D alliances, in terms of their R\&D focus, on the number of intellectual property control rights the primary technology supplying firm retains. I anticipated that the innovation process stage of R\&D alliances would have an impact on the intellectual property control rights assigned to the primary technology supplying partner. As non-contractible efforts of the primary technology supplying firm are a critical contribution to the success of the alliance in early research stages, I expected that this firm would retain a larger number of intellectual property control rights at this stage. As such, my findings suggest that the focus of $\mathrm{R} \& \mathrm{D}$ alliances on either research or development appears to have little or no impact on the intellectual property control rights allocated to the primary technology supplying firm.

One explanation for this finding could be that in fact the focus of an R\&D alliance has two contradicting effects on the number of intellectual property control rights allocated to the primary technology supplying firm. As I posited, the non-contractible efforts of the primary technology supplying firm are crucial in the early research stages of an R\&D alliance and thus this firm should be able to retain a larger number of intellectual property control rights. However, both Lerner, Shane and Tsai (2003) and Higgins (2007) show that when alliance products are not yet in clinical trials, more rights flow to the pharmaceutical firm as the chance of failure is high and the deal size is usually limited. The latter line of reasoning would argue for an alternative positive relationship between the development stage and the number of intellectual property control rights the primary technology supplying firm retains. Such contradicting effects might explain why I end up with a net non-significant effect of innovation process stage on the number of intellectual property control rights assigned to the primary technology supplying firm.

So far, this study considered the allocation of intellectual property control rights, rather than all control rights, from the perspective of the primary technology supplying firm. I motivated this more narrow focus by highlighting the importance of these intellectual property control rights in my empirical setting, i.e., R\&D alliances. Although I believe this more narrow focus is warranted, it is subject to the criticism that control rights are not negotiated in a vacuum and that other control rights might influence the number of intellectual property control rights allocated to the primary technology supplying firm. Also, although I claim that intellectual property control rights are a distinct subset of control rights in general, the results might be interpreted as representing the total allocation of control rights, rather than intellectual property control rights specifically. Therefore, based on relevant literature (e.g. Lerner and Merges, 1998), I examined three other control rights.

First, with R\&D being the main focus in all the alliances, I looked at whether or not the primary technology supplying firm has special voting rights in research and/or development committees. Second, I also considered any special voting rights of the primary technology supplying firm within the overall steering committee or top-management team of the alliance. Third, I investigated whether or not the primary technology supplying firm has the right to terminate the alliance without cause. When these three control rights are included in alternative, unreported regressions, first individually and then as a count variable, I find no significant correlations with the number of intellectual property control rights nor do any of my results change significantly. Similar to Lerner and Merges (1998), I find that the 
correlation between these 'other' control rights and intellectual property control rights is very low.

I also investigated whether or not the same factors that I found to drive the allocation of intellectual property control rights also account for the allocation of the three 'other' control rights. Typically, this is not the case. Interestingly enough, whereas I find no significant relationship between both size asymmetry and innovation process stage and the allocation of intellectual property control rights to the primary technology supplying firm, size asymmetry and innovation process stage are found to be crucial factors in explaining the number of 'other' control rights allocated to this firm. Both Lerner, Shane and Tsai (2003) and Higgins (2007) already demonstrated that in alliances that focus on later innovation stages, fewer control rights flow to the pharmaceutical firm, and thus more to its partner, as the likelihood of success is relatively high. I underline these results and add that the significant and positive relationship between the number of control rights allocated to the primary technology supplying firm and the innovation process stage only holds for other than intellectual property related control rights.

In sum, the empirical findings of this study indicate support for our understanding of the effect of bargaining power, in terms of interfirm asymmetries in innovative capabilities and the breadth of the technology scope, on the allocation of intellectual property control rights. In that context, I take the position of the primary technology supplying partner as the main focus of my analysis, based on the argument that the market structure and the related distribution of R\&D alliances in the biopharmaceutical industry have changed. As argued in the introduction, this change implies that at the turn of the century, this industry demonstrates a less uneven distribution in the roles played by different categories of firms where an alliance between a large pharmaceutical firm and a small biotech firm has become only one of many options. Nevertheless, in this sample of R\&D alliance contracts still about $45 \%$ of the alliances are between biotech firms (of which some have grown substantially over time) and any of the other firms. Hence, one might interpret the current findings through an alternative explanation, based on previous studies (Adegbesan and Higgins, 2011; Higgins, 2007; Lerner and Merges, 1998), where by and large these biotech firms, although many of them are no longer to be characterized as small firms, still act as the primary technology supplying partners in R\&D alliances. As such, my analysis of the role of the primary technology supplying partner could then still be seen in the context of the 'classical' role of the biotech firm. Interestingly, the findings clearly show that there is no significant effect on the allocation of intellectual property control rights when a biotech firm acts as a primary technology supplying partner in an $R \& D$ alliance. This result does indeed indicate that the biopharmaceutical industry has become 'normalized' where the landscape of interfirm R\&D alliances has moved beyond the stereotype 'large pharma - small biotech' collaboration, in which the small biotech firm is the quintessential technology supplying partner of the industry, towards an industry where a broader range of firms establish R\&D alliances (Chiaroni, Chiesa and Frattini, 2008; Cooper, 2007; Ohba and Figueiredo, 2007).

My findings suggest considerable opportunities for further research, opportunities that also point to some of the limitations of the current contribution. Future research could for instance consider other industries. My current contribution only studies the allocation of intellectual property control rights in the biopharmaceutical industry. This industry is important, it is an interesting high-tech sector, but other high-tech industries, as well as medium and low-tech industries, are also relevant industrial settings for the study of 
intellectual property control rights. I do find interesting results but it is of the essence to further assess these findings in the light of other industries where intellectual property rights play a different role (see Cohen, Nelson and Walsh, 2000). In addition, this work is based on the content of the actual contracts that bind partners and I can measure the number of ex-post intellectual property control rights in each contract. However, I have no understanding of the ex-ante preferences of firms for particular control rights or the weight that partners assign to each of these control rights. As such, I have no knowledge regarding the extent to which these control rights were subject to negotiations between partners and how intellectual property control rights are assigned to partners. Knowledge of both the ex-ante preferences and the expost allocation of control rights would already provide some valuable insights into the negotiation process. Also, survey research where partners are questioned on the process of contract negotiations could provide us with useful additional information on the actual importance of individual control rights for alliance partners. Finally, although a substantial share of the partners involved in the alliances and contracts that I studied are not from the U.S., these contracts are typically relevant in the U.S. context as they (partly) fall under the U.S. legal regime. Given the current international context of many alliances, another interesting topic for future research is to be found in the international comparison of alliance contracts, intellectual property control rights, and related legal practice in different legal regimes under which these contracts are governed. 


\section{Appendix 2.1 Intellectual property control rights}

Previous studies (Adegbesan and Higgins, 2011; Hansen and Higgins, 2008; Haeussler and Higgins, 2009; Higgins, 2007; Lerner and Merges, 1998; Lerner, Shane and Tsai, 2003) identified a range of general control rights found in alliance contracts. Given the R\&D nature of the alliance contracts that I analyze, I selected six control rights that are particularly relevant for the intellectual property rights of firms. For each alliance contract, I scanned the contract for clauses that indicate whether a particular intellectual property control right is given to the primary, initial technology supplying firm. Information on these intellectual property control rights were obtained by means of a special text analysis program.

The list below provides the six intellectual property control rights and the actual measures for these control rights, used to search the contracts for relevant text and clauses.

Inventions made by the primary technology supplying firm, during the agreement, will be owned by that firm.

All relevant inventions made by the primary technology supplying firm in the context of the alliance will be owned by that firm.

Primary technology supplying firm is the owner of specific inventions.

Specific inventions, relating to specific technology areas specified in advance, will be owned by the primary technology supplying firm.

Primary technology supplying firm is the owner of trademarks.

The primary technology supplying firm owns trademarks prior to entering the agreement and it will own trademarks developed during the alliance.

Primary technology supplying firm has the right to sublicense.

The primary technology supplying firm has the right to grant sublicenses to third parties.

Primary technology supplying firm grants its partner a partner-specific license.

The partner firm is the only licensee of the primary technology supplying firm, the license specifies the ownership of the technology by the primary technology supplying firm.

Primary technology supplying firm grants its partner a general license.

The partner firm receives a general license, as also granted to other firms, that specifies the ownership of the technology by the primary technology supplying firm. 
Appendix 2.2 Summary statistics of the sample

\begin{tabular}{lcccccc} 
Panel A: Distribution of Observations by Year & 1996 & 1997 & 1998 & 1999 & 2000 \\
\hline Number of contracts signed in year & 21 & 38 & 27 & 42 & 56 \\
\hline & 2001 & 2002 & 2003 & 2004 & 2005 \\
\hline & 40 & 23 & 24 & 13 & 5
\end{tabular}

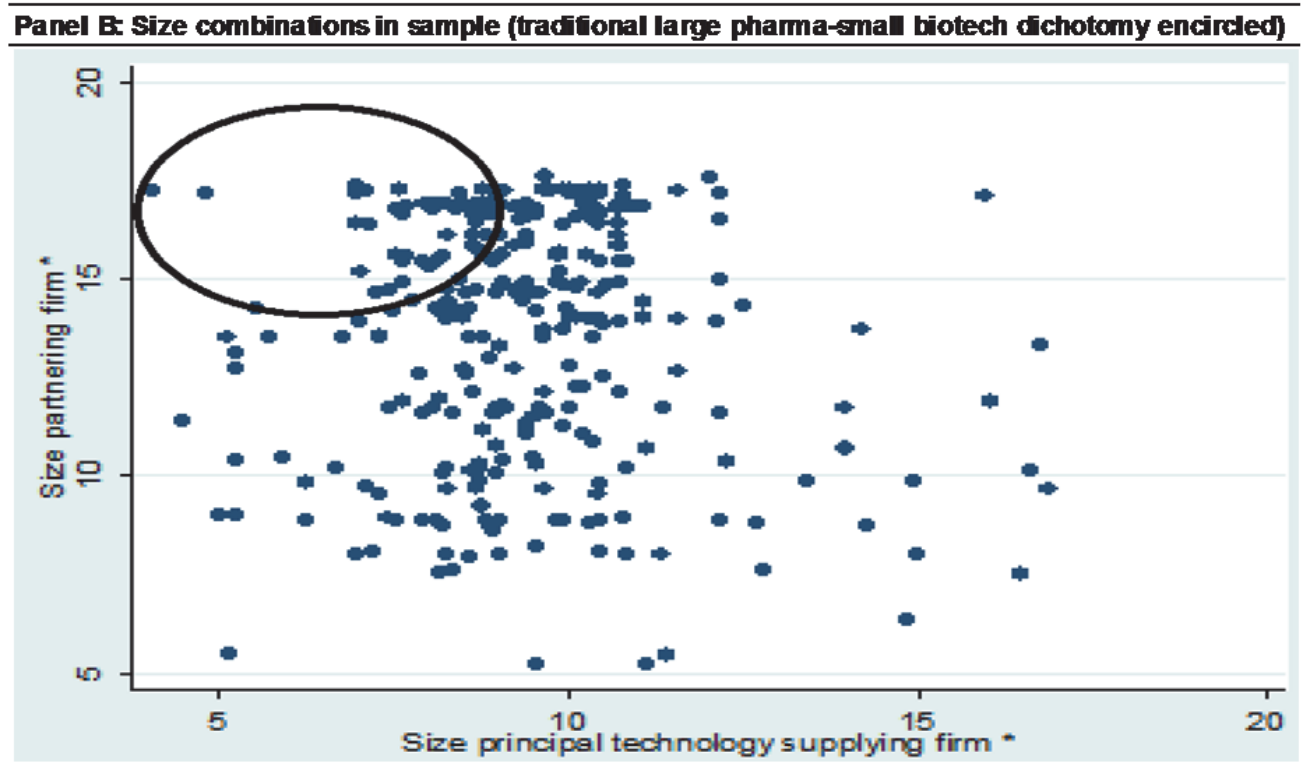

Panel C: Alliance contract characteristics Imovation process stage

Collaborative research (\%)

Co-development (\%)

Alliance characteristics

US Partners (\%)

Potential Applications

Equity investment (\%)

R\&D Plus (\%)

Time-bound (\%)

Competition

Bidech fm (\%)

\section{Allocation of control rights}

Control rights to pincipel technology supplying

fm (out of 6)

$\begin{array}{lllll}0.59 & & & 0 & 1 \\ 218 & 2 & 1.29 & 1 & 8 \\ 0.33 & & & 0 & 1 \\ 0.31 & & & 0 & 1 \\ 0.16 & & & 0 & 1 \\ 0.97 & 1 & 0.88 & 0 & 2 \\ 0.47 & & & 0 & 1\end{array}$

- The size of firms in panel $B$ is in log(net sales)

$\begin{array}{lllll}209 & 2 & 1.20 & 0 & 6\end{array}$


Patenting intensity as such indicates the degree to which a firm, given its size, has successfully obtained patents as a major output of its innovative activities. Patenting intensity asymmetry refers to the difference between a primary, initial technology supplying firm and its alliance partner in terms of the degree to which these firms have developed their innovative capabilities from an innovation output perspective.

For each firm I collected data on the number of its US patents obtained filed in a five year period prior to signing the alliance contract. Assume A is the primary technology supplying firm and $\mathrm{B}$ its partner, this variable is defined as follows:

Patenting Intensity Asymmetry $=\frac{\left(\text { Patenting Intensity }_{A}\right)-\left(\text { Patenting Intensity }_{B}\right)}{\left(\text { Patenting Intensity }_{A}\right)+\left(\text { Patenting Intensity }_{B}\right)}$

Where Patenting Intensity is defined as follows:

Patenting Intensity $=\frac{\text { Number of patents }}{\text { Net sales }}$

As with the R\&D input indicator of innovative capabilities asymmetry, I take the perspective of the primary technology supplying firm, whether this firm is larger or smaller than its partner. Hence, I propose the variable given in equation (3), which generates a value between -1 and +1 .

For about $11 \%$ of the observations in my sample there is no patent registered with the USPTO by at least one of the R\&D alliance partners. In that case one or both partners had either no patent at all or not applied for a patent during a window of five years preceding the alliance. These $11 \%$ might alter the results since in these cases the value of the Patent Intensity Asymmetry measure always takes on a value of 1 or -1 , regardless of the Patent Intensity of firm A or B respectively. Therefore, in unreported analyses, I exclude the $11 \%$ where no patent was registered with the USPTO by one or both partners. Results for these regressions are similar to the results presented below.

Yet another alternative indicator of innovative capabilities that I considered is based on the frequently used measure of citation weighted patent counts, to control for the quality or value of patents. However, apart from the fact that missing values for patent counts implies that I cannot find patent citations for these firms, which already at the start reduces the sample with more than $10 \%$, there is a larger additional problem with the citation time lags that affect the current sample period. The relevant period between patent granted and patent citation covers a period of between two and eight years, with an additional period of at least two years between patent application and patent granted (Hall, Jaffe, and Trajtenberg, 2005). Given the data available at the USPTO, I would, even if I limit the citation lag to a maximum of five years, only be able to include citation weighted patent counts for the period 1996-1998 which would decrease the size of my sample with approximately $70 \%$.

Given such limitations, I present the results of the analysis with patenting intensity asymmetry, based on patent counts, as a second indicator of innovative capabilities asymmetry (see Table 2.2). 


\title{
R\&D Alliance Contracts in the Biopharmaceutical Industry: the Stipulation of Contractual Coordination Committees ${ }^{11}$
}

\begin{abstract}
Alliance contracts between firms serve both to control and to coordinate joint activities. I study alliance governance structures that I label as contractual coordination committees, implemented in these alliance contracts, designed specifically to coordinate the activities of alliance parties. Using a dataset of $304 \mathrm{R} \& \mathrm{D}$ contracts in the biopharmaceutical industry, I find two conditions imperative in explaining the degree to which alliance parties supplement their contract with contractual coordination committees to support and guide the alliance process. The first condition refers to the nature of the alliance activity, in terms of both its transactional complexity and the degree of interfirm dependence between alliance parties. The second condition considers a more dynamic factor namely the alliance experience of contract parties.
\end{abstract}

\footnotetext{
11 This chapter is based on collaborative work with John Hagedoorn. I thank Martin Carree, Hans Frankort, Geerte Hesen, and participants at seminars at Copenhagen Business School, the European School on New Institutional Economics 2011, KU Leuven, Maastricht University, Tilburg University, and participants at the 2012 Academy of Management conference for helpful suggestion and comments on earlier versions of this paper.
} 


\subsection{Introduction}

Interfirm alliance contracts executed under conditions that are subject to frequent changes fall short of comprehensive contracting, i.e., in such a setting it becomes prohibitively costly, if not impossible, for firms to draw up complete contracts (Williamson, 1979). Apart from foregoing alliances all together or organizing the relevant activities internally, firms can search for an alternative, contractually incomplete, interfirm relationship that accounts for changing conditions. Such an alternative interfirm contracting relationship not only preserves interfirm exchange, but it also supplements the contract with additional governance structure(s) that will enable parties to adjust their alliance as it develops (Williamson, 1979). Following amongst others Llewellyn (1931), Macneil (1978; 2000) and Williamson (1979; 1996), I thus perceive an interfirm alliance contract not only as subject to legal rule but also as a framework that governs the relationship between organizations (firms). Seen from this neoclassical contracting perspective, contracts as a framework for governance are characterized by their high degree of adjustability, their informative nature on how the relationship between contract partners should work and develop, and their private ordering that is geared towards problem solving. This neoclassical contracting perspective also stresses that farsighted, incomplete contracting (Williamson, 1996) can use institutions as an effective coordination tool. Within interfirm alliances these institutions are to be primarily seen as micro-institutions that, as stipulated in an interfirm contract, structure and govern the behavior of contract parties through mechanisms for social order and cooperation. ${ }^{12}$ In short, these contractual institutions are set-up to coordinate the activities of contract parties.

Following Malone (1987), I understand this coordination within an alliance contract to focus on joint decision-making and communication among contract parties to improve the performance of a number of tasks in order to achieve broadly pre-defined goals. This definition of coordination encompasses the one given by Gulati and Singh (1998) who highlight the uncertainty that parties experience at the outset of the alliance, uncertainty which results from the anticipation of an ex-post need for mutual adaption and adjustment.

I define alliance coordination committees, stipulated in interfirm alliance contracts, as the actual coordinating institutions that contract parties use for their alliances. In the following, I investigate which factors are related to the number of coordination committees specified in R\&D alliance contracts, i.e., those alliances for which the joint $R \& D$ and $R \& D$ based technology sharing is a major objective of the agreement. These coordination committees define key interfirm personnel to facilitate mutual decision-making and they specify a minimum number of meetings per year to promote communication (Adler, 1995). As alliance contracts are inevitably incomplete (Williamson, 1985), ex-ante stipulation of a number of coordination committees facilitates ex-post communication concerning non-contractible alliance activities. By frequently discussing the progress of an alliance activity, parties will find it easier to adjust the initial plan laid out in the contract in response to recent developments. Referring to Simon's (1976) differentiation into procedural and substantial coordination, the coordination committees stipulated in the alliance contracts that I study are both of a substantial and a procedural nature. The main tasks of these coordination

\footnotetext{
12 Based on Hagedoorn (1993) and Gulati and Singh (1998) I define an interfirm alliance as an arrangement through which partners share resources and assets, which can take a variety of organizational forms and refer to a wide range of motives and goals.
} 
committees are specified in terms of what is to be done in the alliance, the expected behavior of contract parties, and the nature of their relationship.

The goal of this paper is to fill a gap in the literature on the interfirm coordination aspect of alliance contracts. Alliances require considerable coordination efforts aimed at jointproblem solving to avert alliance failure (see Doz, 1996). Alliance contracts with provisions that facilitate real-time information sharing and feedback between alliance parties will help to minimize misperceptions and strengthen cooperative behavior (Parkhe, 1993). While the literature on interfirm coordination recognizes that different interfirm alliances also require different coordination mechanisms (see for instance Grandori, 1997), the claim that the contract itself reveals aspects of coordination has received only scant attention in the literature (Furlotti, 2007; Reuer and Ariño, 2007). By and large, studies on contract design usually associate interfirm coordination with contractual complexity (Hagedoorn and Hesen, 2009; Poppo and Zenger, 2002; Reuer and Ariño, 2007; Reuer, Ariño and Mellewigt, 2006; Ryall and Sampson, 2009). However, the kind of coordination that is studied in the current contribution refers to a more fine-grained construct than contractual complexity as indicated previously by studies on intrafirm level coordination (e.g. Adler, 1995; van de Ven, Delbecq and Koenig, 1976). That line of research demonstrates that as tasks for teams within organizations become more interdependent and uncertain, reliance on formal rules and plans tend to decline. Moreover, for uncertain and interdependent tasks the usage of coordination committees to facilitate communication and mutual adjustment between teams in organizations increases substantially.

Similar to the observed variation in coordination in integrated structures, ${ }^{13}$ I expect the degree of coordination (the intensity of the interfirm coordination) and the kind of coordination (relatively rigid use of rules stipulated in a contract or more flexibility through committees) to vary with the diversity in alliance contracts. When alliance activities are intrinsically complex, as is the case when combining different types of know-how in pursuit of a common objective, coordination difficulties are especially profound and designing adequate coordination mechanisms in the contract is not a straightforward task and will demand alliance experience (Grandori, 1997; Schreiner, Kale and Corsten, 2009). As such, in addition to transaction related elements, I also expect a strong experience effect in establishing these interfirm coordination mechanisms.

In light of the above, this paper makes three contributions to the existing literature on contract design. First, it sheds a light on the notion of contracts as frameworks by specifically investigating the contractual mechanisms parties put in place to support and guide collaborative activities. Second, contingent on the assumption that alliances lacking sufficient interfirm coordination are more prone to fail (Doz, 1996, Park and Ungson, 2001), I investigate the factors associated with the number of coordination committees. If, at the contract signing date, alliance partners are particularly concerned with ex-post coordination requirements (Gulati and Singh, 1998), investigating the factors associated with the number of coordination committees can provide fruitful insights into the conditions under which parties opt for more or less interfirm coordination. Third, previous research mainly stressed the proper allocation of unilateral control rights over decisions that cannot be contractually

\footnotetext{
${ }^{13}$ For instance, van de Ven, Delbecq and Koenig (1976) find that work units in a firm meet more often through committees when the interdependence of their activities increases. However, the use of pre-defined plans and rules declines as the interdependence increases.
} 
specified as critical to guide and control the alliance as circumstances change (e.g. Lerner and Merges, 1998). However, in the context of the R\&D alliances that I study, technology complementarity is an important motive for the formation of these alliances (Hagedoorn, 1993). Given this complementarity, changing conditions, unforeseen at the outset of the alliance, require mutual adaptations between parties rather than unilateral control of one party over another. In fact, as opposed to a zero-sum game approach in which one party wins and the other party loses, the R\&D alliance process can often be more adequately characterized as supportive and cooperative (Grandori, 1997). In this study, I highlight this supportive and cooperative nature by investigating the association of several factors with a particular type of mechanism, i.e., coordination committees, by which parties can communicate over noncontractible activities and make alterations to the initial contract if circumstances so dictate. I extend literature on coordination within firms (e.g. Adler, 1995; van de Ven, Delbecq and Koenig, 1976), by focusing on the level of interfirm coordination. I believe this shift in attention is warranted, as facilitating the supportive and cooperative nature of the collaborative R\&D process is an important, yet insufficiently highlighted, function of interfirm contracts.

Inspired by organizational economics, strategy, and organization literatures on the design of contracts, I focus on three conditions likely to be associated with the number of coordination committees stipulated in an R\&D alliance contract. The first condition refers to the nature of the alliance activities, underlying the R\&D alliance, i.e., I consider technological uncertainty, transactional complexity, and interfirm dependence (Brousseau, Coeurderoy and Chaserant, 2007; Mowery, Oxley and Silverman, 1996; Ryall and Sampson, 2009; Shelanski and Klein, 1995). The second condition deals with the geographical distance between alliance partners (Andersen, 1999; Grinter, Herbsleb and Perry, 1999; Hoegl and Proserpio, 2004; Olsen and Olsen, 2000; Torre and Rallet, 2005; Whittington, Owen-Smith and Powell, 2009). The third condition refers to a more dynamic element namely the previous alliance experience of alliance parties (Kale, Dyer and Singh, 2002; Levitt and March, 1988). Throughout this paper, the emphasis will, given the possible correlations of error terms with explanatory variables and the dependent variable, be on association rather than on causal inference. As such, I think that in this particular setting, where I face endogeneity issues, I prefer to obtain reliable associations rather than causal effects.

I find support for three out of five hypotheses. Transactional complexity, the interdependence of alliance contract parties, and the alliance experience of firms are related to the number of coordination committees stipulated in an R\&D alliance contract. However, auxiliary analyses hint at the proposition that the relationship between transactional complexity, in terms of additional alliance activities, and the number of coordination committees stipulated in an R\&D alliance contract appears to be not straightforward, i.e., some additional activities appear to be unrelated with the number of stipulated committees. Contrary to my expectations, I find no significant relationship between technological uncertainty and the number of coordination committees, nor a significant relationship between geographical distance and the number of coordination committees stipulated in an $R \& D$ alliance contract. 


\subsection{Theoretical background and hypotheses}

\subsubsection{Coordination committees}

For alliances pooling complementary knowledge and capabilities, the intrinsic sophistication of activities (e.g. R\&D) - which requires resources from both firms - increases the need for interfirm coordination (Grandori, 1997; Hagedoorn, 1993). For this type of alliances, coordination mechanisms are expected to guide collaborative efforts and to facilitate real time adjustment of the initial alliance contract within and between activities undertaken in an alliance.

One particular mechanism through which firms can guide collaborative efforts and facilitate mutual adjustments in an alliance is to include coordination committees in an alliance contract (Adler, 1995). These coordination committees refer to a subset of committees that parties can stipulate in their contract to guide and monitor the alliance. More specifically, the literature on contract design proposes two different functions of committees, i.e., to control and to coordinate. So far, much of the previous literature on contract design focuses on control through the allocation of unilateral control rights (e.g. Adegbesan and Higgins, 2011; Higgins, 2007). In terms of committees, Lerner and Merges (1998) highlight the role committees can play in the allocation of these control rights, i.e., they classify the decisive vote in a top project management body as a critical control right. However, interfirm coordination in general and more specifically the coordination function of committees remains relatively unexplored (Grandori, 1997). In the following, I do focus on those committees that facilitate coordination, hereafter labeled as coordination committees (see Adler (1995) for a similar classification). ${ }^{14}$ These coordination committees are expected to facilitate mutual decision-making and communication, amongst others, by stipulating key interfirm personnel and a minimum number of meetings per year.

There are three reasons why firms may want to specify a range of coordination committees in an alliance contract. First, long-term contracting under changing conditions results in incomplete contracts (Williamson, 1985). As such, while executing the contract, alliance parties run the risk that particular circumstances have changed (e.g. due to technological development) which requires alterations to the original contract. Obviously, at the signing date of the alliance, these new circumstances and the required alterations to the contract were unknown. Nevertheless, parties do, to some extent, have the ability to look ahead and recognize potential problems (Williamson, 1996; 1999). As stated by Macneil: "[t]wo common characteristics of long-term contracts are the existence of gaps in their planning and the presence of a range of processes and techniques used by contract planners to create flexibility in lieu of either leaving gaps or trying to plan rigidly" (Macneil, 1978, p. 865). Therefore, alliance parties are expected to supplement formal contracts with the stipulation of a number of coordination committees for areas of collaboration for which flexible, bilateral coordination is most needed. Consistent with a neoclassical view on contracting (Williamson, 1979), with the initial contract as reference point, parties can make changes to the contract over time as the alliance progresses and conditions change (Williamson, 1979).

\footnotetext{
${ }^{14}$ As such, this research purposely excludes those committees that refer to unilateral control rights.
} 
Second, in their definitions of coordination, both Malone (1987) and Gulati and Singh (1998) highlight communication between parties as an important element of coordination. Coordination committees, by requiring frequent meetings between key personnel, can facilitate communication between alliance parties. As can be seen in the example presented below, an inherent part of drafting coordination committee clauses in an alliance contract refers to the specification of minimum ex-post communication requirements. As parties discuss recent developments and their impact on the alliance, transparency of (collaborative) efforts in pursuit of common goals is increased (Faems et al., 2008). Consequently, it is less likely that a situation will occur in which set-backs in research, development or another activity will be attributed to sluggishness on the part of one of the alliance parties. Absent sufficient coordination committees to facilitate communication, alliance parties might try to unilaterally play a coordination role within the alliance while the collaborative activities actually call for a bilateral response (Ariño and de la Torre, 1998; Doz, 1996). The above is illustrated by the following excerpt from an alliance contract between Dyax and Epix Medical (June 20 $0^{\text {th }}$ 1997):

"The Steering Committee shall conduct monthly telephone conferences during the Research Program, and quarterly telephone conferences during the MRI Development Program and RadioPharma Development Program, and shall prepare and deliver a brief written report describing the significant issues and discussions that take place during such conferences. (...). The Steering Committee shall meet at least once each quarter alternately at the parties' locations, or at such other times and locations as the Steering Committee determines."

Third, joint-decision making is a key aspect of coordination in order to achieve broadly predefined goals (Gulati and Singh, 1998; Malone, 1987). Many coordination committees include statements such as "...such amendments to be mutually agreed to by ImClone and CombiChem" (excerpt from an alliance contract between CombiChem and ImClone Systems, October $\left.10^{\text {th }}, 1997\right)$, highlighting this joint decision making. The main advantage of this joint decision-making as part of coordination is that the outcome is more likely to be acceptable for both parties (Malone, 1987), because both parties feel they are actively involved in shaping the direction of their collaboration (Faems et al., 2008).

As mentioned in the above, the organizational economics, strategy, and organization literatures suggest three conditions likely to be associated with the number of coordination committees stipulated in alliance contracts. These conditions, elaborated upon further below, refer to the nature of alliance activities, the geographical distance between alliance parties, and the alliance experience of contract parties.

\subsubsection{Nature of the alliance activity}

Concerning the nature of the alliance activities, I expect three factors to be related to the number of coordination committees that parties stipulate in their R\&D contract. The first factor I consider is the technological uncertainty surrounding the alliance. More specifically, I expect a positive association between the technological uncertainty surrounding an alliance and the number of coordination committees. 
As firms are subject to bounded rationality when drafting an alliance contract, there are certain limits to the number of possible future disturbances these firms can anticipate. In particular in alliances characterized by high technological uncertainty, standardization of activities by inclusion of detailed provisions in the alliance contract is difficult as many deviations from this contract might be required (Pisano, 1989; van de Ven, Delbecq and Koenig, 1976). The trial-and-error method of problem solving, typical for alliances involving highly uncertain technologies, makes the non-contractible efforts of parties critical to alliance success (Lerner and Malmendier, 2010). Therefore, alliance parties need to frequently communicate with each other to monitor the progress of highly uncertain collaborative activities to achieve broadly pre-defined goals as specified in their contract (Malone, 1987). Also, the non-contractible nature of alliance activities requires flexible adjustment mechanisms to alter the work undertaken through the alliance in response to unforeseen disturbances. Consequently, I expect parties to an alliance characterized by high levels of technological uncertainty to stipulate more coordination committees in their contract. As the number of deviations from the initial contract, due to task uncertainty, increases and adherence to strict rules becomes more difficult, these coordination committees guide the collaboration of firms (Grandori, 1997; van de Ven, Delbecq and Koenig, 1976). Alternatively, I expect that for alliances characterized by lower levels of technological uncertainty, with fewer unexpected changes and disturbances, there is less need for parties to frequently communicate with each other and to monitor the progress of their collaborative activities. Therefore:

Hypothesis 1. The number of coordination committees stipulated in an alliance contract is larger for an alliance characterized by high technological uncertainty compared to an alliance characterized by low technological uncertainty.

Alliance contracts are also known to vary in their transactional complexity (see, for instance, Hagedoorn and Hesen, 2009) which is characterized by the number of interrelated activities undertaken within the scope of the alliance. I understand this transactional complexity in terms of the number of interrelated activities as a second factor representing the nature of alliance activity.

Alliance contracts characterized by low transactional complexity include a limited set of interrelated activities and require little bilateral adjustment between alliance parties (Grandori, 1997; Gulati and Singh, 1998; Ryall and Sampson, 2009). Contracts including a limited number of interrelated activities thus put less ex-post coordination strains on alliance parties. For example, in an alliance solely focusing on collaborative research with no close-to-themarket related activities (e.g. production, logistics, or marketing), the main burden of coordination will fall on key R\&D personnel from both partners that will have to frequently communicate with each other. As the alliance focuses on only one particular activity, there is no need to communicate with key personnel of both parties that represent other activities down the value chain. Therefore, for contracts characterized by relatively low complexity, the need to stipulate a multitude of coordination committees is low.

Contrary to the above, contracts characterized by high transactional complexity involve a larger set of interrelated activities and require more bilateral adjustment between alliance parties (Gulati and Singh, 1998; Ryall and Sampson, 2009). A mere summation of activities in an alliance is even likely to underestimate transactional complexity as interrelations 
between activities also bring about additional complexity. For instance, in alliances that include joint research activities, production, and marketing, key R\&D, production, and marketing personnel from both parties will not only have to coordinate efforts within their own field but also with each other. This puts additional strains on ex-post coordination requirements as the interrelations between activities have to be managed. Parties can stipulate more formal rules to facilitate coordination regarding these additional activities. However, due to bounded rationality of parties, their farsightedness in anticipating these coordination issues is limited (Williamson, 1985; 1996; 1999). As such, for contracts characterized by high transactional complexity, I expect parties to implement additional (more flexible) governance structures to support and guide the alliance process (Grandori and Soda, 1995). Hence:

\section{Hypothesis 2. The number of coordination committees stipulated in an alliance contract is larger for an alliance characterized by high transactional complexity compared to an alliance characterized by low transactional complexity.}

The third factor of the nature of alliance activity refers to the relatedness of the activities of partner firms, i.e. their interfirm dependence (Grandori and Soda, 1995; Gulati and Singh, 1998; Tushman, 1977; van de Ven, Delbecq and Koenig, 1976). In terms of interfirm dependence, one side of the spectrum is occupied by alliances that require considerable joint efforts of parties in order to achieve the goals set forth in the alliance contract (for instance, joint research projects). The other side of the spectrum consists of fairly simple alliances (for instance, 'technology for cash' agreements) where there is little interfirm dependence in the actual work being done through an alliance (Mowery, Oxley and Silverman, 1996).

At the outset of an alliance, i.e. the contract signing date, the anticipated level of the degree to which parties need to work together in order to achieve alliance goals creates ambiguity about how to coordinate these efforts (Gulati and Singh, 1998). In alliances in which there is a strict separation between both the activities to be performed under the contract and the different roles of both parties, the need for mutual adaptation and communication can be characterized as low. In contrast, in alliances where it is difficult, or even impossible, to attribute individual activities to a particular alliance partner, i.e., the activities of firms are highly interdependent, parties need to frequently communicate and coordinate their efforts in order to achieve the alliance goals. As such, I anticipate that for alliances that involve a higher level of interfirm dependence induced by collaborative activities, the number of stipulated coordination committees will be larger compared to alliances which are characterized by relatively lower levels of interfirm dependence. ${ }^{15}$

15 The proposed relationship is to some extent subject to the criticism that both the dependent and the independent variable are conceptually related, i.e., the number of coordination committees may itself be a measure for the level of interfirm dependence. However, similar to previous contributions (e.g. Gulati and Singh, 1998; van de Ven, Delbecq and Koenig, 1976) I maintain that studying the proposed relationship has merit for two reasons. First, studies on the intrafirm level show that increased task interdependence increases the use of some coordination mechanisms, but decreases the use of other coordination mechanisms (van de Ven, Delbecq and Koenig, 1976). In that sense, a large number of committees stipulated in a collaboration contract may actually be a sign of a relatively low level of task interdependence between parties. Indeed, when task interdependence is low, firms may be unaware of each other's day-to-day activities and developments, and stipulate several coordination committees to periodically assess each other's progress under the agreement and to make adjustments to their collaboration if necessary. Second, low or high task interdependence may not be reflected in the number of coordination mechanisms, but rather in the extent to which they are used ex-post. 
Hypothesis 3. The number of coordination committees stipulated in an alliance contract is larger for an alliance characterized by high interfirm dependence compared to an alliance characterized by lower interfirm dependence.

\subsubsection{Geographical distance}

Departing from a focus on the nature of the alliance activity, I turn to the geographical distance between firms in explaining their propensity to stipulate coordination committees. Based on a number of previous studies, I suggest that the number of coordination committees is positively related to the geographical distance between partner firms.

Collaborative R\&D tasks require an ongoing coordination of activities and interfirm communication (Hoegl and Proserpio, 2004). Nevertheless, previous research suggests that parties' ability to engage in information rich and informal communication is largely dependent on the geographical distance between them (Andersen, 1999; Grinter, Herbsleb and Perry, 1999; Hoegl and Proserpio, 2004; Olsen and Olsen, 2000; Torre and Rallet, 2005; Whittington, Owen-Smith and Powell, 2009). For geographically dispersed firms, casual and unplanned meetings to discuss progress of collaborative endeavors might be problematic. By comparison, geographically proximate firms are likely to be able to rely on informal communication to coordinate their collaborative activities. As a result, geographically dispersed firms might turn to more formal mechanisms of coordination to substitute for their lacking ability to meet on an ad hoc basis (Hoegl and Proserpio, 2004; Olsen and Olsen, 2000; Whittington, Owen-Smith and Powell, 2009). Ad hoc communication is just one method by which alliance parties can coordinate their activities (Grinter, Herbsleb and Perry, 1999), and alternative coordination mechanisms such as coordination committees might substitute for them.

In light of the above arguments, I expect that alliance partners located in close geographical proximity stipulate only few coordination committees. As the geographical distance increases, I expect that the number of coordination committees increases to compensate for the diminished possibility of meeting informally. Hence:

Hypothesis 4. There is a positive association between the geographical distance between alliance parties and the number of incorporated coordination committees in an alliance contract.

The above four hypotheses all focus on relatively static elements, i.e., transaction related features and geographical distance between partner firms, and the relationship with the number of stipulated coordination committees in R\&D alliance contracts. However, ample evidence exists that parties do not contract in a vacuum but learn from previous experiences and adapt subsequent contracts accordingly (e.g. Argyres, Bercovitz and Mayer, 2007). For relatively complex alliances, such as R\&D collaborations, designing adequate contractual coordination mechanisms is a non-straightforward task (Grandori, 1997; Schreiner, Kale and Corsten, 2009) and I expect strong dynamic, experience-based features in the design of these coordination devices. 


\subsubsection{Alliance experience}

From a neoclassical contracting perspective, interfirm contracts serve a twofold purpose. First, contracts set out the legal rules and responsibilities parties are deemed to adhere to during contract execution. Second, contracts are designed to facilitate collaboration and communication in order to achieve the alliance goals. In the latter context, Doz (1996) finds that, over time, parties learn to device coordination mechanisms in order to support their collaborative endeavors. This is supported by Grandori (1997) and Schreiner, Kale and Corsten (2009) who state that designing these contractual coordination mechanisms is not a simple and straightforward task but a task that requires experience. Firms with more alliance experience often possess dedicated alliance personnel, such as R\&D alliance managers, primarily tasked with facilitating interorganizational coordination (Kale, Dyer and Singh, 2002; Schilke and Goerzen, 2010). This suggests that inexperienced alliance parties tend to underestimate the importance of the coordination aspect of contracts and furthermore lack the ability to maintain elaborate coordination committee structures, while more experienced alliance parties probably do not.

In light of the above, I expect that experienced alliance parties will contractually specify more coordination committees for two reasons. First, although drafting complete contracts is prohibitively costly and often impossible (Williamson, 1985), parties can learn from previous experiences (Levitt and March, 1988) and incorporate subsequent changes in their alliance contracts (Argyres, Bercovitz and Mayer, 2007; Luo, 2002). As lack of sufficient interfirm coordination is often associated with alliance failure (Doz, 1996; Park and Ungson, 2001), I expect that, in terms of the number of contractually specified coordination committees, experienced alliance parties are inclined to pay more attention to the second function of an alliance contract, namely, to facilitate collaboration and communication. Second, I not only expect that experienced alliance firms are more aware of the necessity to collaboratively guide the alliance and to frequently communicate with their partner, but they are also more able to do so. Compared to relatively inexperienced firms, more experienced firms have a better understanding of where and how to tap into their internal resources and to employ these resources in support of the alliance objectives (Kale, Dyer and Singh, 2002; Kotabe, Martin and Domoto, 2003). In addition, Schilke and Goerzen (2010) find a significant and positive relationship between the alliance experience of firms and alliance structures, i.e., "...specialized organizational units and personnel dedicated to the management of strategic alliances" (Schilke and Goerzen, 2010, p. 1194). Firms with more alliance experience are thus more likely to have dedicated alliance personnel such as alliance managers, R\&D project leaders, and communication liaisons tasked with interfirm communication and coordination. I therefore posit that when both firms have at least some alliance experience, one is more likely to observe a range of coordination committees. If one alliance party has none or only limited alliance experience, I expect that it will fail to supply the demanded dedicated alliance personnel necessary to maintain a host of coordination committees. Hence:

Hypothesis 5. There is a positive association between the alliance experience of the least experienced alliance party and the number of incorporated coordination committees in an alliance contract. 


\subsection{Data, methods, and sample description}

My sample covers a set of 304 R\&D alliance contracts in the biopharmaceutical industry obtained from Pharmaventures, a UK-based information and consulting firm. Pharmaventures has identified thousands of alliances in the biopharmaceutical sector in their PharmaDeals database. The collected deals are grouped into a number of categories, such as collaborative R\&D, distribution/marketing, manufacturing/supply, and business acquisition. For each agreement, the PharmaDeals database provides information on the names of the partners, type of contractual relationship, date deal signed, equity investment, relevant product areas and technology fields, press releases and, where available, the actual contracts. These actual contracts were obtained from the U.S. Securities and Exchange Commission (SEC) filings and Pharmaventures' clients.

My dataset covers R\&D alliance contracts and additional information for the period 1996 through 2005. I collected information on alliances where the main focus is on collaborative R\&D and for which PharmaDeals includes an actual legal document (contract). In addition, all alliances fall within the biopharmaceutical industry. By specifically focusing on the biopharmaceutical industry, I can be assured that variation in contracting terms and coordination committees does not come from a variation in the underlying industrial contracting environment. Moreover, by only including R\&D alliances, I do not contaminate the sample with alliances that focus primarily on different parts in the value chain that might differ in degree and kind in terms of coordination requirements.

The preliminary sample comprised 587 deals for the period 1996-2005. To avoid further unnecessary heterogeneity I excluded all the agreements where:

- one of the parties is a government agency or university

- the alliance is, as stated in the contract, a renegotiation or restatement of a previous alliance between the firms

- there is no R\&D component to the alliance

- one firm has a controlling interest in the other firm (greater than 50\%)

- contracts involve more than two parties.

The final contract database contains a set of 304 contracts. These contracts represent the first interaction between the firms as found in the PharmaDeals dataset for the period 19962005. Because I look at the first interaction of parties in the period 1996-2005, an alliance contract between firms A and B appears only once in the final dataset.

The agreements include both U.S. (domestic) contracts, i.e., the contracting parties are both U.S.-based firms (176 alliances), and international contracts, i.e., a U.S.-based firm collaborates with a non-U.S. based firm (128 alliances). A total of 284 firms were involved in the 304 contracts and about $55 \%$ of the agreements were concluded between a biotech firm and a pharmaceutical or a chemical firm.

I collected additional information on the size of firms, their R\&D expenditures, their US patents, alliance experience, and prior ties between partners for the firms participating in these 304 deals. The complete dataset combines information from PharmaDeals with data retrieved from firm annual reports, the Cooperative Agreements and Technology Indicators (CATI) database, Datastream, Compustat, LexisNexis, Corptech, and the USPTO. 


\subsubsection{Dependent variable}

Coordination committees. I measure coordination committees by counting the number of committees stipulated by parties in an R\&D alliance contract excluding those which assign unilateral control rights. Previous research in this area has mainly equated contingency planning with contractual complexity (e.g. Poppo and Zenger, 2002). More specifically, this stream of research investigates the determinants of the degree to which contracts between alliance parties are customized. Similar to Reuer and Ariño (2007) I sidestep such an approach, by taking a more focused look at the specific contractual coordination mechanisms through which alliance parties guide their alliance. In addition, I focus on the number of bilateral contractual coordination mechanisms that parties stipulate in their contract. Given the joint R\&D nature of my sample, the alliance process is often perceived as cooperative, emphasizing joint problem solving (Grandori, 1997). As such, looking at coordination committees that facilitate mutual adjustment between parties (Adler, 1995), seems more appropriate.

Previous studies on interfirm coordination (e.g. Reuer and Ariño, 2007) look at the addition of clauses such as 'Notification rights for departures from the agreement' and 'Auditing rights'. I subscribe to the importance of contracts as coordination mechanisms, but deviate from this line of research on three crucial elements. First, the clauses mentioned in the above have a strong control connotation as they seem to be more related to monitoring than to interfirm bilateral coordination that requires input from both parties. This could, for instance, explain the negative relationship between prior ties and coordination provisions found by Reuer and Ariño (2007). Here, I focus on more collaborative interfirm coordination mechanisms, i.e., coordination committees. These coordination committees are put in place to facilitate mutual problem solving and aid in the collaborative guidance of the alliance.

Second, papers focusing on contractual complexity (Poppo and Zenger, 2002; Hagedoorn and Hesen, 2009) usually assume that more comprehensive contracts include responses to a wider array of known contingencies. I extend this perspective by explicitly focusing on coordination mechanisms used to promote mutual decision making and to facilitate communication concerning contingencies unknown at the signing date of the alliance.

Third, in most previous research, interfirm coordination through contracts is measured through survey responses (Poppo and Zenger, 2002; Reuer and Ariño, 2007). I operationalize interfirm coordination through a count of coordination committees as mentioned in the actual contract. While most literature does underline that different alliances require different coordination mechanisms in support of their formal contracts (see for instance Grandori, 1997), the number of empirical studies actually focusing on these coordination provisions in contracts is limited (Furlotti, 2007).

\subsubsection{Independent variables}

Technological uncertainty. The PharmaDeals database provides information on the stages of the innovation process underlying the deal. These stages refer to an early stage of collaborative research and a later stage of co-development of new products. Alliances focusing on the later development stage often start from a pre-defined set of technologies that are further developed into commercial applications (Freeman and Soete, 1997), and hence, represent limited technological uncertainty. In contrast to this, alliances that involve more 
research oriented activities are characterized by a multitude of possible research options and inherent uncertainty caused by the experimental nature of these activities (Freeman and Soete, 1997; Nelson, 1961). I use a dummy variable that equals 0 if the alliance contract concerns co-development of products and 1 if it refers to collaborative research endeavors.

Transactional complexity. As indicated in the above, all alliances in the sample have an R\&D component. However, many alliances also include additional activities such as marketing, distribution and/or manufacturing. Such additional activities increase the transactional complexity of the alliance by broadening its scope (Ryall and Sampson, 2009; Sampson, 2004b). Moreover, the interdependent nature of these activities introduces additional complexity as these interrelations have to be managed. I therefore include a dummy variable that equals 1 if any additional activities are included besides R\&D and 0 otherwise.

Interfirm dependence. Although all alliances in my dataset involve two firms working together in research and/or development, responsibilities for particular tasks are not necessarily symmetrically divided. In fact, it is not unusual in the biopharmaceutical industry that one firm is responsible for the bulk of the research activities while its partner is more involved with market-oriented activities such as marketing (Lerner and Malmendier, 2010). An alliance can involve a rather unidirectional work flow whereby, for instance, one firm screens validated targets against molecules, i.e., compounds, provided by the other firm (see Stuart, Ozdemir and Ding (2007) for a short summary of the drug development process). I proxy interfirm dependence by whether or not the alliance involves contract $R \& D$, i.e., whether the bulk of the research and/or development is the main responsibility of one the alliance parties. In such a case, activities within the scope of the alliance require less mutual adaptation which is likely to be reflected in the number of stipulated coordination committees (van de Ven, Delbecq and Koenig, 1976). Most R\&D alliances include an R\&D plan with specific responsibilities for these R\&D activities. If it is stated in the contract that the tasks and deliverables defined under the R\&D plan guide the efforts of only one party, the interdependent nature of alliance activities is relatively low. As such, I use a dummy variable that equals 0 if the $R \& D$ plan guides the efforts of only one party, i.e., the interfirm dependence is low, and 1 otherwise. ${ }^{16}$

Geographical distance. Using data from PharmaDeals I was able to determine the geographical locations of both firms participating in an alliance on a city level. Previous literature has measured the geographical distance between two regions or cities in various ways. Most common are driving time, driving distance, and geodetic distance. I use the direct great circle distance ('as the crow flies'). Given the latitudes and longitudes of two cities, distance is calculated as:

Distance $=\varphi * \omega$, with;

$\varphi=$ earth radius

$\omega=\arccos \left(\cos \left(90-l a t_{2}\right) \cos \left(90-l a t_{1}\right)+\sin \left(90-l a t_{2}\right) \sin \left(90-l a t_{1}\right) \cos \left(\operatorname{lon}_{2}-\right.\right.$ $\left.\left.\operatorname{lon}_{1}\right)\right)$

And geographical distance $=\log (1+$ Distance $)$

\footnotetext{
${ }^{16}$ The definition of this variable implies that those alliances that do not include an R\&D plan are classified as involving high interfirm dependence. I therefore rerun the models on the subset of alliances in which parties stipulate an R\&D plan. Results are similar to those presented here.
} 
I add plus one to the distance to account for a few firms that are located in the same city.

Alliance experience. Using the CATI database, I obtained the prior R\&D alliance experience of both firms in a five year window prior to the start of the R\&D alliance. Based on interpretations of past alliance experiences (Levitt and March, 1998), firms may alter the degree and kind of coordination provisions stipulated in an R\&D alliance contract. In addition, firms with more alliance experience are more likely to have routines in place to support the focal alliance and have a more comprehensive overview of where and how to leverage internal resources in support of the alliance objectives (Kale, Dyer and Singh, 2002). For each R\&D alliance, I take the five-year alliance experience of the partner firm with the least experience. ${ }^{17}$

\subsubsection{Control variables}

Size asymmetry. This asymmetry indicates a dependence of a smaller alliance party on its larger partner in terms of market capabilities (e.g. distribution or marketing) and financial resources (Park and Ungson, 2001). ${ }^{18}$ Consequently, size asymmetry might influence the willingness of the larger partner to work things out and to put less effort in collaborative decision making mechanisms. I control for the effect of this inequality in interfirm dependency on the number of coordination committees by subtracting the logarithm of the net sales of the smallest firm from the largest.

$R \& D$ asymmetry. For complex technologies, the difficulty of transferring knowledge across firm boundaries is substantial if the recipient firm does not have the capabilities to absorb the technology (Teece, 1977). A large gap in R\&D capabilities between partner firms might increase coordination difficulties as parties will find it more difficult to coordinate technical aspects of the $R \& D$ alliance with each other. Therefore, I construct a measure similar to size asymmetry by subtracting the logarithm of R\&D expenses of the firm with the smallest R\&D budget from its partner.

Alliance experience asymmetry. For my hypothesis 5, I am interested in the alliance experience of the firm with the least alliance experience. To rule out any confounding effects of the difference in alliance experience between partner firms with the alliance experience of the least experienced alliance firm, I control for the former (see the description of the variable 'alliance experience' for a more elaborate description of the data). ${ }^{19}$

Prior ties. Using the CATI database, I searched for the number of prior ties between alliance partners, counting back five years from the start of the R\&D alliance (see also Gulati, 1995). I take these prior ties to measure the earlier interaction between parties that indicates the degree to which partners have been able to learn about each other's capabilities (see also Argyres, Bercovitz, and Mayer, 2007; Kalnins and Mayer, 2004; Ryall and Sampson, 2009).

\footnotetext{
${ }^{17}$ I also considered whether the results for alliance experience are due to minimum partner size and/or minimum partner R\&D expenses by explicitly controlling for these factors. These variables do not seem to be significantly related to the number of coordination committees and do not alter the current findings for alliance experience. Hence, they are not included.

${ }^{18}$ I also considered a more explicit measure of financial constraints asymmetry based on net income. This measure was not significant, and left the results unaltered. Therefore, I do not explicitly control for financial constraints asymmetry.

${ }^{19}$ Alternatively, I control for the maximum alliance experience. Results remain similar to those presented here.
} 
Competition. Collaborating firms that can be regarded as competitors are likely to be more careful in exposing and sharing information via coordination committees. Indeed, partnerships between competitors are characterized by an increased effort of firms to limit the chance of unintended knowledge leakage (Lhuillery and Pfister, 2009). Therefore, I control for the level of competition between alliance participants based on their SIC codes (Mowery, Oxley and Silverman, 1996). Using data from Thomson ONE Banker, this variable takes on a value of 2 if both parties operate in the same primary 4-digit SIC code, 1 if both parties do not operate in the same primary 4-digit SIC code but do operate in the same 3-digit SIC code, and 0 otherwise.

Equity. For each R\&D alliance contract, PharmaDeals reports whether or not equity is involved. As the acquisition of part of a firm generates control in the R\&D alliance (Oxley, 1997), this could be reflected in the number of stipulated coordination committees. A dummy variable was created which equals 1 if one of the firms takes an equity stake in its partner and 0 otherwise.

Potential technology applications. For each R\&D alliance, PharmaDeals lists the number of possible technological interest areas for the products and/or technologies developed through that alliance, with a maximum of eight interest areas. I interpret these interest areas for a product and/or a technology in terms of the number of potential technology applications. $^{20}$

Finite time horizon. There are two reasons why contracts with a finite time horizon are likely to differ from open-ended alliances in terms of the number of stipulated coordination committees. First, the anticipated gains from mutual cooperation are likely to be smaller in contracts with a finite time horizon compared to more open-ended contracts (Parkhe, 1993). This shadow of the future might influence the willingness of parties to stipulate a number of coordination committees at the contract signing date. Second, although contracts with a finite time horizon are not necessarily shorter in duration compared to more open-ended alliances, they often are. The longer the term of the contract, the more difficult it becomes to ex-ante specify all possible contingencies. For R\&D contracts with a longer time horizon, it can even be desirable to fill in some details later during the R\&D alliance (Coase, 1937). Especially for contracts with no predefined ending date, parties' ability to ex-ante stipulate responses to all possible disturbances is low.

In light of the above, I expect that whether or not an R\&D alliance has a finite time horizon will affect the number of coordination committees incorporated in a contract. This dummy variable takes on a value of 1 if there is a predefined ending date of the alliance contract, and 0 otherwise.

Deal value. For each R\&D alliance, PharmaDeals gives information about the (potential) deal value if available. In addition, I collected additional deal value data from the LexisNexis database. For alliances with a larger deal value, parties have incentives to communicate and respond collaboratively to unanticipated contingencies in order to increase the chances of success of the alliance (Doz, 1996). Therefore, I control for the effect of (potential) deal value on the number of coordination committees by incorporating the logarithm of (potential) deal value in millions of dollars. If information about the deal value is missing, this variable is equaled to zero.

\footnotetext{
${ }^{20}$ This measure also relates to technological complexity, as the combination of different knowledge sets will inevitably complicate the R\&D process.
} 
Deal value dummy. I control for missing information concerning deal value. If information concerning the (potential) deal value of an alliance is missing, this dummy variable takes on a value of 1 and 0 otherwise. ${ }^{21}$

Year fixed effects. I control for temporal trends in alliances and include dummy variables for the period 1996-2005 with the year 1996 as the reference year.

\subsubsection{Analysis}

In the following, I present a Poisson model using robust standard errors with the total number of coordination committees as dependent variable. In addition and in unreported regressions, I used a ordered logit estimator, and a tobit estimator that specifically takes into account the lower and upper bound of the dependent variable. Results of these analyses are similar to those presented in this paper.

Some firms in my sample appear more than once. It is probable that firm A's behavior in alliance A-B with partner B is not independent of firm A's behavior in alliance A-C with partner C. Correlated error terms at the firm level can cause underestimated standard errors for firm attributes that remain constant over multiple contracts. PharmaDeals makes a distinction between the principal technology supplying firm, and the partner firm. I cluster the standard errors in the empirical analysis by partner firm, because these firms have the largest likelihood of repeat occurrence in the sample. In unreported regressions I additionally, similar to the approach followed by Lerner and Malmendier (2010), include firm dummies for the 10 most frequently occurring firms in my sample. While some of these frequently occurring firms seem to consistently and significantly stipulate more or less coordination committees, the variables of interest are little affected regarding both their statistical significance as their economic magnitude. Besides alleviating the concern that reoccurring firms in my sample bias the presented results, this approach also, to some extent, lessens endogeneity concerns. More specifically, the approach relaxes the concern that unobserved firm characteristics actually drive the presented results. For example, by including firm dummies, we can be more confident in the result that the level of interfirm dependence is actually related to the number of stipulated coordination committees, rather than certain types of companies only entering into agreements with relatively low or high levels of interfirm dependence combined with a relatively low or high number of coordination committees.

\subsection{Results}

Descriptive statistics detailing the mean, standard deviations and bivariate correlations of the variables are shown in Table 3.1. None of the bivariate correlations exceed the usual 0.7 cutoff value except for the correlation between deal value and deal value dummy, and the

\footnotetext{
21 Although frequently used (see, for instance, Bastos (2010), Griliches (1976), Khorana, Servaes and Tufano (2009), Singh (2008); Smith and Huang (1995)), this method of dealing with missing values has its drawbacks, as do alternative methods. In unreported analyses, I use four other methods to deal with missing values to investigate whether or not results change depending on which method I use. First, I run a regression without controlling for value. Second, I run a regression in which I only control for whether or not information on value is missing. Third, I limit the sample to only those observations for which I was able to retrieve information on the value of alliances. Fourth and last, based on a host of observable variables, I estimate the value of an alliance if this information is missing, and use these estimates in the full model. Results were not strikingly different and in general agreed with the results reported here.
} 
average VIF statistics remain well under the cut-off value of 10 . I refer to footnote 21 for a more elaborate discussion on deal value and deal value dummy. Table 3.2 presents the results of the Poisson estimator. Model 1 in Table 3.2 refers to the basic model with only control variables included. In subsequent models 2-6, each hypothesis-related independent variable is added and in model 7 all independent variables and control variables are incorporated. Alternatively, starting with the basic model and for each model adding an independent variable does not alter my results. 


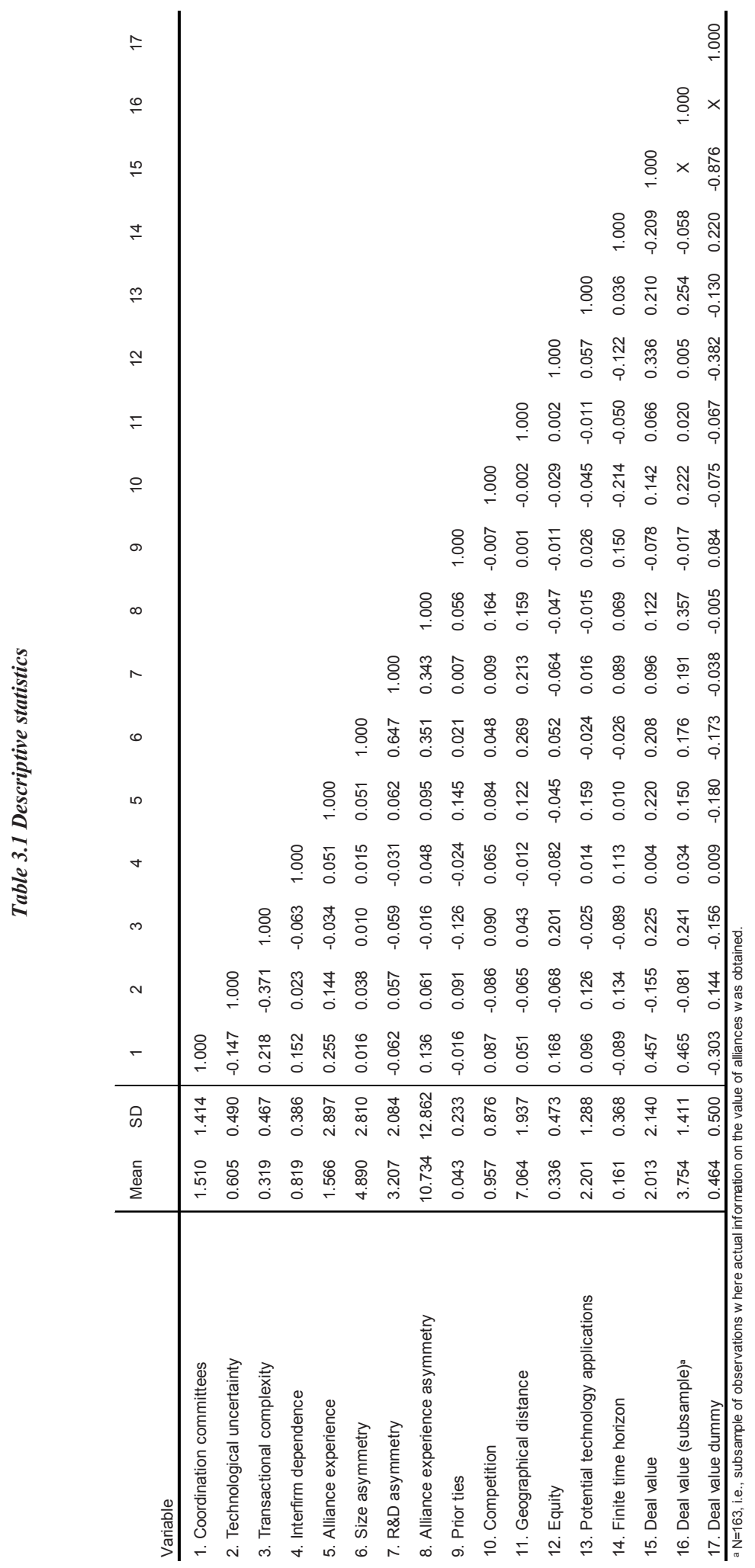


Hypothesis 1 states that parties to an alliance characterized by high technological uncertainty, compared to an R\&D alliance characterized by lower technological uncertainty, specify more coordination committees in their contract. I find no support for this hypothesis in models 2 and 7. I do find support, see models 3 and 7, for hypothesis 2 which predicts that the number of coordination committees stipulated in an alliance contract increases with the transactional complexity of that alliance. I also find support for hypothesis 3 that predicts that the number of coordination committees specified in an R\&D alliance contract is larger for an alliance characterized by high interfirm dependence. Models 4 and 7 show the expected significant and positive signs. I do not find any support for my hypothesis 4 which posited that geographically dispersed firms stipulate more coordination committees, see models 5 and 7 . Finally, I also find support for hypothesis 5 which states that alliance experience is positively related to the number of coordination committees stipulated by alliance parties. Models 6 and 7 show the expected significant positive relationship. 
Table 3.2 Poisson model estimation results of coordination committees

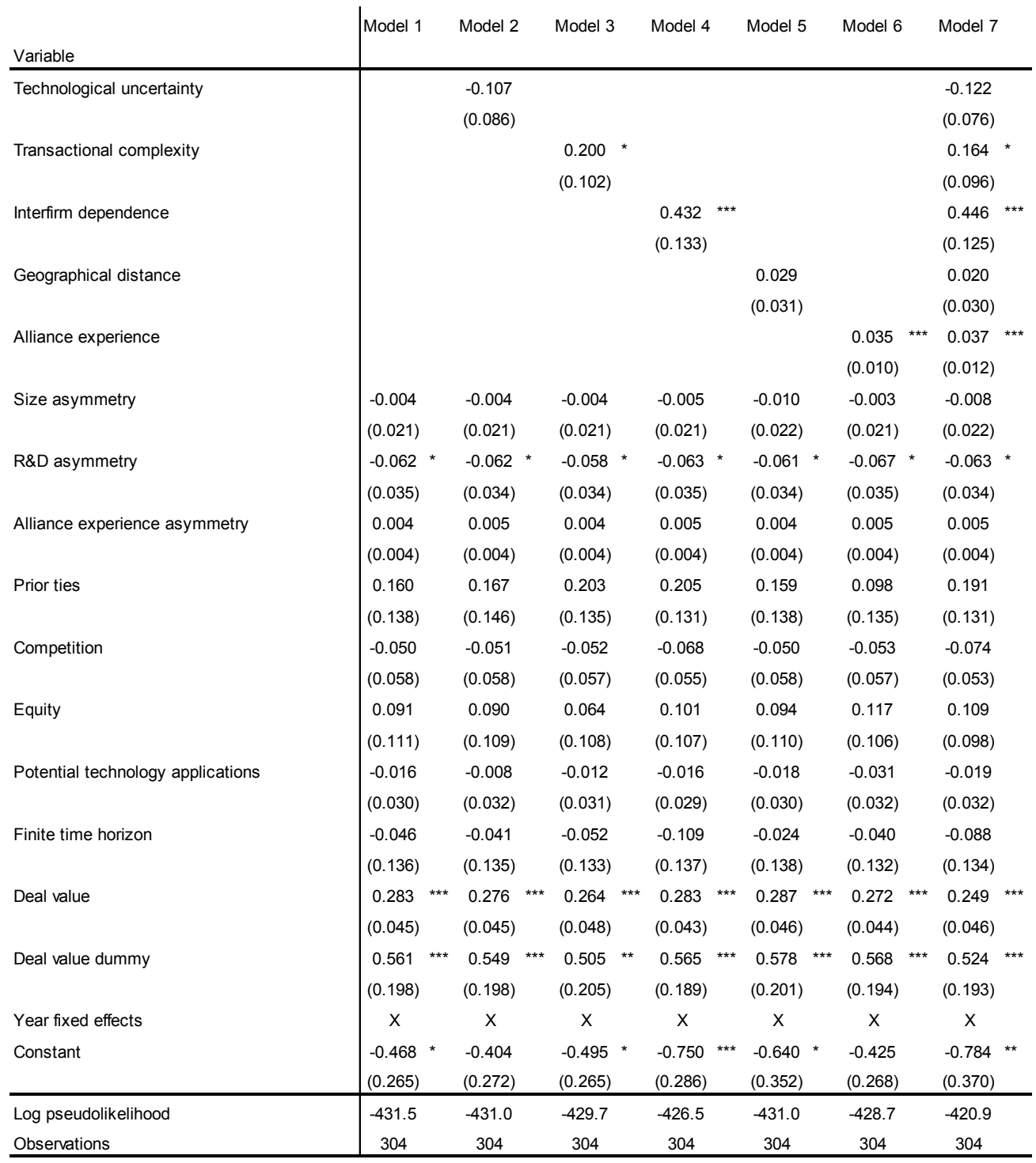

Notes: Poisson model, robust standard errors clustered by firm in parentheses.

* significance at the $10 \%$ level; ${ }^{* *}$ significance at the $5 \%$ level; ${ }^{* * *}$ significance at the $1 \%$ level. 
Regarding the control variables, I find consistent significant effects for two variables. First, I find that a larger R\&D asymmetry is negatively related to the propensity of alliance parties to stipulate a number of coordination committees. Second, I find a significant and positive relationship between the (potential) deal value of the alliance and the number of coordination committees.

\subsection{Alternative explanations}

Coordination committees. Although most coordination committees have a similar function, some coordination committees differ in kind. More specifically, I investigated the possibility that more hierarchical decision making actually drives the results. To do so, I first excluded steering committees from the count of the number of coordination committees when other committees are also stipulated in the contract. In these cases, the steering committee often functions as a management committee that supervises the other committees and coordinates the overall strategy of the alliance. Results remain qualitatively similar to those presented in this paper. In addition, I investigated whether committees are incorporated in contracts individually, in which case the correlations between the occurrence of different kinds of committees can be expected to be relatively low, or as a bundle, in which case I expect higher correlations between the occurrence of different kinds of committees. Therefore, I investigated the correlations between the most frequently occurring committees (to exclude the possibility of spurious significant correlations because of limited observations). I find no evidence of clustering of coordination committees as correlations remain (very) low.

Also, I excluded committees that allocate unilateral control to one party from my dependent variable based on my interest in the interfirm coordination aspect of contracts, rather than the interfirm control aspect that is highlighted in much of the previous literature on alliance contracts. In an additional and unreported analysis, I control for the number of committees aimed at control in the main regressions. I find a significant and negative correlation between the number of committees aimed at coordination and those aimed at control, while the presented results remain intact. This hints at the proposition that contracts seem to be either coordination focused, or more oriented towards control (Salbu, 1997).

Transactional complexity and interfirm coordination. The proxy I use for transactional complexity refers to the scope of an alliance (Ryall and Sampson, 2009; Sampson, 2004b). Stated otherwise, I check whether the parties perform additional activities besides R\&D. The hypothesis and finding that additional activities in an alliance increase the need for more coordination committees perhaps seems obvious at first. It is however possible, that not all additional activities will influence the number of coordination committees equally, or even significantly. The low level of significance (10\%) for the transactional complexity variable already indicates the plausibility of such an explanation. Additional analyses provide some support for this claim. For instance, inclusion of 'manufacture/supply' in addition to R\&D activities does not seem to significantly increase the number of coordination committees stipulated by alliance parties. The aforementioned indicates that in general additional activities besides $R \& D$ increase the number of stipulated coordination committees, but that this finding could depend on the specific types of additional activities. Further research leveraging a more detailed dataset could further investigate this.

Geographical distance. The hypothesis for geographical distance is largely dependent on the claim that proximate alliance parties have informal means of coordination at their disposal 
not directly available to geographically dispersed firms. Of course, this level of informal coordination might drop rapidly after a certain cut-off point. Therefore, I empirically investigated this possibility using dummy variables for 10,20,50, 100 and 250 miles of distance between collaborating firms. The presented results remain unchanged as I do not find any significant link between the geographical distance between alliance parties and their propensity to stipulate coordination committees.

\subsection{Discussion and conclusions}

From my theoretical perspective, interfirm contracts are not to be seen as mere legal devices but also as mechanisms to promote adjustability, joint problem solving and communication, i.e., I subscribe to a neoclassical contracting perspective. In line with this neoclassical contracting perspective, I argue that to some extent parties have the ability to ex-ante include institutions in their agreement to govern their behavior and guide the alliance while the legal core of the contract still functions as a reference point for adaptations (Williamson, 1979). In my current contribution I apply this neoclassical contracting perspective to study several conditions associated with varying reliance on coordination committees as stipulated in $R \& D$ alliance contracts in the biopharmaceutical industry. These conditions stem from farsighted, but incomplete, contracting (Williamson, 1996). Thus while parties to an alliance do have the ability to ex-ante include responses to contingencies, they only have so to a limited degree. Similar to observed variation in coordination at the intrafirm level (e.g. van de Ven, Delbecq and Koenig, 1976), I find several conditions critical in explaining the number of stipulated coordination committees in these interfirm alliances. More specifically, the nature of alliance activities in terms of transactional complexity and interfirm dependence, and the alliance experience of partners are found to be relevant in explaining the number of contractually specified coordination committees in R\&D alliances.

Transactional complexity of alliances is one of the elements of the condition that refers to the nature of the activities undertaken within the scope of alliances. For R\&D alliances characterized by low transactional complexity, with only a limited set of interrelated activities, parties can be relatively farsighted in terms of including contingencies in their contract (Williamson, 1996; 1999). Consequently, parties to an alliance low on transactional complexity have the ability to include a wide array of potential disturbances in their alliance contract, i.e., these contracts are less incomplete. Hence, the need for interfirm communication and mutual adjustment during contract execution is limited. However, for alliances characterized by higher transactional complexity, with a wider set of interrelated activities, the farsightedness of parties is limited (Williamson, 1996; 1999). These alliances involve a larger set of interrelated activities which decreases the ability of parties to ex-ante stipulate contingencies in the contract. Therefore, alliances characterized by higher transactional complexity require more communication and mutual adjustment during contract execution. Hence, R\&D alliance contracts characterized by higher transactional complexity are associated with the stipulation of a larger number of coordination committees that facilitate communication and promote mutual adjustments in response to changing circumstances. However, as discussed in the section on alternative explanations, this relationship could be contingent on the specific types of additional activities.

Another element regarding the nature of alliance activities refers to interfirm dependence, i.e., the extent to which partners are dependent on each other for execution of the activities 
within the scope of the alliance. For relatively simple contracts, i.e., those that require only limited joint efforts, I find that the number of stipulated coordination committees is significantly lower compared to alliances of a more collaborative nature. In that sense, my findings align with studies at the intrafirm level (e.g. van de Ven, Delbecq and Koenig, 1976) which find that as unit personnel becomes more dependent on each other to execute their individual jobs, the number of meetings through committees increases. My results indicate that a similar mechanism occurs at the interfirm level, i.e., as the interdependence between firms for execution of the activities within the scope of the alliance increases, the number of coordination committees to communicate and facilitate joint-decision making also rises.

I posited that through previous collaborations with other parties, firms gain experience and learn about best practices and adjust subsequent contracts accordingly. As a lack of sufficient interfirm coordination has frequently been associated with alliance failure, one can expect that experienced firms pay more attention to designing and drafting the coordination element of alliance contracts. In addition, besides an increased willingness to adapt subsequent contracts based on coordination struggles in the past, more experienced firms are also better able to make the required changes in the level of interfirm coordination. These firms often have a more comprehensive overview of the required internal resources and they know how to configure these resources in order to support collaborative alliance objectives. In addition, more experienced firms are very likely to have more personnel available specifically tasked with managing and coordinating alliances. Therefore, these firms are better able to maintain and support elaborate committee structures to promote interorganizational coordination. In line with these arguments, I indeed find that the alliance experience of partners is positively associated with the number of coordination committees stipulated in an R\&D alliance contract. ${ }^{22}$ This finding extends research on firm learning (e.g. Argyres, Bercovitz and Mayer, 2007; Argyres and Mayer, 2007; Luo, 2002; Reuer, Ariño and Mellewigt, 2006; Ryall and Sampson, 2009) by claiming that more experienced firms, compared to relatively inexperienced firms, draft more contractual coordination mechanisms to support and guide the overall alliance endeavors. This finding also speaks to the debate about a firms' ability to tap into internal resources and leverage these resources in support of collaborative alliance goals (Kale, Dyer and Singh, 2002; Kotabe, Martin and Domoto, 2003), and their ability to maintain elaborate committee structures by means of dedicated alliance personnel (Kale, Dyer and Singh, 2002; Schilke and Goerzen, 2010). Indeed, experienced alliance firms seem to have an innate capability to maintain high levels of interfirm coordination (Schilke and Goerzen, 2010).

Contrary to my expectations, there appears to be no relationship between technological uncertainty and the number of coordination committees stipulated in an R\&D alliance contract. I anticipated that higher levels of technological uncertainty could, given unexpected changes, potentially lead to more deviations from the initial contract. Under these conditions, contract parties would rather translate these deviations into a larger number of coordination

\footnotetext{
${ }^{22}$ Alternatively, one could claim that the total alliance experience rather than the minimum alliance experience is what matters in explaining the number of coordination committees. Based on model 7 in Table 3.2, I am able to exclude this explanation. Tot $=2 \mathrm{Min}+$ Dif. Let $\alpha$ be the coefficient for the minimum, and $\beta$ the coefficient for the difference in alliance experience. Now suppose $\alpha=2 \beta$. Then $Y=\alpha$ Min $+\beta$ Dif $=2 \beta$ Min $+\beta$ Dif $=\beta(2$ Min + Dif $)=\beta$ Tot. As $\alpha \neq 2 \beta$ (at the 5\% level), I can conclude that the distribution within the total alliance experience matters.
} 
committees to collaboratively respond to contingencies not accounted for in the initial contract. A possible explanation for the lack of empirical support for the aforementioned proposed relationship is that technological uncertainty is translated into ex-post usage of coordination committees. In the current research setting, I am only to some extent able to make inferences about ex-post usage of coordination committees as they stipulate a minimum number of meetings per year. To do so, I further inspect the contractual structure of research committees. More specifically, I investigate the minimum number of meetings as stipulated within these research committee clauses. Most research committees (around 69\%) meet a minimum of four times per year, followed by not stipulated (15\%), two times $(9 \%)$, twelve times $(5 \%)$, and three times $(2 \%)$ per year. However, parties can meet more often than the minimum number of meetings per year. Therefore, while technological uncertainty is not reflected in the number of stipulated coordination committees, technological uncertainty could be translated in more intensive ex-post usage of these coordination committees.

This paper is susceptible to the criticism that I paint an overly positive image of interfirm coordination. Indeed, I assume that more communication between alliance partners is positive when pursuing collaborative goals. However, a number of previous contributions point toward negative byproducts of (too much) interfirm communication for alliance firms. One particularly salient concern for alliance firms is the unintended loss of knowledge through extensive coordination mechanisms such as coordination committees (Contractor, Woodley and Piepenbrink, 2011; Faems et al., 2008; Gerwin, 2004; Oxley and Sampson, 2004), especially when collaborating with a competitor (Gerwin, 2004). My results shown in Table 3.2 initially seem to provide little support for the claim that competitors limit the number of coordination committees in a contract. However, the absence of a relationship between the level of competition and the number of coordination committees could be partly attributed to the inclusion of many alliances in my sample that include equity investments. Equity investments align the incentives of involved parties and generate control (Pisano, 1989). A possible relationship between the level of competition and the number of coordination committees might therefore only hold in the subsample of non-equity alliances where parties can exert little control over each other's behavior. In order to test the aforementioned, in unreported regressions, I run model 7 of Table 3.2 on the subsample of non-equity alliances. I indeed find a strong negative relationship between the level of competition between partner firms and the number of stipulated coordination committees in the subsample of non-equity alliances. This could indicate that absent control induced by equity participation, competitors conscientiously try to limit their interaction points via their contract to limit unintended knowledge leakage.

The empirical findings of my study indicate strong support for our understanding of the relation between the nature of the alliance activities, alliance experience, and the level of interfirm coordination. In that context, I take a more cooperative and supportive perspective on interfirm coordination by moving away from unilateral decision rights as stressed in most previous research (e.g. Lerner and Merges, 1998). The motivation for this shift is induced by findings about coordination at the intrafirm level, and the claim that alliances are often perceived as being much more supportive and cooperative than envisioned in most of the literature (Grandori, 1997). The results indicate that although the factors associated with varying degrees of interfirm coordination show resemblance to research examining coordination within firms (concerning the nature of activities), alliance experience and 
competitive pressures are paramount in understanding contractually designed interfirm coordination.

\subsection{Limitations and future research directions}

Like any other study, this research has its limitations. These limitations offer interesting areas for further research. First, similar to other recent studies on contract design (e.g. Bengtsson, 2011; Lumineau and Oxley, 2011), I am conservative in the empirical inferences I draw due to possible correlations of the error terms. Although I tried to minimize this risk by employing a range of control variables and performing several robustness checks, I stop short of claiming any causal link between exchange features and the inclusion of a number of coordination committees in the contract. I encourage future research that aims at unraveling the link(s) between exchange features and contractual governance structures. Second, I relate interfirm coordination to the stipulation of coordination committees in alliance contracts but I only have a limited understanding of the ex-post usage of these provisions. This could explain why I did not find a significant positive association between technological uncertainty and the number of coordination committees specified in a contract. Future research could focus more on the link between ex-ante interfirm coordination intent and the actual ex-post interfirm coordination. Third, it would be worthwhile to replicate this study in a different industrial contracting environment. In the current contribution, I focus on one industry, i.e., biopharmaceuticals, where the interdependence of alliance activities induces mutual problem solving. It would be interesting to see how the current findings hold up in different industrial contexts. Fourth, although this study leverages unique data while simultaneously controlling for a myriad of alternative explanations, the cross-sectional nature of my sample poses some restrictions. More specifically, I cannot observe changes in coordination committee clauses over time. Therefore, while the current research allows for inferences concerning the factors associated with the number of stipulated coordination committees in a contract, future research is necessary to focus on the evolving nature of these provisions over time. Fifth, the section on alternative explanations and robustness checks shows that not all additional activities seem to increase the propensity of parties to increase the number of stipulated coordination committees. Further research using a more fine-grained dataset could further investigate which specific activities warrant the stipulation of more coordination committees. 



\title{
The Contractual Governance of Disputes in Biopharmaceutical Alliances ${ }^{23}$
}

\begin{abstract}
This paper examines how exchange complexity, environmental uncertainty, and the presence of a high-growth firm, may affect the choice of partnering firms engaging in a collaborative R\&D alliance, to opt for different dispute resolution mechanisms. I distinguish between internal dispute resolution via hierarchy, and arbitration. Hypotheses are tested using a dataset of 304 R\&D alliance contracts in the biopharmaceutical industry. The results suggest that firms experiencing increased exchange complexity shift their focus towards internal dispute resolution. More specifically, parties are more likely to place emphasis on internal dispute resolution when their alliance focuses on a relatively complex technology, or when the alliance has no pre-defined ending date. Parties to an international alliance are more likely to opt for arbitration in their contract. For domestic deals, the presence of a high-growth firm in an alliance is positively related to the likelihood of observing an arbitration clause in the corresponding contract. The results have implications for general TCE literature, and more specific literature on non-traditional dispute resolution mechanisms.
\end{abstract}

\footnotetext{
23 This work has benefited from helpful comments and suggestions by Martin Carree, Ranjay Gulati, John Hagedoorn, Geerte Hesen, Josh Lerner, Fabrice Lumineau, Kyle Mayer, and participants at seminars at Maastricht University, and participants at the 2012 Academy of Management conference and the 2012 Canadian Law and Economics conference.
} 


\subsection{Introduction}

Parties to an alliance characterized by substantial complexity and uncertainty inevitably have to deal with disputes emerging during their collaboration (Mayer and Teece, 2008). More general literature on interfirm contracting has recognized that parties conscientiously seek to limit the possibility that disputes will occur during their collaboration. For instance, Argyres and Mayer (2007) and Argyres, Bercovitz and Mayer (2007) suggest that over time managers and engineers more clearly stipulate roles and responsibilities in their contract to limit the possibility of future disputes. These contributions suggest that contract parties learn from previous disputes and design future contracts in such a way as to minimize the risk of potential disputes. Although these contributions significantly add to our understanding of how contract parties structure their contracts, they remain silent on predicting in which case what particular dispute resolution mechanism is more suitable. The link between alliance and firm properties and various dispute resolution mechanisms is conspicuously bereft of any empirical evidence. This despite its theoretical relevance as dispute resolution properties of contracts are important elements of different governance arrangements (Williamson, 1991). A quite vibrant stream of literature has developed which highlights the use of non-traditional dispute resolution mechanisms in various contexts (e.g. Bernstein, 1992). More descriptive work on interfirm technology partnerships (e.g. Hagedoorn and Hesen, 2007), has indicated that alliance parties have several contractual options available to control how potential disputes will be resolved. Here I posit that different contractual safeguards, i.e., dispute resolution clauses, are a response to exchange complexity, environmental uncertainty, and the presence of high-growth firms.

Recent studies show that on average two thirds of all alliances run into serious disputes within the first two years, and that failure rates are as high as seventy percent (Das and Teng, 2000a; Koza and Lewin, 2000). It is therefore not surprising that alliance partners foresee the possibility of their collaboration ending in a dispute and design contractual safeguards accordingly (Hagedoorn and Hesen, 2007; Mayer and Teece, 2008). Here, I make a distinction between two particular dispute resolution mechanisms. First, I focus on internal dispute resolution through hierarchy. Studies on the intrafirm level have highlighted that disputes are often resolved by management intervention (e.g. Elangovan, 1995; Karambayya and Brett, 1989; Pinkley et al., 1995). Although in interfirm arrangements senior managers have only limited ability to reach decisions through fiat (Williamson, 1994), they can use motivational control in the form of threats or incentives (Karambayya and Brett, 1989, Sheppard, 1983; 1984), guide resolution of a dispute, and act as a judge on a disputed matter (Karambayya and Brett, 1989). Senior manager discussions are seen as a particularly credible effort of parties to achieve a negotiated settlement of a dispute. Second, I consider external dispute resolution via arbitration which is defined as a voluntary arrangement between parties to refer a dispute to a neutral third party and to be bound by the decision of that third party (Bonn, 1972; Mattli, 2001). ${ }^{24}$ Over the last decades, arbitration has become an increasingly

\footnotetext{
${ }^{24}$ Note that by focusing on internal dispute resolution and arbitration, I purposely exclude hybrid forms of dispute resolution such as mediation, and other forms of adjudication such as litigation. I believe this focus is warranted because, first, mediation and litigation clauses occur much less frequently than internal dispute resolution and arbitration clauses, and second, the hybrid nature of mediation makes it difficult to classify. By relying on a third-party to structure the dispute resolution process, mediation is neither negotiation nor adjudication. Also, the likelihood that parties will opt to have their dispute settled by means of arbitration after a
} 
popular method of dispute resolution (Mattli, 2001). Its reliance on custom rather than law, and the veil of secrecy surrounding arbitration proceedings, have been lauded as two of the most significant benefits of arbitration (Bonn, 1972; Mattli, 2001). However, benefits of arbitration can turn into disadvantages in particular situations. For instance, the limited grounds under which a party can appeal an arbitral decision can provide certainty when collaborating with a firm situated in a country with a different and unknown legal system. In domestic alliances, the limited appeal possibilities can be a risk rather than a benefit when parties have faith in their respective legal system. Both for theory and managers, we need a more fine-grained understanding of what drives contracting parties to opt for certain (alternative) dispute resolution mechanisms, despite possible risks.

TCE reasoning suggests that alliance parties have different methods available to govern their collaboration and that, dependent on certain attributes (see Shelanski and Klein, 1995), some governance structures are more suitable than others. The attributes I consider refer to the level of exchange complexity (Killing, 1988; Phene and Tallman, 2012), in terms of technological complexity and whether or not an alliance has a fixed temporal duration, and environmental uncertainty (Killing, 1988; Luo, 2007). In addition, related to the concept of leakage stressed by TCE literature (Williamson, 1992), I consider the presence of a highgrowth firm in an alliance. These elements are related to two forms of dispute resolution in a discriminating way. Internal dispute resolution is related to the level of exchange complexity of an alliance, while arbitration is related to the level of environmental uncertainty surrounding an alliance and the presence of a high-growth firm. Parties to an alliance characterized by high exchange complexity often possess idiosyncratic knowledge about disputed issues that is difficult and costly to transfer to a neutral third-party (Sampson, 2004a; Williamson, 1991; 1994). Because humans are subject to bounded rationality, contracts will be incomplete when the exchange complexity is high. Disputes between parties to an alliance characterized by high exchange complexity will often center around the initial unmet interests and expectations of parties rather than their legal rights (Edelman, Erlanger and Lande, 1993). Forward-looking disputes aimed at changing the current setup are best addressed by internal dispute resolution mechanisms (Elangovan, 1995). As Johnson, McMillan and Woodruff (2002) put it: "... [the decision of market participants] can be more nuanced than the binary decision of liability or no liability that the court must make. (...). [T] hey can consider information that cannot be introduced in court, such as impressionistic evidence about business trends or judgments about the quality of items sold. They can base their decisions on a firm's behavior over time, on probabilistic patterns that would not be admissible evidence in court" (Johnson, McMillan and Woodruff, 2002; p. 229). Therefore, ceteris paribus, one would expect to more frequently observe internal dispute resolution mechanisms stipulated in contracts as the exchange complexity of alliances increases.

Arbitration differs in a number of ways from internal dispute resolution highlighted earlier. Most notably, arbitration produces a mandated settlement of a dispute by a neutral third party, rather than a consensual solution reached by parties themselves. There are two reasons why arbitration as a dispute resolution mechanism is particularly well-suited to handle disputes arising out of alliances characterized by substantial environmental uncertainty, or alliances that include a high-growth firm. First, arbitration allows custom rather than law to

dispute actually emerges, without having stipulated an arbitration clause in their contract, is low (Allison, 1990). As such, parties that do not opt for arbitration in their contract, will most likely have their future disputes resolved via traditional public forums. 
guide resolution of disputes (Bonn, 1972). In that sense, arbitration can be an especially valued dispute resolution mechanism when parties operate in a uncertain setting where they are confronted with unknown legal rules and procedures. Second, arbitration proceedings and awards are confidential (Allison, 1990; Mattli, 2001). Indeed, the private nature of arbitration proceedings have long been recognized, and criticized, in more law oriented literature (e.g. Goldman, 2003). As such, arbitration can serve as a contractual safeguard to hedge against the risk of leakage in a broad sense (Hill, 1992; Williamson, 1992), which is an especially salient property of arbitration for high-growth firms.

I aim to contribute to the literature by viewing the dispute resolution procedures that parties contractually specify as clauses sui generis. Much of the previous literature has viewed the contractual specification of how disputes are to be solved as part of contractual complexity (Lumineau and Quélin, 2012; Parkhe, 1993; Reuer and Arińo, 2007). Although this stream of literature has provided valuable insights in the structure of contracts in general and the antecedents of contractual complexity more specifically, it speaks little to the debate about what drives contracting parties to include particular dispute resolution mechanisms. As indicated by Williamson (1991), the dispute resolution properties of contracts are a particularly salient feature of alternative governance arrangements (Lumineau and Oxley, 2012), and the initial contract plays an important role in determining how future disputes will be resolved. ${ }^{25}$ Rather than encapsulating dispute resolution mechanisms in an aggregate measure of contractual complexity, this paper aims to show that different mechanisms of dispute resolution respond to different factors. To the author's knowledge, although these different mechanisms of dispute resolution are highlighted in more theoretical contributions (e.g. Hagedoorn and Hesen, 2007), this is a first attempt to more carefully explain their occurrence in R\&D alliance contracts. Gaining a more comprehensive overview of why parties select different forms of dispute resolution has the potential to significantly aid in our understanding of the governance structures of alliance contracts (Lumineau and Oxley, 2012). Studying different forms of alternative dispute resolution mechanisms is theoretically important, as it can point towards inefficiencies of the traditional legal system.

One can make a distinction between dispute resolution arrangements before and after a dispute has arisen. To date, the bulk of empirical studies on dispute resolution in alliances has focused on the period after a dispute materializes (e.g. Lumineau and Malhotra, 2011; Lumineau and Oxley, 2012; Lumineau and Quélin, 2012), thereby only observing disputes that are serious enough to get lawyers involved. However, many contracts contain internal mechanisms (Ring and van de Ven, 1992), such as involvement of senior managers (Sampson, 2004a), aimed at precisely avoiding involvement of lawyers in the dispute resolution process. Most disputes are actually resolved by parties themselves as they are most knowledgeable on the issues at hand and need not conform to general legal rules that may or may not be applicable to their dispute (Galanter, 1981; Macaulay, 1963). Therefore, in this contribution, I focus solely on the period before an actual dispute has arisen to get a more comprehensive picture of dispute resolution preferences of alliance parties.

\footnotetext{
${ }^{25}$ As one manager from a large biopharmaceutical company states: “...It is my firm conviction, that the only satisfactory way of dispute resolution in alliances is internal, within the governance framework described in the contract...".
} 


\subsection{Theoretical background and hypotheses}

A central tenet of Transaction Cost Economics (TCE) is that alliance attributes should be aligned with governance structures. In line with TCE reasoning, alliances subject to substantial hazards for parties warrant additional contractual safeguards (Shelanski and Klein, 1995), such as more extensive enforcement and monitoring provisions (Oxley, 1997). My framework is based upon two premises. First, hazards can stem from exchange complexity and environmental uncertainty (Killing, 1988; Oxley and Sampson, 2004; Phene and Tallman, 2012; Robson, Katsikeas and Bello, 2008; Shelanski and Klein, 1995). Also, leakage of information and know-how is a particularly salient concern for firms (Williamson, 1992), especially for high-growth firms. Second, the likelihood of observing various contractual dispute resolution mechanisms is a function of the three elements highlighted earlier. More specifically, internal dispute resolution provisions are expected to be a response of parties to high levels of exchange complexity. Parties are expected to opt for arbitration in their contract when they experience substantial environmental uncertainty, or when a high-growth firm is involved.

Literature to date suggests three underlying mechanisms that drive a positive relationship between exchange complexity and internal dispute resolution. First, parties to a dispute have idiosyncratic knowledge about their disputed case that is only transferable to third parties at great costs (Williamson, 1991). Parties are often quite knowledgeable about the underlying intricacies of their collaboration and are therefore well-suited to solve disputes amongst themselves. For simple agreements characterized by "[s]harp in by clear agreement; sharp out by clear performance" (Macneil, 1974; p. 738), a third party is unlikely to err in its judgment over a dispute, thus alleviating the need for extensive governance structures regulating dispute resolution. When alliances get more complex, in terms of their technology or time dimension, it becomes increasingly more difficult for third parties to verify the efforts each party has exerted under an agreement (Hart and Moore, 1988). ${ }^{26}$ Parties can implement contractual safeguards, i.e., internal dispute resolution mechanisms, that allows them to use information which would not be admissible under third party adjudication. Third parties are often unpredictable in their understanding of issues that involve complex technologies (Klitgaard and Mussman, 1992), and therefore disputants will often reach a more satisfying solution when they are able to make use of their idiosyncratic knowledge about the technology and the dispute. In alliances lacking a predefined end date, parties are prone to develop a working relationship different from the one initially stipulated in the contract. These alliances without a predefined end date are characterized by substantial exchange complexity as parties find it more difficult to include all contingencies in a contract that might affect their alliance (Ariño and Reuer, 2004; Crocker and Reynolds, 1993). Firms participating in these alliances are therefore expected to promote internal dispute resolution. The contract maintains its function as a reference point (Hart and Moore, 2008), but parties can use additional (non-legal) information accumulated over time in attempting to solve a dispute. Second, by and large, exchange complexity drives contracting difficulties as it becomes difficult to draft complete contracts that set out all possible contingencies. As such,

\footnotetext{
${ }^{26}$ As one manager from a large biopharmaceutical company comments: "... Some of our most simple contracts such as straight in-licensing agreements do not have formalized governance structures [to solve disputes] as they are not the basis for any active collaboration. Hence, arbitration is the only described dispute resolution mechanism...".
} 
disputes for highly complex exchanges will often revolve around changing the existing setup to accommodate circumstances unforeseen at the start of a collaboration (Elangovan, 1995). Internal dispute resolution is most suitable for these future-oriented disputes as the underlying goal is to maintain a working relationship with the interests of both parties in mind rather than their rights (Edelman, Erlanger and Lande, 1993; Elangovan, 1995; Pinkley et al., 1995). For instance, lacking a predefined ending date of their collaboration, disputes may arise between parties on how to adjust to an unforeseen contingency. Parties would then most likely rely on probabilistic reasoning to choose the most promising way forward, rather than trying to assign legal blame. Third, for complex exchanges, the variability of preferences, situations and solutions is widespread whereas formal legal rules can only take a subset of this variability into account (Galanter, 1981). As a result, for highly complex exchanges, there is an inevitable loss of information when transforming a disagreement into legal argumentation. As it is quite common that parties refrain from planning their collaboration in a detailed contract (Macaulay, 1963), formulating coherent legal arguments encapsulating the full extent of a dispute becomes even more difficult. Internal dispute resolution does not need to adhere to any formal rules or procedures (Edelman, Erlanger and Lande, 1993; Johnson, McMillan and Woodruff, 2002; Pinkley et al., 1995), thereby giving parties the possibility to use all information deemed relevant in solving their dispute.

\subsubsection{Technological complexity}

Human actors experience bounded rationality problems when confronted with complex problems (Slater and Spencer, 2000). For technological complex alliances, the technological development process is relatively ill-defined at the contract signing date (Macher, 2006; Nickerson and Zenger, 2004), because parties cannot make causal statements between exerted efforts and observed outcomes (Lumineau and Oxley, 2012). From the perspective of a neutral third party called in to render judgment on a dispute involving a complex technology, the alliance contract offers little guidance about the initial intent under the agreement (Klitgaard and Mussman, 1992; Lumineau and Oxley, 2012; Sampson, 2004a). From the perspective of the (potential) disputants, i.e., the alliance parties, disputes about complex technologies will often revolve around how to change the existing setup to conditions unforeseen at the contract signing date. When the development process is relatively ill-defined beforehand, disagreements can occur during collaboration about how to proceed when new information accumulates. Often, disputes then do not revolve around legally justifiable claims, but rather on how to proceed forward in an amicable manner (Edelman, Erlanger and Lande, 1993; Elangovan, 1995). Parties possess idiosyncratic knowledge of underlying intentions under an agreement (Williamson, 1991), that is often not admissible in adjudication proceedings (Johnson, McMillan, and Woodruff, 2002), but that is critical in resolving a dispute involving a complex technology. As a result, parties themselves are best equipped to deal with disputes originating from alliances that involve complex technologies (Klitgaard and Mussman, 1992), and as such:

Hypothesis 1. There is a positive relationship between the technological complexity of an alliance, and the inclusion of an internal dispute resolution clause in an $R \& D$ alliance contract. 


\subsubsection{Time-bound alliances}

Parties to a contract possess feasible foresight, which is defined as the capacity to look ahead, recognize hazards, and develop appropriate responses ex-ante as reflected in the actual alliance contract (Williamson, 1996). Arguably, this ability of foresight is much greater for parties committing to a time-bound exchange, where the likelihood that conditions change during contract execution is relatively small (Ariño and Reuer, 2004; Crocker and Reynolds, 1993; Phene and Tallman, 2012). Therefore, these time-bound contracts can be considered more complete when compared to open-ended contracts (Ariño and Reuer, 2004). It is quite difficult for firms to create complete contracts for open-ended alliances as changing conditions can require alterations to the initial contract (Crocker and Reynolds, 1993; Phene and Tallman, 2012). This claim is supported by Reuer and Arińo (2007), who find that in time-bound alliances parties place less emphasis on interfirm coordination. In terms of internal dispute resolution mechanisms, this hints at the proposition that internal dispute resolution procedures are less often used by parties in time-bound alliances, compared to open-ended alliances, as the gap between the contract and the actual state of the world will be smaller, and there is less need to interpret the contract as it has developed over time.

In addition, whereas third-party involvement in disputes has a large potential to signal the end of collaborative endeavors (Bonn, 1972; Mayer and Teece, 2008), internal dispute resolution mechanisms seek to settle disputes rather quickly and in a manner that preserves the exchange relationship. Open-ended alliances signal a long-term interdependence between parties which increases the need for fair and internal dispute resolution mechanisms in order to make sure disputes, which are inevitable to occur in complex environments (Mayer and Teece, 2008), do not threaten continuity of the relationship. The need to preserve continuity in time-bound alliances is arguably much weaker as they are designed to last only a pre-defined period of time. ${ }^{27}$ Indeed, the existence of a fixed temporal endpoint shifts attention to each individual party trying to maximize its gain under an alliance (Ness and Haugland, 2005). Therefore, preserving continuity is not a priority of partners to a time-bound alliance, and as such, I expect that:

Hypothesis 2. There is a negative relationship between the time boundedness of an alliance, and the inclusion of an internal dispute resolution clause in an $R \& D$ alliance contract.

The above two hypotheses center around factors associated with more or less emphasis on internal dispute resolution in $\mathrm{R} \& \mathrm{D}$ contracts. Now, we turn our attention towards the point where parties need a binding third party decision, and focus on the choice of alliance parties to opt for arbitration in their contract. I expect that arbitration is a response to environmental uncertainty, and that arbitration is more likely to be the preferred method of dispute resolution if at least one of the firms participating in an alliance can be considered a high-growth firm. Firms operating in different legal regimes experience uncertainty as they risk having their future disputes heard in unknown legal environments. Taking a firm perspective, high-growth

27 One manager from a large biopharmaceutical company, when asked about the hypothesized relationship between time-boundedness of an alliance and internal dispute resolution, states: "...You would expect to have less elaborate conflict resolution mechanisms in (...) short term contracts, as the longer term interdependence is smaller...". 
firms are susceptible to substantial hazards as they face the possibility that the source(s) of their recent commercial success leaks out should their current alliance end in a dispute. Because arbitration is both based on custom rather than law and facilitates the private resolution of disputes, I anticipate that arbitration will be the preferred method of dispute resolution in the two situations sketched before.

\subsubsection{International alliances and similarity of legal regimes}

Parties engaging in an international alliance face a wide variety of different legal rules and procedures (Oxley, 1999). In most cases, parties are more familiar with their respective domestic legal rules and procedures compared to the foreign legal rules and procedures of their partnering firm. Partners often distrust each other's legal regime and fear a potential bias of foreign national judicial systems (Eisenberg and Miller, 2007). If not remedied by contractual safeguards, parties to an international alliance face substantial ex-ante uncertainty that stems from operating in a complex legal setting, where unknown laws and rules might govern future disputes. In this context, these contractual safeguards refer to alternative methods of resolving disputes that do not rely on foreign legal rules and procedures (Bernstein, 1992). Stated otherwise, for international alliances, parties are expected to find recourse to a system which avoids party 'A' having to submit disputes to the legal system of party 'B', and vice versa (Redfern, 1976).

Parties opting for arbitration voluntarily commit themselves to have disputes resolved by a neutral third party and to be bound by the decision of that neutral third party, i.e., the arbitrator (Bonn, 1972). The rules that govern the decision of the neutral can be determined in the contract by the parties themselves (Mattli, 2001), rather than imposed by a specific legal system. Under the New York Convention, arbitral decrees are widely recognized and enforced (Eisenberg and Miller, 2007). The chance of eventually ending up in court despite stipulation of an arbitration clause is small as the appeal possibilities against the decision of an arbitrator are limited, and grounds for refusal of an arbitral award are seldom granted.

From a legal perspective, parties experience substantial environmental uncertainty when participating in an international alliance as unfamiliar legal rules and procedures might govern interpretation of their contract in case of a dispute. With its limited appeal possibilities and the ability to let custom, rather than law, guide resolution of disputes (Bonn, 1972), arbitration can substantially reduce the perceived environmental uncertainty for parties that participate in an international alliance. Therefore:

Hypothesis 3a. Parties to an international alliance are more likely to stipulate an arbitration clause in their $R \& D$ alliance contract.

Different legal systems stipulate certain rules and procedures that are to be followed in order to resolve a dispute (Djankov et al., 2003). This suggests that if the legal systems of parties are more alike, parties experience less environmental uncertainty, and their propensity to opt for arbitration by contract should decline.

Common law and civil law traditions differ significantly in the way dispute resolution is approached (Elsing and Townsend, 2002). One major difference refers to the very beginning of dispute resolution proceedings; the formulation of the statement of claim (Elsing and Townsend, 2002). In most common law countries, especially in the U.S., a plaintiff submits a 
short overview of facts and the basis for the claim, extensive enough for the defendant to begin preparing its defense. During later proceedings, the exact details of the claim evolve. By comparison, in most civil law countries, cases are expected to be fully developed before they are filed (Elsing and Townsend, 2002). To further develop the exact details of a claim under the common law tradition, parties rely extensively on discovery procedures (Hagedoorn and Hesen, 2007), where parties can through various methods (e.g. requests for production of documents), collect evidence which might be relevant to the case at hand, although not necessarily so. Discovery procedures are used extensively in common law traditions, but it is difficult to overstate the reluctance with which (alliance) parties operating in civil law countries participate in common law style discovery procedures (Rubinstein, 2004). In most civil law countries, discovery procedures are rarely permitted and viewed upon as intruding the inherent confidentiality of private business information (Rubinstein, 2004). Dispute resolution under common law versus civil law jurisdictions also differs with respect to the role of the judge in the proceedings. In civil law jurisdictions courts take an active stance towards investigating the facts underlying a dispute whereas in common law jurisdictions courts remain more on the background (La Porta, Lopez-De-Silanes and Schleifer, 2008).

Although these differences are by no means exhaustive, ${ }^{28}$ it serves the purpose of highlighting the distinctive approach to dispute resolution under the two legal regimes. Considering these differences, it is not surprising that arbitration proceedings are often crafted in such a way as to strike a careful balance between common law and civil law rules (Rubinstein, 2004). As lawyers are usually educated in either civil law or common law rules (Rubinstein, 2004), and are mainly responsible for drafting dispute resolution clauses (Argyres and Mayer, 2007), I expect that parties experience less environmental uncertainty when both parties operate in similar legal regimes. Therefore, I posit:

Hypothesis 3b. Parties that operate in similar legal regimes are, compared to parties operating in different legal regimes, less likely to stipulate an arbitration clause in their $R \& D$ alliance contract.

Domestic partners still frequently opt for arbitration. To explain this choice, differences in legal rules and procedures is a much weaker argument. This begs the question why parties to a domestic alliance would opt for arbitration.

\subsubsection{High-growth firms}

Among the benefits accredited to arbitration, the confidential nature of the proceedings and the award is undoubtedly one of the most frequently mentioned benefits (e.g. Allison, 1990; Bonn, 1972; Goldman, 2003; Mattli, 2001). In contracts between businesses and consumers, the confidential nature of the arbitration proceedings decreases the risk of negative publicity for a business (Ware, 2001). In contracts between businesses, the private nature of the arbitration proceedings can prevent third parties, most notably competitors, from gaining valuable confidential information about a disputed issue (Brenowitz, 2004; Mattli, 2001). As such, arbitration is expected to be particularly valued by firms that seek to safeguard their

\footnotetext{
${ }^{28}$ I refer to Joireman (2001) and Legrand (1997) for a more elaborate rendition on common law versus civil law.
} 
competitive advantage by preventing leakage of crucial business information to the public, i.e., competitors.

Following Schumpeter, innovation is a broad concept. Indeed, "[i]nnovation in the Schumpeterian sense deals with new products and processes, product differentiation, new markets, diversification, new raw materials and new market structures. Furthermore, these new combinations will be carried out by new companies replacing the older ones" (Hagedoorn, 1989; p. 31). Innovation as referred to by Schumpeter often leads to explosive firm growth. Indeed, new processes and products can lead to significant firm growth (Mansfield, 1962). "Firms grow by successfully identifying, pursuing, and capturing a competitive advantage in an environmental niche" (Fombrun and Wally, 1989; p. 110). Irrespective of the specific innovation or competitive advantage that spurs firm growth, firms that experience a revenue surge can be expected to try and limit the unintended outflow of business information to non-alliance participants when their alliance ends in a dispute. The anticipation that high-growth firms are more concerned with information leakage compared to firms experiencing low to mediocre growth, or even decline, aligns to some extent with more industry level observations where firms operating in high-growth industries are claimed to be more protective of their innovation ideas (Gooroochurn and Hanley, 2007). When no standard product design has emerged yet in an industry, indicating that individual firms have the potential to achieve substantial growth if they can capitalize on the opportunity, firms are more protective of their ideas and capabilities (Gooroochurn and Hanley, 2007). Likewise, firms that have recently grown substantially by attaining a competitive advantage in a particular niche (Fombrun and Wally, 1989), can be expected to be somewhat protective of their ideas and capabilities (Slaby, Chapman and O'Hara, 1989). However, while collaborating, firms often become aware of each other's capabilities (Hamel, 1991). While a high-growth firm might anticipate and accept some loss of knowledge to its partner firm, unanticipated loss of information to non-alliance participants can be prevented by adequate contractual safeguards. Negative publicity via public proceedings might stifle firm growth, thus providing extra incentives for high-growth firms to limit leakage of information concerning their dispute to the environment. When an alliance runs into a dispute, the ability of high-growth firms to keep the source(s) of their success secret depends, in part, on the chosen dispute resolution method (Brenowitz, 2004). As previously mentioned, arbitration proceedings and the associated award are private. Facing leakage hazards (Williamson, 1992), high-growth firms are expected to implement additional contractual safeguards in the form of arbitration clauses that limit the unintended outflow of crucial business information.

Hypothesis 4. Parties to a domestic alliance involving a high-growth firm are more likely to include an arbitration clause in their $R \& D$ alliance contract.

\subsection{Data, methods, and sample description}

\subsubsection{Empirical setting}

This paper empirically examines the decision of firms active in the biopharmaceutical industry to opt for certain types of dispute resolution mechanisms in their contract. The biopharmaceutical industry is a well-suited arena to test my theoretical predictions, because it closely matches the setting depicted in the literature (as also noted by Lerner and Merges, 
1998). Biopharmaceutical projects are complex, uncertain, and costly. As a direct result, contracting difficulties are an especially salient feature of collaborative biopharmaceutical research and development projects. Firms also have constant incentives to unilaterally defect from an agreement (Lerner and Malmendier, 2010; Parkhe, 1993), increasing the likelihood that a dispute materializes during a collaboration. In case of a dispute, third party enforcement is troublesome (Lerner and Merges, 1998). The proposed relationships, if any, will thus most likely be observable in the biopharmaceutical industry. ${ }^{29}$

\subsubsection{Sample description}

The preliminary sample comprised 587 deals for the period 1996-2005 obtained from Pharmaventures, a UK-based information and consulting firm. Pharmaventures has identified thousands of alliances in the biopharmaceutical sector in their PharmaDeals database. The collected deals are grouped into a number of categories, such as collaborative R\&D, distribution/marketing, manufacturing/supply, and business acquisition. For each agreement, the PharmaDeals database provides information on the names of the partners, type of contractual relationship, date deal signed, equity investment, relevant product areas and technology fields, press releases and, where available, the actual contracts. Pharmaventures acquired these actual contracts from the U.S. Securities and Exchange Commission (SEC) filings and their clients. To avoid unnecessary heterogeneity, I excluded all agreements where:

- one of the parties is a government agency or university

- the alliance is, as stated in the contract, a renegotiation or restatement of a previous alliance between the firms

- there is no R\&D component to the alliance

- one firm has a controlling interest in the other firm (greater than 50\%)

- contracts involve more than two parties.

The final contract database contains a set of 304 contracts between unique partner sets. The dataset covers R\&D alliance contracts and additional information for the period 1996 through 2005. In addition, all alliances fall within the biopharmaceutical industry. As elaborated on earlier, the inherent complexity, lengthiness, costs, and low success rate of biopharmaceutical projects makes the biopharmaceutical industry an especially appropriate arena to investigate how parties intend to solve potential disputes as indicated by their contracts. In addition, by specifically focusing on the biopharmaceutical industry, we can be assured that variation in contracting terms does not come from a variation in the underlying contracting environment.

The agreements include both U.S. (domestic) contracts, i.e., the contracting parties are both U.S.-based firms (176 alliances), and international contracts, i.e., a U.S.-based firm collaborates with a non-U.S. based firm (128 alliances). A total of 284 firms were involved in the 304 contracts and about $55 \%$ of the agreements were concluded between a biotech firm and a pharmaceutical or a chemical firm.

\footnotetext{
${ }^{29}$ One manager from a large biopharmaceutical company states: “...R\&D alliances [are] often (...) strategic, complex and more or less open-ended and require a lot of complex decisions to be made. Based on this, I think it is fair to say that $R \& D$ alliances have a lot of potential to end in disputes..."
} 
I collected additional information on for instance the size of firms, alliance experience, and contract value. The complete dataset combines information from PharmaDeals with data retrieved from firm annual reports, the Cooperative Agreements and Technology Indicators (CATI) database, Datastream, USPTO, Compustat, LexisNexis, and Corptech.

\subsubsection{Dependent variables}

Internal dispute resolution. Based on interviews with legal experts, I focus here on one particularly credible signal of parties' intentions to solve disputes internally namely mandatory involvement of CEO's or heads of research in dispute resolution meetings (Hagedoorn and Hesen, 2007; Karambayya and Brett, 1989; Sampson, 2004a). ${ }^{30}$ I scanned each contract for the inclusion of clauses which mandate that CEO's or heads of research are to meet in case a dispute between parties escalates. The involvement of CEO's or heads of research in the dispute resolution process is envisioned as a last effort of parties to resolve a dispute internally (Sampson, 2004a). ${ }^{31}$ To illustrate, consider the following excerpt from the contract between Aerogen and Becton, Dickinson \& Company (May, 2000):

"The Parties shall try to settle their differences amicably between themselves by referring the disputed matter to the Chief Executive Officer of AeroGen and the Vice President and General Manager of BD Consumer Healthcare for discussion and resolution. Either Party may initiate such informal dispute resolution by sending written notice of the dispute to the other Party, and within ten (10) days of such notice the Chief Executive Officer of AeroGen and the Vice President and General Manager of BD Consumer Healthcare shall meet for attempted resolution..."

These internal dispute resolution mechanisms resemble minitrials highlighted in more law oriented literature (e.g. Klitgaard and Mussman, 1992), where senior executives of both parties are involved in rendering judgment on a dispute originating from lower hierarchical ranks. If the contract stipulates that CEO's or heads of research are to meet in case of a dispute, this dummy variable takes on a value of 1 and 0 otherwise.

Arbitration. Over the years, literature has paid increasing attention to non-traditional methods of external dispute resolution (Argyres and Mayer, 2007; Bernstein, 1992; Eisenberg and Miller, 2007; Lumineau and Oxley, 2012), most prominently arbitration (Mattli, 2001). By opting for arbitration, parties allow a neutral third party to render a binding decision on any future dispute (Bonn, 1972). I scanned each contract for the inclusion of clauses which mandate that disputes are to be forwarded to arbitration. To illustrate, consider the following excerpt from the contract between Progenics Pharmaceuticals and Bristol-Myers Squibb Company (April, 1997):

\footnotetext{
${ }^{30}$ One manager from a small biopharmaceutical company states: “...Practically speaking, no one wants to be embarrassed in front of their boss. If disputes can go straight from the project owner to the legal department, there is less incentive for a project owner to be reasonable...".

${ }^{31}$ One manager from a large biopharmaceutical company states: “...Most of our R\&D alliances stipulate our CSO [chief scientific officer] as last escalation point...The CEO/CSO should only be a last resort of highly strategic disputes...".
} 
“Any dispute (...) shall be (...) settled by arbitration to be held in New York, New York, under the auspices and then current commercial arbitration rules of the American Arbitration Association."

If the contract stipulates that disputes are to be forwarded to arbitration, this dummy variable takes on a value of 1 and 0 otherwise.

\subsubsection{Independent variables}

Technological complexity. For each R\&D alliance, PharmaDeals lists the number of technological interests areas for the products and/or technologies developed through that alliance, with a maximum of eight interest areas. These interest areas are likely to increase the potential application areas of a technology. In the context of the current contribution, I interpret these technological interest areas as different, albeit related, technological fields which parties need to combine in order to advance through technological development. I consider an alliance involving a broader technology as more complex compared to an alliance solely focusing on one or a few technological fields (Garcia-Canal, 1996).

This definition of complexity resembles to some extent the definition given by Nickerson and Zenger (2004) and Argyres and Mayer (2007) who define an alliance as more complex when parties have to rely on the knowledge sets of multiple individuals and groups within the contracting parties, and Oxley (1997) who defines an alliance that involves multiple technologies as more complex. ${ }^{32}$ Similarly, Wang and von Tunzelmann (2000) state that combining different bodies of knowledge complicates technology in terms of its breadth.

Time-bound. Contracts between alliance parties can be open-ended, i.e., with no predefined ending date, or be bound by a fixed temporal duration (Ness and Haugland, 2005). I focus on whether or not an alliance is time-bound, i.e., whether there is a pre-defined ending date of an alliance as stipulated in the contract. This dummy variable takes on a value of 1 if the contract has a pre-defined ending date, and 0 otherwise.

International alliance. Firms involved in cross-border alliances face substantial environmental uncertainty as they try to cope with a variety of complex rules and procedures when enforcing their contract rights in a foreign legal system (Oxley, 1999). Based on information provided by PharmaDeals, I include a dummy variable which equals 1 if firms are headquartered in different countries, and 0 if they are both headquartered in the US.

Similar legal regimes. The literature classifying the legal origins of countries has largely distinguished between common law and civil law jurisdictions. In turn, the civil law countries are often subdivided into French, German, socialist and Scandinavian legal origins (Djankov et al., 2003). Here, based on Djankov et al. (2003) and for the international alliances, I include a dummy variable which equals 1 if the alliance is between a US firm and another common law country (i.e. English legal origin), and 0 if the alliance is between a US firm and a country with a non-common law background, i.e., civil law. Key features of legal origin are quite

\footnotetext{
32 This measure has previously been used to establish the number of potential application areas of a technology. Firms might consider a technology with multiple potential applications more valuable compared to a single application technology, and therefore put additional effort in solving disputes cooperatively. Although I am unable to formally rule out this alternative explanation, this explanation is unlikely to dominate the findings reported here. The main reason is that if the prime objective of firms is to solve disputes cooperatively, they would also be more likely to opt for arbitration as it has stronger continuity-preserving properties compared to alternatives. However, I find no support for such a relationship.
} 
often preserved in the legal system of individual countries (Djankov et al., 2003; La Porta et al., 1998).

High-growth firm. Since 1996, Deloitte has made an annual ranking of the 500 fastest growing technology companies in terms of revenues in the U.S. and Canada called the Deloitte Technology Fast 500. To be eligible for inclusion in the Deloitte Technology Fast 500, a company must first and foremost be a technology company (Deloitte Technology Fast 500, 1996-2005). These companies own proprietary technology or IP that contributes significantly to their revenues, manufacture a technology-related product, or have welldeveloped R\&D capabilities (Deloitte Technology Fast 500, 1996-2005). Firms must meet certain minimum levels of operating revenues in their base year, be in business for a number of years to calculate firm growth, and be headquartered in the U.S. or Canada (Deloitte Technology Fast 500, 1996-2005). The rankings are a measure of past growth, thus not including current year revenues. Using a listing of high-growth firms resembles the approach taken by Oxley and Sampson (2004), who use a different list, i.e., a ranking of the Top 100 Technology Companies, to separate market leaders from laggards. The measure that I use has two advantages. First, it compares the growth of a firm to other firms operating in the same time span, i.e., it is a relative measure. Second, it provides information on both public and private firms.

I collected data on the annual top 500 technology companies for the period 1996 to 2005. The variable high-growth firm equals 1 if in the year of the alliance, or in the previous year, one of the firms participating in an alliance is incorporated in the Deloitte Technology Fast 500 , and 0 otherwise.

\subsubsection{Control variables}

Size asymmetry. A large difference in sizes indicates a dependence of the smaller alliance partner on its larger counterpart (Park and Ungson, 2001), ${ }^{33}$ and consequently might influence the degree to which partners are equally motivated to 'work things out'. ${ }^{34}$ As such, I deduct the logarithm of the number of employees of the smaller firm from its larger counterpart.

$R \& D$ asymmetry. Although I expect no specific relationship between asymmetry in partners' R\&D expenses and their propensity to stipulate internal dispute resolution and/or arbitration provisions, I do want to control for possible effects. As such, I use a measure similar to size asymmetry by deducting the logarithm of R\&D expenses of the partner firm with the smallest R\&D expenses from its larger counterpart.

Alliance experience asymmetry. I obtained the prior R\&D alliance experience of both firms in a five year window prior to the start of their R\&D alliance (see also Gulati, 1995).

\footnotetext{
33 In unreported analyses I also considered an asymmetry measure based on net income and a more direct measure for the interdependence of activities based on the R\&D plan. Both variables have no significant influence on the dependent variables, and leave the presented results unaltered. Due to the large number of control variables already present in the analyses, these additional control variables are therefore omitted.

${ }^{34}$ When asked about the different types of dispute resolution and when certain modes are preferred over others, one manager from a small biopharmaceutical company states: “...My experience after 20 years in large Pharma (...), medium sized Pharma (...) and small biotech (...) is that the answer is different for different companies. The larger the company the more important it is for there to be an "escalation clause" in which a more senior person than someone who is involved in the day-to-day operations of the collaboration can drive resolution of disputes (...). Stated differently, when an employee of a big company has to involve his boss or his boss's boss, they are more motivated to be reasonable and resolve any disputes...".
} 
Firms might learn from previous alliance experiences, and adapt consequent contracts accordingly. Also, firms with more alliance experience are more likely to possess dedicated alliance personnel (Schilke and Goerzen, 2010). As such, these firms might benefit from dedicated legal personnel tasked with drafting dispute resolution clauses. Substantial asymmetry in alliance experience between partners may be indicative of different preferences for particular dispute resolution mechanisms. Firms with more alliance experience might prefer more formal, legal-based, methods of dispute resolution while firms with less alliance experience might prefer more informal mechanisms. As such, I control for alliance experience asymmetry by subtracting the alliance experience of the firm with the least alliance experience from the alliance experience of its counterpart.

Early stage research. The PharmaDeals database provides information on the stages of the innovation process underlying each deal. In alliances that focus on early stage research, collaborating firms face a range of research options and, therefore, a variety of directions for their joint research projects (Freeman and Soete, 1997; Nelson, 1961; 1982). In general, the open nature of the range of options that firms still have at this early stage indicates that there is little or no information on the concrete new products and processes that will eventually be developed. When parties have different interpretations about the material aspects of their collaboration, disputes might be more prone to occur. Indeed, Argyres and Mayer (2007) and Argyres, Bercovitz and Mayer (2007) suggest that over time parties more clearly stipulate roles and responsibilities in their contract to avoid disputes from occurring during their collaboration. This would hint at the proposition that disputes are especially likely to occur in the more early research stages when many aspects of a collaboration are non-contractible. I control for the innovation stage of an alliance by using a dummy variable that equals 1 if an alliance focuses on early stage research, and 0 otherwise.

$R \& D$ Plus. I control for any additional activities undertaken within the scope of an alliance. These additional activities might complicate the alliance (Sampson, 2004b), and lead to more misunderstandings between parties. As such, parties may be inclined to spend more effort on drafting elaborate dispute resolution procedures when the scope of an alliance is broader. I therefore include a dummy variable that equals 1 if any additional activities (e.g. marketing) are included besides $\mathrm{R} \& \mathrm{D}$ and 0 otherwise.

Equity. Based on information provided by PharmaDeals, I control for whether or not equity is involved. As the acquisition of a part of a firm generates control in the R\&D alliance (Oxley, 1997), this could be reflected in the dispute resolution mechanisms that parties stipulate. For instance, the incentive alignment induced by an equity stake might decrease the need for more formal methods of dispute resolution. I control for a possible effect of equity on different types of dispute resolution by including a dummy variable that equals 1 if one of the firms takes an equity stake in its partner and 0 otherwise.

Competition. Alliances involve a careful balancing act between cooperation and competition (Das and Teng, 2000a). Parties that are direct competitors in their product markets may exhibit non-cooperative behavior thereby negatively affecting the stability of their alliance (Das and Teng, 2000a). As such, alliances between competitors seem to be especially susceptible to the emergence of disputes during contract execution. I control for the level of competition between alliance participants based on their SIC codes (Mowery, Oxley and Silverman, 1996). Using data from Thomson ONE Banker, this variable takes on a value of 2 if both parties operate in the same primary 4-digit SIC code, 1 if both parties do not 
operate in the same primary 4-digit SIC code but do operate in the same 3-digit SIC code, and 0 otherwise.

Interstate alliance. In the subset of domestic alliances, I want to control for the possibility that parties to interstate alliances experience more environmental uncertainty. In the regressions only involving domestic alliances, I therefore include a dummy variable that equals 1 if parties operate in different states and 0 otherwise.

Prior ties. I control for any previous collaborations between parties in a five-year window before the focal alliance, as familiarity can increase the willingness to 'work things out' (Lumineau and Oxley, 2012). In the context of this study, this could indicate that repeat collaborators are more likely to promote internal dispute resolution, while shunting external dispute resolution mechanisms such as arbitration. Using the CATI database, I searched for the number of prior ties between alliance partners, counting back five years from the start of the R\&D alliance (see also Gulati, 1995).

Value. For each R\&D alliance, PharmaDeals gives information about the (potential) deal value if available. In addition, I collected additional deal value data from the LexisNexis database. I expect that a larger deal value is reflected in parties' desire to work things out when disagreements occur. As such, I include the value of the alliance in millions of dollars. Because the distribution of this variable is highly skewed, I perform a logarithmic transformation. This variable takes on a value of zero if information concerning deal value is missing.

Value dummy. I only have information concerning the deal value of alliances in about $55 \%$ of the cases and as such want to control for the other $45 \%$. Therefore I include a dummy variable which equals 1 if information about the deal value is missing and 0 otherwise. ${ }^{35}$

Year fixed effects. I control for temporal trends in alliances and include dummy variables for the period 1996-2005 with the year 1996 as the reference year.

\subsubsection{Analysis}

In the following, I use Probit models and a Bivariate Probit model using robust standard errors with inclusion of an internal dispute resolution clause and/or an arbitration clause as my dependent variables. Standard errors are clustered by firm. In the section on alternative explanations and robustness checks I alternatively use multinomial logit and probit models.

\subsection{Results}

Table 4.1 shows descriptive statistics of all the variables included. None of the bivariate correlations exceed the usual 0.7 cut-off value, except for the correlation between value and value dummy. I refer to footnote 35 for a more elaborate discussion of this issue. Table 4.2

\footnotetext{
35 Although frequently used (see, for instance, Bastos (2010), Griliches (1976), Khorana, Servaes and Tufano (2009), Singh (2008); Smith and Huang (1995)), this method of dealing with missing values has its drawbacks, as do alternative methods. In unreported analyses, I use four other methods to deal with missing values to investigate whether or not results change depending on which method I use. First, I run a regression without controlling for value. Second, I run a regression in which I only control for whether or not information on value is missing. Third, I limit the sample to only those observations for which I was able to retrieve information on the value of alliances. Fourth and last, based on a host of observable variables, I estimate the value of an alliance if this information is missing, and use these estimates in the full model. Results were not strikingly different and in general agreed with the results reported here.
} 
shows the results of the probit and bivariate probit estimations. Model 1 in Table 4.2 refers to the basic model with only control variables included and with internal dispute resolution as the dependent variable. In subsequent models 2 and 3, I individually add each variable relating to hypotheses 1 and 2. Model 4 in Table 4.2 refers to the basic model with only control variables included and with arbitration as the dependent variable. In subsequent model 5 I include the variable relating to hypothesis 3a. Model 6 introduces a joint estimation with both internal dispute resolution and arbitration as dependent variables, with all independent variables relating to hypotheses 1 to $3 \mathrm{a}$ and all control variables included. This joint estimation allows us to take into account the correlation of error terms of the internal dispute resolution and arbitration equations. Models 7 to 10 are models that focus on a subsample of the total sample. Model 7 is run on a subsample of international alliances in which I include all control variables. In model 8, I add the variable relating to hypothesis $3 \mathrm{~b}$. Model 9 is run on a subsample of domestic alliances in which I include all control variables. In model 10, I add the variable relating to hypothesis 4 . 


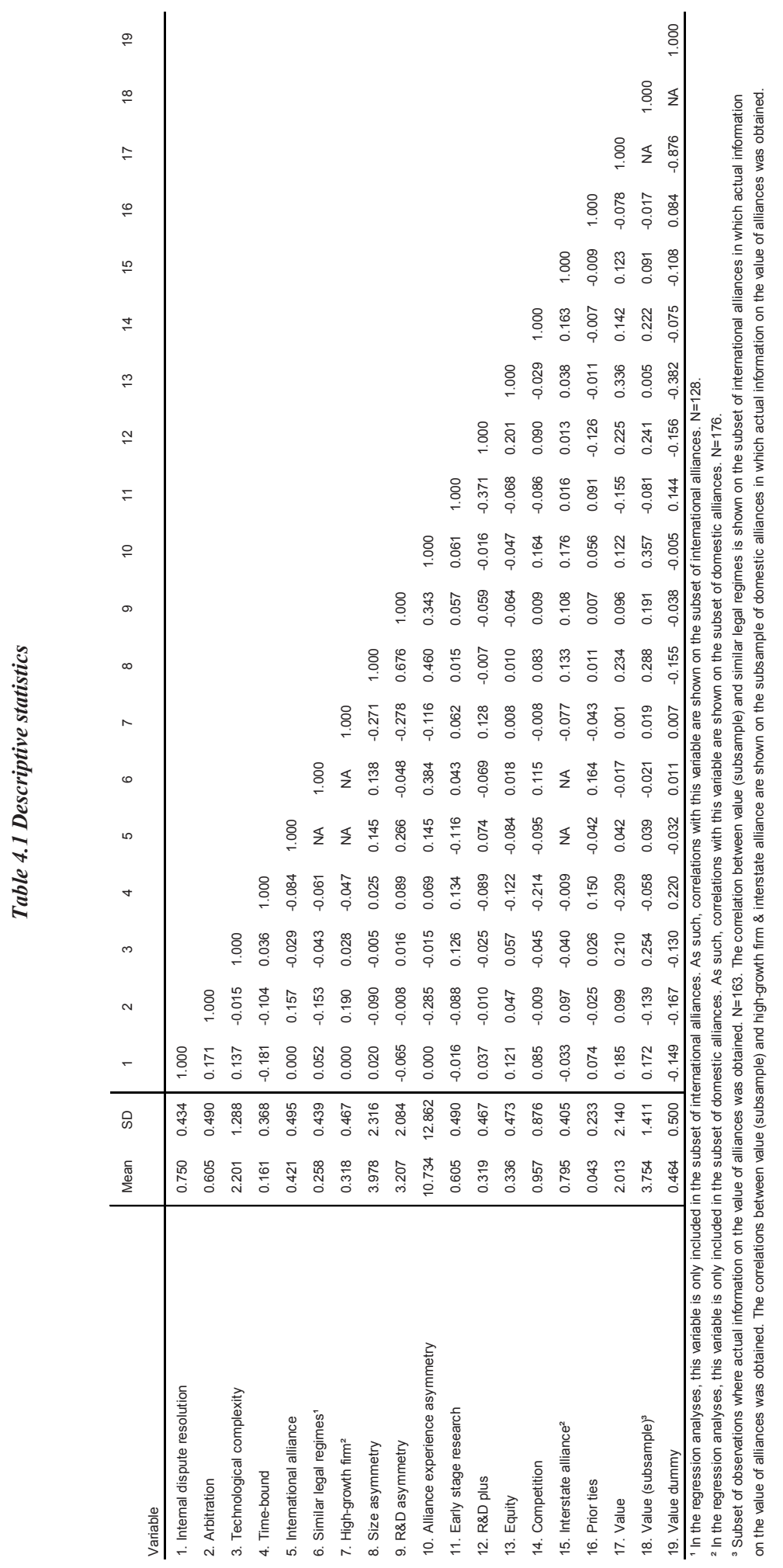


Hypothesis 1 states that there is a positive association between the technological complexity of an alliance and the likelihood of observing an internal dispute resolution clause in a contract. In models 2 and 6, I find support for the proposition that technological complexity is positively associated with the inclusion of an internal dispute resolution clause. Referring to models 3 and 6, I also find support for hypothesis 2 which predicted that parties to a timebound alliance are less likely to include an internal dispute resolution clause in their contract. Hypothesis $3 \mathrm{a}$ predicted that parties operating in different countries are more likely to stipulate an arbitration clause in their contract. Models 5 and 6 show the expected significant positive effect. Hypothesis $3 \mathrm{~b}$ predicted that, compared to alliances in which parties operate in more distinct legal regimes, international partners that operate in similar legal regimes are less likely to stipulate an arbitration clause in their contract. Although bivariate correlations support the expected negative relationship at the $10 \%$ level, this result does not hold up in the regression analyses. Model 8 shows no significant negative relationship between the similar legal regimes variable and arbitration. I do find support for my hypothesis 4 which predicted that in domestic alliances, parties to an alliance that involve a high-growth firm are more inclined to stipulate an arbitration clause in their contract. Model 10 shows the expected significant positive effect. 
Table 4.2 Probit or Bivariate Probit model estimation results of internal dispute resolution and/or arbitration

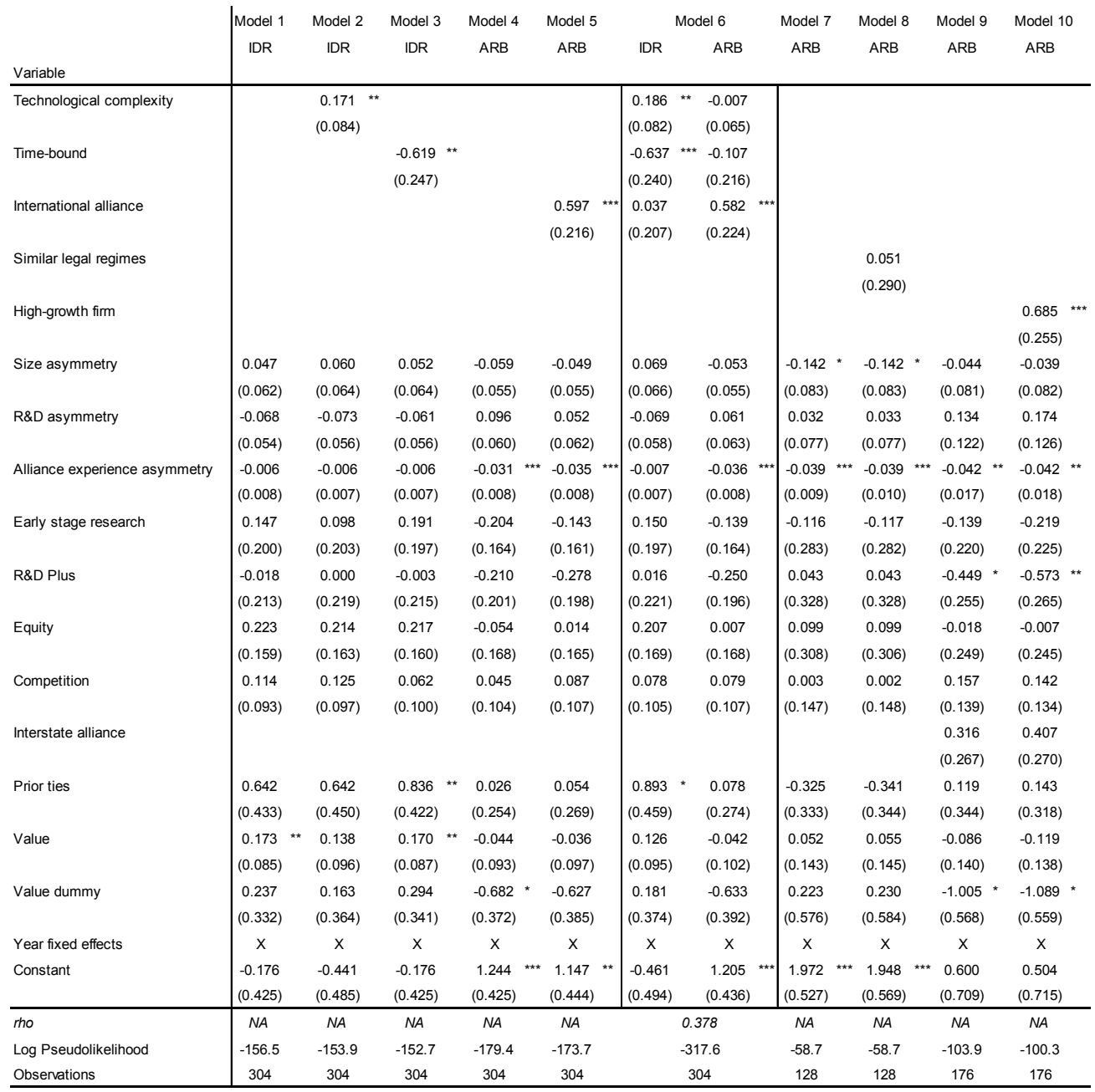

Notes: Probit regressions where the dependent variables are Internal Dispute Resolution (models 1, 2, and 3), Arbitration (models 4, 5, 7, 8, 9, and 10) or both (model 6). Models $7 \& 8$ and $9 \& 10$ are run on a subsample of international and domestic alliances, respectively.

Robust standard errors, clustered by firm, in parentheses.

* significance at the $10 \%$ level; ** significance at the $5 \%$ level; ${ }^{\star \star \star}$ significance at the $1 \%$ level. 
Regarding the control variables, I find that asymmetry in alliance experience has a significant and negative effect on the propensity of parties to opt for arbitration in their contract. Firms that frequently enter into alliances most likely have considerable experience with interfirm disputes, and possess specialized legal departments. It could therefore be that this finding reflects a propensity of more experienced firms to avoid alternative dispute resolution mechanisms.

\subsection{Alternative explanations and robustness checks}

In this section, I discuss some alternative explanations of my findings and deliberate on some additional robustness checks.

Involvement of CEO's as a proxy for internal dispute resolution. Arguably, parties have several options available to promote internal dispute resolution. Here, based on interviews with legal experts, I focus on one particularly salient method of internal dispute resolution namely the involvement of CEO's or heads of research (Sampson, 2004a). In that sense, this study aligns with research on the intrafirm level (e.g. Elangovan, 1995; Karambayya and Brett, 1989; Pinkley et al., 1995) that sees managers as logical internal third-parties to which disputants can turn when they are unable to solve a dispute. However, undoubtedly, parties have additional contractual mechanisms available that support internal dispute resolution. Here, I focus on whether or not parties establish a steering committee as stipulated in their contract. Although the main responsibility of these steering committees is to coordinate alliance activities, they are occasionally tasked with dispute resolution (Gulati and Singh, 1998). Inclusion of this variable as an additional control variable in the regressions leaves the presented results unaltered.

High-growth firm. I run a set of different specifications of the presented models. First, I do not have data available on the ranking in the year 1995. As such, the variable capturing the presence of a high-growth firm for those alliances signed in 1996 is based on the presence of a firm in the Deloitte's Technology Fast 500 ranking of the year 1996 only. I reran the regressions excluding those alliances in the year 1996, and results remain consistent with those presented. Second, I included a new measure for 'high-growth firm' which equals 1 if an alliance firm is included in the Deloitte's Technology Fast 500 ranking in the year of the alliance, in the previous year, or in two years before the alliance. Running a regression on all alliances between 1998 and 2005, due to the increased time-lag, generates similar results. Third, I considered that it might be easier for small firm combinations to achieve high growth rates compared to somewhat larger firm combinations. I split the domestic alliances into a group containing firm combinations where both partners have less than 250 employees (33 observations), a group containing firms combinations where both partners have more than 250 employees (30 observations), and a rest group. In all three subsets there is a positive correlation between the high-growth variable and the propensity of parties to opt for arbitration. Fourth, it is possible that over time the biopharmaceutical industry has gained momentum, and that as a result, it becomes easier for firms to reach the Deloitte ranking. I split the sample into a period before 2000, and a period during and after 2000. In both subsamples, parties to an alliance that include a high-growth firm are more likely to include an arbitration provision in their contract.

Relationship between internal dispute resolution and arbitration. Throughout the analyses, I used probit and bivariate probit models to investigate the relationship between my 
independent variables and my two dependent variables. Although the latter method specifically takes into account correlation of errors terms, it does not take into account that the likelihood of observing one particular type of dispute resolution clause (e.g. arbitration) might increase with the use of another type of dispute resolution clause (e.g. internal dispute resolution). There is some evidence of co-occurrence of these dispute resolution mechanisms as indicated by a weak positive correlation shown in Table 4.1. This opens up the possibility of not just predicting when one clause will be used, but when it might be used in conjunction with the other or specifically without the other.

Table 4.3 Internal dispute resolution and arbitration

\begin{tabular}{l|c|c|c|}
\multicolumn{1}{c}{} & \multicolumn{3}{c}{ Arbitration } \\
\cline { 2 - 4 } & & 0 & 1 \\
\cline { 2 - 4 } & 0 & (1) $13.5 \%$ & (2) $11.5 \%$ \\
\cline { 2 - 3 } $\begin{array}{l}\text { Internal } \\
\text { dispute } \\
\text { resolution }\end{array}$ & & & \\
\cline { 2 - 4 } & 1 & (3) $26.0 \%$ & (4) $49.0 \%$ \\
\hline
\end{tabular}

In unreported multinomial logit models, ${ }^{36}$ I compare the four quadrants shown in Table 4.3. First I use quadrant 1 as the base category, which encompasses contracts that contain neither internal dispute resolution mechanisms nor arbitration provisions, after which I use quadrant 4 as the base category, which encompasses contracts that contain both internal dispute resolution mechanisms and arbitration provisions. Quadrants 2 and 4, that both include arbitration clauses, are more likely to occur compared to quadrant 1 when firms are headquartered in different countries. Quadrants 3 and 4 show the expected signs in terms of technological complexity and whether or not an alliance is time-bound when compared to quadrant 1 , although these variables are not significant at conventional levels. Nevertheless, these variables are not far from statistical significance. Using quadrant 4 as a base category, quadrant 2 (only arbitration, no internal dispute resolution) is significantly less likely when the technological complexity of an alliance increases, and more likely when alliances are time-bound. Quadrants 1 and 3 (no arbitration) are significantly less likely to occur compared to quadrant 4 when parties are headquartered in different countries. As such, the results of these additional analyses correspond quite well with the results shown in Table 4.2. I also considered using a similar multinomial logit approach to the regressions involving subsets of international and domestic alliances. These analyses in general agreed with the results as shown in Table 4.2. However, these analyses come with a caveat as the number of observations per quadrant drops to non-acceptable levels thereby inhibiting the obtainment of reliable estimates for the parameters of interest.

\footnotetext{
${ }^{36}$ I also considered multinomial probit models. A multinomial probit model relaxes certain assumptions of the multinomial logit model, but is often more difficult to apply because, one, the likelihood function can be relatively flat near its optimum, and two, estimating the unknown parameters requires approximating multivariate normal integrals (Dow and Endersby, 2004; Hausman and McFadden, 1984; McCulloch and Rossi, 1994). In unreported regressions, I repeat the analyses using a multinomial probit estimator. Results remain consistent with those discussed in this section.
} 


\subsection{Discussion and conclusions}

The results presented in this paper add to more theoretical contributions (e.g. Hagedoorn and Hesen, 2007), which highlight that alliance parties have several contractual options available to guide resolution of their disputes. Dispute resolution properties of contracts are a particularly salient feature of alternative governance arrangements (Williamson, 1991). The results presented in this paper shed a light on different contractual dispute resolution mechanisms. I add to previous literature which states that most disputes are actually resolved by parties themselves without the use of formal, legal rules that may not be applicable to their dispute (Galanter, 1981; Johnson, McMillan and Woodruff, 2002; Macaulay, 1963). Here, I show that alliance parties often implement contractual safeguards that promote internal resolution of disputes. These internal dispute resolution clauses are not randomly distributed across contracts, but appear to respond to various levels of exchange complexity. This paper also contributes to a burgeoning stream of literature that highlights methods of dispute resolution that seek to avoid the traditional legal system (e.g. Bernstein, 1992; Eisenberg and Miller, 2007; Mattli, 2001). Environmental uncertainty and the presence of a high-growth firm in an alliance seem positively associated with the likelihood of observing arbitration clauses in alliance contracts. These findings add to more general TCE literature and literature on neoclassical contracts (e.g. Williamson, 1991) by, first, affirming that alliance parties frequently opt for specialized governance features (e.g. arbitration) and, second, empirically investigating the conditions under which these specialized governance features are more or less likely to occur.

Technological complexity, as a first element of exchange complexity, is positively associated with the likelihood of observing an internal dispute resolution clause. Parties suffer from bounded rationality and when technologies get more complex, it becomes more difficult to write a complete contract. Parties themselves are best equipped to deal with disputes concerning highly complex technologies, as they possess idiosyncratic knowledge of the underlying intentions under an agreement (Williamson, 1991), and can make use of all information necessary in resolving a dispute (Johnson, McMillan and Woodruff, 2002). I observe internal dispute resolution clauses more frequently when alliances get technologically more complex. This finding adds to more theoretical literature (e.g. Klitgaard and Mussman, 1992), which highlights that parties, when dealing with a complex technology, often experience uncertainty as to whether or not a third party will understand the intricacies of their technology. As a result, parties develop specialized governance features (Williamson, 1991), to cope with complex technologies (Klitgaard and Mussman, 1992). The results in this paper lend credence to such a claim by showing that the propensity of parties to stress internal dispute resolution increases as the underlying technology of their collaboration becomes more complex.

As a second element of exchange complexity, I find that parties to a time-bound alliance are less likely to stipulate internal dispute resolution clauses. For time-bound alliances, i.e., alliances with a fixed temporal duration, parties are less likely to experience changing conditions during contract execution (Phene and Tallman, 2012). For instance, Reuer and Arińo (2007) find that in time-bound alliances, parties place less emphasis on interfirm coordination as the need to adapt to changes during their collaboration is small (see also Ariño and Reuer (2004) and Crocker and Reynolds (1993)). Time-bound contracts are more complete and firms experience less pressure to stress internal dispute resolution in their time- 
bound contracts. These time-bound alliances are 'meant to end', and the long-term interdependence is rather low. The perceived need to preserve continuity in time-bound alliances is thus lower, and the attention lays more on maximizing individual gains (Ness and Haugland, 2005), rather than stressing cooperative dispute resolution. By comparison, openended alliances increase the exchange complexity for parties as contingencies unforeseen at the contract signing date can interfere with the initial plan laid out in the contract. Flexible adjustment mechanisms are thus required. Here I find that parties are more likely to promote internal dispute resolution when alliances are relatively open-ended.

Concerning the environmental uncertainty surrounding an alliance, I find that parties involved in international alliances have an increased likelihood of opting for arbitration in their contracts, compared to domestic deals. International alliances are more uncertain as both parties dread the possibility of having their contract interpreted by a foreign judicial system applying unknown legal rules and procedures. Simply put, party 'A' does not want to end up resolving a dispute in the legal system of party 'B', and vice versa (Redfern, 1976). As such, additional contractual safeguards are warranted. By opting for arbitration, contracting parties essentially forego their opportunity to resolve a dispute in the traditional legal system, i.e., parties allow for custom rather than law to render a verdict on a potential dispute (Bonn, 1972). As the appeal possibilities against an arbitral decree are limited, and "arbitral decrees are widely recognized and enforced under the New York Convention" (Eisenberg and Miller, 2007; p. 342), arbitration is a particularly effective contractual safeguard for international parties to cope with different legal systems.

I also considered the relationship between the presence of a high-growth firm in an alliance and the likelihood of observing an arbitration clause in the corresponding contract. For alliances between domestic parties, I find strong support for the claim that if at least one party has experienced recent rapid growth, the alliance contract is more likely to include an arbitration clause. Firms that experience recent commercial success are often wary of leaking valuable business information to outsiders when their alliance runs into a dispute. These firms often possess a competitive advantage over other firms which they seek to protect from appropriation by (outside) competitors (Fombrun and Wally, 1989; Slaby, Chapman and O'Hara, 1989). When technology companies experience explosive growth, i.e., commercial success, they implement contractual safeguards in their alliance contracts aimed at limiting the outflow of information and knowledge to outside competitors. This study thus finds support for the claim that the confidential nature of arbitration proceedings and the award (Mattli, 2001), is paramount in explaining the preference of some firms to have disputes settled by arbitration.

A counterargument to the reasoning laid out before is that if high-growth firms are particularly keen on preventing leakage, they are also more likely to promote internal dispute resolution. This counterargument has merit, but is ultimately flawed. Its benefits notwithstanding, extensive internal dispute resolution does not limit parties in their ultimate choice for a mandated third party dispute resolution. Parties could therefore stress internal dispute resolution, but still ultimately find themselves in public forums settling their dispute. As such, it makes sense for high-growth firms to particularly stress arbitration as the preferred method of dispute resolution. In unreported regressions I checked whether or not internal dispute resolution mechanisms are more likely to be stipulated in an alliance contract in the presence of a high-growth firm. However, I find no empirical support for such a claim. 
Contrary to my expectations, I find no significant relationship between the similarity of parties' legal regimes and their propensity to stipulate an arbitration clause in their R\&D alliance contract. The measure that I use, however, might pick up other cross-national differences that interfere with the presented results. Two particularly salient cross-national differences refer to differences in rule of law and national culture. According to The World Bank Group, rule of law partially refers to the extent to which agents have confidence in quality of contract enforcement (also see Kaufmann, Kraay and Mastruzzi, 2010). The average value for the U.S. in the period between 1996 and 2005 for this rule of law measure equals around 1.5. Countries in my dataset with a somewhat weaker rule of law include Belgium, China, France, Italy, Japan, and the Republic of Korea. At first sight, in unreported regressions on the subset of international alliances, it indeed appears that rule of law has a negative correlation with the propensity of parties to stipulate an arbitration provision. This would indicate that when parties have more confidence in their contract rights being enforced by a foreign - to the U.S. firm - court, they would be less inclined to opt for arbitration in their contract. However, further investigation shows that this is mainly a 'Japan effect', i.e., nearly all contracts (92\%) that involve a Japanese and U.S. firm include arbitration provisions. In some respects, the Japanese legal system differs significantly from both common law and civil law systems. For instance, Japanese courts possess only few coercive powers and Japanese companies strongly rely on extralegal methods of dispute resolution (Haley, 1991). As such, differences in their respective legal systems might explain why U.S.Japan firm pairs are so inclined to contractually stipulate that potential disputes will be forwarded to arbitration. In a similar vein, it could be argued that differences in national cultures spurs relationship conflict and hampers the development of a successful collaboration (Sirmon and Lane, 2004). Similar to Oxley (1999) and using Hofstede's 'dimensions of culture' (Hofstede, 1980), I account for differences in national cultures in unreported regressions. It indeed appears that cultural distance is positively related to the propensity of international alliance parties to stipulate an arbitration clause in their agreement. Nevertheless, similar to the rule of law discussion, this finding can be contributed to a large 'Japan effect'. In terms of power distance, uncertainty avoidance, individualism and masculinity, Japan differs quiet significantly from the U.S. In light of the previous arguments and findings, it is possible that rule of law and culture have a negative and positive, respectively, effect on the propensity of alliance partners to stipulate an arbitration clause in their contract. However, these relationships come with a caveat as they appear to be solely driven by U.S.-Japan firm pairs. As such, future research covering a more heterogeneous set of international firm pairs could seek to unravel the exact link between rule of law, cultural distance and the propensity of international firm pairs to opt for arbitration in their contract.

\subsection{Limitations and future research directions}

This research has certain limitations which point to interesting areas for future research. First, similar to other recent research on the design of contracts, I am conservative in the empirical inferences I draw due to possible correlations of the error terms. As I observe no relevant exogenous shocks during the period in which the contracts in the sample were signed, I am unable to claim any causal relations between exchange features and the preference of contracting parties for certain dispute resolution mechanisms. To generate further confidence in the presented results, in unreported regressions, I used firm fixed effects for the most 
frequently occurring firms in my sample to account for unobserved firm effects (Lerner and Malmendier, 2010). Presented results remain unaltered. We can thus be relatively confident in the finding that elements of exchange complexity drive the choice for internal dispute resolution, rather than certain types of companies entering into more or less complex alliances while simultaneously placing more or less emphasis on internal dispute resolution mechanisms. Nevertheless, additional analyses using longitudinal data could yield interesting supplemental results. Second, parties can deviate from the contract when a dispute arises. Further research is necessary to uncover how contractual clauses are translated into dispute resolution when a dispute actually occurs. ${ }^{37}$ Third, more research is necessary into the consequences of CEO involvement in disputes, as lower organizational levels get disempowered, possibly leading to more and more disputes being forwarded to higher hierarchical levels. ${ }^{38}$ Fourth and last, I focus on firm growth because "[f]irms grow by successfully identifying, pursuing, and capturing a competitive advantage in an environmental niche" (Fombrun and Wally, 1989; p. 110). Firms seek to protect the source(s) of their competitive advantage, especially from appropriation by competitors. However, I am currently unable to rule out that other mechanisms might actually drive this observed positive correlation. Do these firms face more appropriation concerns regarding their capabilities? Are these firms especially worried about their external image (Fombrun and Wally, 1989)? Or are these firms compensating for their turbulent development (Hambrick and Crozier, 1985), by generating control over how potential disputes will be resolved? I encourage future research to answer these questions.

\footnotetext{
37 As one manager from a large electronics company states: “...Parties each agree to a certain type of dispute resolution ex-ante, in the contract, and you never know exactly how this will work out in case a dispute actually arises...".

38 As one manager from a large biopharmaceutical company states: “...Disputes should be solved at lowest possible level. However, if need they [CEO involvement] are quite efficient [in] the short term as they short-cut the normal process and allow the outcome to be communicated from a high platform. However, the process can tend to be somewhat segregated from the day-to-day operation of the alliance, and if the CEO/CSO do not show discipline in involving their internal stakeholders (Project VP etc.) the decision might end out to be blurred, disintegrated with reality and hard to implement. (...). [C] are should be taken when involving CEO/CSO. Escalation can become a vicious circle: dis-empowering the lower organizational level in their decision-making capability [thereby] leading (...) to more and more escalation of lesser and lesser issues...".
} 


\title{
Current Employee, Future Competitor? Limiting the Outflow of Human Capital to Collaboration Partners ${ }^{39}$
}

\begin{abstract}
This paper explores contractual limitations on the hiring behavior of firms that participate in collaborative R\&D alliances. I categorize these contractual limitations in terms of duration, scope, and definition. Interestingly, I find that many clauses may affect employees that are not directly involved in a collaboration. Hypotheses are tested using a dataset of $302 \mathrm{R} \& \mathrm{D}$ alliance contracts in the biopharmaceutical industry. Results indicate that the presence of a firm located in a pro-mobility environment decreases the likelihood of observing contractual limitations on employee mobility. Furthermore, scientifically oriented firms are more likely to contractually limit each other's hiring behavior.
\end{abstract}

\footnotetext{
${ }^{39}$ This work has benefited from helpful comments and suggestions by Hans Frankort, John Hagedoorn, Katrin Hussinger, Fabrice Lumineau, Gerard Pfann, and participants at seminars at KU Leuven and Maastricht University.
} 


\subsection{Introduction}

In recent years a growing body of research has aimed to answer the question how firms combine resources to support innovation activities. In the search for a response to this question, research has usually focused on either alliances (Das and Teng, 2000b; Hagedoorn, 1993), or on employee mobility (Corredoira and Rosenkopf, 2010; Somaya, Williamson and Lorinkova, 2008; Wezel, Cattani and Pennings, 2006), although rarely in tandem (some exceptions are Hess and Rothaermel, 2011; Rosenkopf and Almeida, 2003; Rothaermel and Hess, 2007). Both mechanisms, i.e., alliances and employee mobility, aim to tap into knowledge resources not currently possessed by a particular firm. As already indicated by Kenneth Arrow in 1962, "[m] obility of personnel among firms provides a way of spreading information" (Arrow, 1962; p. 615). Alliances seek to achieve a similar goal by combining resources, i.e., valuable information, embedded in two or more different organizations (Das and Teng, 2000b). Irrespective of their similarities, firms can be expected to be concerned about employee mobility in collaborative arrangements (Oxley and Wada, 2009). For a particular firm, loss of key employees can have devastating consequences (Phillips, 2002; Wezel, Cattani and Pennings, 2006). If information asymmetry between firms complicates the identification of each other's valuable employees (Horn, 2011), and alliances reduce this information asymmetry (Das and Teng, 2000b; Hamel, 1991), then firms can be expected to try and control employee mobility to partner firms (Oxley and Wada, 2009). As a collaboration progresses, parties often get a good feel for each other's resources and capabilities (Das and Teng, 2000b; Hamel, 1991), and are thus righteously concerned with the possibility of key employees being identified by the other party, and consequently hired away. Indeed, previous research suggests that alliances are sometimes used as a cover by firms to assess and appropriate knowledge outside of the initial intentions under an agreement (Das and Teng, 2000b; Inkpen and Beamish, 1997). Alliances can thus be used as a cover for firms to hire away knowledgeable employees of collaboration partners. Such aggressive hiring practices are no exception. Kerstetter (2000) illustrates this point nicely when stating: "If you have trouble with the competition, simply raid its talent" (Kerstetter, 2000; p. 43). Similarly, de Rond and Bouchikhi (2004) describe an alliance where the pharmaceutical firm hired away an employee of its alliance partner, a biotechnology firm, during their collaboration. This employee had been actively involved in their collaboration and had taken the lead in several joint projects (de Rond and Bouchikhi, 2004). As a direct consequence of this employee poaching by the pharmaceutical firm, trust immediately broke down, and the alliance destabilized. Over the course of the collaboration, the biotechnology firm continued to allege the pharmaceutical firm of attempting to hire away its key personnel. This paper sets out to investigate contractual safeguards that aim to limit the unintended outflow of information, in the form of employees, in arrangements intended to share information, i.e., alliances. In doing so, I move beyond a more general focus on joint venture establishment by alliance parties as a mechanism to increase control over employee mobility (Oxley and Wada, 2009), and specifically focus on the design and antecedents of contractual mechanisms aimed at discouraging employee mobility between alliance partners.

At this point it is worthwhile to mention that although the central tenet underlying this paper is that the loss of key personnel can have negative consequences for firms, this arguably represents a somewhat truncated view of the literature. Recent evidence by Corredoira and Rosenkopf (2010) suggests that employee mobility can have positive consequences for source 
firms, especially when employees move to geographically distant alters. This raises the question why firms would want to limit employee mobility to their alliance partner. First, recent literature on alliances indicates that control over employee mobility is especially important for firms participating in an alliance as failure to do so significantly increases the risk of unintended knowledge leakage (Oxley and Wada, 2009). Second, when employees move to a new employer, they transfer not only knowledge but also other resources and routines (Philips, 2002). As such, while the source firm, i.e., the firm from which the employees depart, might experience some benefits in terms of knowledge transfer through employee mobility (Corredoira and Rosenkopf, 2010), the net effect for this source firm might still be negative (Philips, 2002; Wezel, Cattani and Pennings, 2006). Third, it is doubtful whether existing findings on the beneficial effects of employee mobility hold for those firm pairs that are currently engaged in a collaboration or recently were. Indeed, most previous findings on the beneficial effects of employee mobility for source firms seem to be predicated on the assumption that mobility ties can be used to access distant and non-redundant information. The departing employee creates a communication channel between the old and new employer, and makes the old employer aware of the potentially valuable knowledge possessed by the new employer (Corredoira and Rosenkopf, 2010). It is difficult to imagine that similar benefits accrue to the old employer when its employees depart to its collaboration partner. In that case, the communication channels have already been established as part of their collaboration, and they are at least partially aware of each other's knowledge and expertise. The departing employee adds little to the social capital of the source firm causing a human capital argument, i.e., a departing employee signals a loss of human capital for the source firm, to dominate. De Rond and Bouchikhi (2004) describe a case in which a pharmaceutical firm approached and hired an employee of a biotechnology firm during their collaboration. The employee was actively involved in their collaboration, and possessed a lot of know-how. The source firm, i.e., the biotechnology firm, was not pleased with losing human capital to its alliance partner which lead to a total breakdown of trust in a once trusting relationship (De Rond and Bouchikhi, 2004). In light of these arguments, I acknowledge that employee mobility can have beneficial effects for (source) firms, but maintain that these beneficial effects are unlikely to dominate in this particular context.

I aim to contribute to existing research on four points. First, by focusing on clauses that limit employee mobility between alliance partners, I seek to combine extant research on alliances (e.g. Das and Teng, 2000b; Gulati, 1995; Hagedoorn, 1993) with research on employee mobility (Corredoira and Rosenkopf, 2010; Somaya, Williamson and Lorinkova, 2008; Wezel, Cattani and Pennings, 2006). Firms constantly seek to add human capital to their labor force to reinforce their existing knowledge base, but are often constrained by impermeable firm boundaries. Individual contributions of employees to the success of a firm are often unclear from the outside. An alliance diminishes the information asymmetry between firms and allows for a much more accurate assessment of each other's key employees. Therefore, in this contribution, I specifically focus on clauses that aim to prevent mobility of employees between alliance partners.

Second, although the effects of employee mobility have received considerable attention over the last years (Corredoira and Rosenkopf, 2010; Somaya, Williamson and Lorinkova, 2008; Wezel, Cattani and Pennings, 2006), specific safeguards in alliance contracts that seek to restrain the hiring behavior of firms remain less explored. Labor economists have investigated, mostly from a theoretical perspective, the optimal contract structure for the 
retention of scientific employees that are hired to work on a project but can depart at some point to use their gained knowledge in a rival enterprise (Pakes and Nitzan, 1983). The results of Pakes and Nitzan (1983) imply that formal restrictions on employee mobility are actually irrelevant, as an employer should always be able to outbid a rival enterprise or a new start-up (Hyde, 2012). Nevertheless in practice, contractual restrictions on employee mobility are commonplace (Horn, 2011). Until now, attention for the role of interfirm contracts in retaining employees seems absent. This is somewhat disconcerting as previous literature already noticed that contractual limitations on the hiring behavior of firms occur frequently in alliance contracts (e.g. Reuer and Arińo, 2007), and aggressive hiring practices are the rule rather than the exception in knowledge-intensive industries such as the biopharmaceutical industry (Horn, 2011). Case in point is the complaint filed by Affymetrix, Inc. against Pacific BioSciences, Inc. stating that the latter firm enticed employees of the former firm, bound by their employment contracts, to abandon their employment in order to access their (scientific) knowledge and gain an unfair competitive advantage. ${ }^{40}$ Recent literature highlights that one way of limiting unintended knowledge leakage via employee mobility is for alliance partners to opt for more hierarchical governance structures (Oxley and Wada, 2009). Control of employee mobility is important as it reduces the possibility of unwanted knowledge leakage as a negative byproduct of an alliance (Oxley and Wada, 2009). Here I explore another method of limiting unwanted employee mobility, i.e., voluntary contractual safeguards that restrain the hiring behavior of firms participating in an alliance.

Third, I seek to investigate the design of clauses that limit employee mobility between alliance partners. Recent research has expressed concern that overly broad anticompetitive clauses allowed under procompetitive agreements (R\&D alliances), might decrease competition between collaborating partners in other markets (Cooper and Ross, 2007). Inspired by this line of research, I provide more information on how limitations on employee mobility found in alliance contracts are constructed in terms of duration, scope, and definition.

Fourth, Human Resources (HR) literature signals that over the last years competitor recruitment has become an important mechanism for firms to try and gain a competitive advantage (for a comprehensive overview of the literature on competitor recruitment, see Horn (2011)), especially for those firms active in research-intensive industries such as the biopharmaceutical industry. Although this literature acknowledges the role of information asymmetry between firms in complicating the competitor recruitment process, it remains somewhat silent on the role of alliances in overcoming this information asymmetry. Competitor recruitment usually involves a costly information search on what candidates to approach for employment (Horn, 2011). These costly information searches are avoided when a firm identifies skilled employees of its collaboration partner, and consequently hires these employees away during or after the collaboration. As such, I believe that a more in-depth understanding of the contractual mechanisms used by alliance parties to limit each other's hiring behavior has the potential to significantly advance the burgeoning stream of literature on competitor recruitment.

I find that, in my sample, $50 \%$ of all clauses that aim to limit interfirm employee mobility are not specified with regard to the employees they affect. This could indicate that many

\footnotetext{
40 Affymetrix, Inc. vs. Pacific Biosciences, Inc. Case No : 110CV186536. (Superior Court of the State of California, County of Santa Clara November 3, 2010), (Demand for jury trial).
} 
clauses have an influence on the mobility of employees that were not directly involved in a collaboration. I also find that the propensity of firms to include contractual limitations on interfirm employee mobility declines when at least one firm is located in a pro-mobility environment. In addition, more scientifically oriented firm pairs appear to be especially prone to try and limit interfirm employee mobility via their contract. The results have implications for the literatures on alliances, employee mobility, and employee poaching.

\subsection{Theoretical background and hypotheses}

Human assets, such as talented scientists and managers, can bring about a sustainable competitive advantage for a firm (Coff, 1997). However, human assets differ from traditional assets as the former are not owned by a firm and can therefore leave to (competing) firms. As a result, managing human assets as a sustainable competitive advantage poses significant challenges for a firm (Coff, 1997). These difficulties are exacerbated when a firm enters into an alliance. Previous literature on alliances indicates that a major driver behind alliance formation is the combination of distinct resources and technological complementarity (Das and Teng, 2000b; Hagedoorn, 1993). During a collaboration firms may learn about each other's capabilities and resources (Frankort, Hagedoorn and Letterie, 2012; Hamel, 1991), and more in particular, about each other's valuable employees. Even more worrisome for firms are observations made in previous literature that alliances are sometimes used as a cover to appropriate knowledge that is not directly part of a collaboration (Baughn et al., 1997; Das and Teng, 2000b; Inkpen and Beamish, 1997). Hill (1992) refers to this unintended knowledge leakage as the risk of second-order diffusion of technological know-how. To counter the hazard of unwanted employee mobility, previous literature suggests that parties take recourse to a more hierarchical governance structure such as a JV (Oxley and Wada, 2009). The formal disconnect between a joint venture and parent organizations allows for more control over employee mobility. Although employee mobility has a slightly different interpretation in this study compared to that of Oxley and Wada (2009), the basic tenet remains the same, i.e., it is both difficult and important for firms that participate in an alliance to control the movement of their employees. ${ }^{41}$

In a nutshell, the above indicates that managing human assets can be troublesome and not a straightforward task for firms. Taking the difficulty of managing human assets as a given, Transaction Cost Economics (TCE) studies how parties cope with certain hazards that are associated with particular exchange relationships (Shelanski and Klein, 1995), while simultaneously acknowledging the influence of the institutional environment in which parties operate (Oxley, 1999; Roberts and Greenwood, 1997; Williamson, 1991; 1992). TCE predicts that farsighted alliance parties design contracts that reflect underlying exchange hazards (Williamson, 1993). In the context of this study, alliance parties can be expected to supplement their contract with limitations on interfirm employee mobility, when they perceive the risks and consequences of unwanted interfirm employee mobility to be especially great. Nevertheless, firms are constrained by the environment in which they operate (Oxley, 1999; Roberts and Greenwood, 1997; Williamson, 1991; 1992; 1993), i.e., whereas some

\footnotetext{
${ }^{41}$ This study focuses on unwanted employee mobility between firms in terms of hiring behavior while Oxley and Wada (2009) seem to focus more on unwanted interactions between employees of collaborating firms.
} 
environments are supportive of clauses that intend to limit interfirm employee mobility, others are not.

\subsubsection{Pro-mobility environment}

Firms do not operate in a vacuum, but are influenced by larger institutional environments in which they reside. More specifically, these institutional environments can restrain choices made by firms (Roberts and Greenwood, 1997; Williamson, 1992). The definition of an institutional environment employed here is that it is "[t]he set of fundamental political, social, and legal ground rules that establishes the basis for production, exchange, and distribution..." (Davis and North, 1971; p. 6). In the context of the current study, the institutional environment in which firms reside is expected to have a profound impact on the propensity of these firms to limit employee mobility via their alliance contract. More specifically, I posit that when at least one firm is located in a pro-mobility environment the likelihood of observing contractual limitations on employee mobility declines. It is important to note that the following arguments do not imply, and it would strain credulity to do so, that contractual limitations regarding employee mobility ancillary to procompetitive agreements are per se unenforceable when a firm from a pro-mobility environment is involved. Rather, I refer to a more general tendency of a certain environment to disapprove contractual limitations on employee mobility.

One crucial element in explaining an environment's antipathy towards contractual restrictions on employee mobility refers to the legal ground rules of that environment (Marx, Strumsky and Fleming, 2009). Case in point is California with its California's Business and Professions Code section $16600^{42}$ which states that "[E]very contract by which anyone is restrained from engaging in a lawful profession, trade, or business of any kind is to that extend void". "One cannot directly infer from the aforementioned legal rule that all clauses ancillary to procompetitive agreements restricting the hiring behavior of firms are per se unenforceable. ${ }^{44}$ Instead, such a legal rule signals a strong public policy in favor of employee mobility, ${ }^{45}$ casting doubt on the extent to which limitations on the mobility of employees will

\footnotetext{
42 As stated by Hyde (1998), some states have similar statures as California's Business and Professions Code section 16600. Nevertheless, California is a good example for two reasons. First, in the context of the biopharmaceutical industry, California houses two of the largest biotechnology regions in the world. As such, Californian firms are quite prevalent in my sample compared to states which might have similar legal statures, but no significant presence in the biotechnology sector. Second, although a few states have similar statures to California's Business and Professions Code 16600, they have been interpreted quite loosely by their courts (Hyde, 1998).

${ }^{43}$ See United States vs. Adobe Systems Inc., Apple Inc., Google Inc., Intel Corporation, Intuit Inc., and Pixar. Case No: 1:10-cv-01629. (DOJ Sept 24, 2010), (competitive impact statement). Here, it states that nonsolicitation clauses as ancillary to pro-competitive agreements are not prohibited per se, although a footnote indicates that these clauses might run afoul of the California's Business and Professions Code section 16600.

44 See VL Systems, Inc. vs. Unisen, Inc. Case No: G037334. (Court of Appeal, Fourth District, Division 3, California, June 25, 2007). In this particular case the Court of Appeal reversed an earlier decision by a lower Court and decided that a no-hire clause as implemented in a consulting contract between VL System Inc. and Unisen Inc. was unenforceable as a matter of law. In its explanation of the verdict, the Appellate Court specifically mentioned that more narrowly drawn clauses could pass muster under California law. One specific point the Appellate Court emphasized was that due to the broadness of the clause, the no-hire clause could impact employees that did not perform actual work under the contract.

${ }^{45}$ See Application Group, Inc. vs. Hunter Group, Inc. Case No: A071528. (Court of Appeal, First District, Division 3, California, February 23, 1998). Here, a Californian Court refused to enforce a non-compete
} 
be enforced, which could in turn transform itself into a local set of beliefs, i.e., culture, whereby high turnover rates and aggressive hiring practices are considered part of doing business (Audretsch, 2001; Casper, 2007; Fallick, Fleischman and Rebitzer, 2006; Gilson, 1999; Kerstetter, 2000; Saxenian, 1994). It follows that conditional on being located in a promobility environment, a firm's general tendency to restrain the mobility of its employees can be expected to be low.

Hypothesis 1. There is a negative association between the inclusion of a firm located in a pro-mobility environment in an alliance, and the likelihood of observing a contractual restriction on employee mobility in an $R \& D$ alliance contract.

\subsubsection{Geographical distance}

Previous literature highlights the important role of geographical distance in explaining informal linkages and intensity of information exchange between teams within an organization, and between alliance parties. In terms of organizational teams, social contact and face-to-face communication substantially decreases when teams are more geographically dispersed (e.g. Polzer et al., 2006). A similar observation has been made in the literature on alliances. Geographical proximity makes informal contact between managers and scientists of collaborating firms more likely (Almeida, Dokko and Rosenkopf, 2003; Arita and McCann, 2000; Bengtsson and Ravid, 2009; Decarolis and Deeds, 1999; Gittelman, 2007; Rosenkopf and Almeida, 2003), and increases the intensity by which information is exchanged (Arita and McCann, 2000). As a result, via informal linkages and face-to-face communication (Gittelman, 2007), firm boundaries of geographically proximate alliance partners can become relatively permeable, and firms will be in a better position to assess each other's critical employees and their abilities. In addition, if employees in general exhibit a tendency to move within the same geographic area (Decarolis and Deeds, 1999), then firms ought to be more concerned about unwanted employee mobility when collaborating with a geographically proximate firm. Therefore:

Hypothesis 2. There is a negative association between the geographical distance between partner firms, and the likelihood of observing a contractual restriction on employee mobility in an $R \& D$ alliance contract.

\subsubsection{Scientific orientation}

Science forms the foundation of many high technology industries. In these industries, firms need to maintain and expand their scientific capabilities in order for them to ensure long-term survival. For instance, science aids biopharmaceutical firms in developing new methods to advance through drug development by acting as a knowledge repository (Almeida, Hohberger and Parada, 2011; Gittelman and Kogut, 2003). "[T]he most important source of new technological opportunities has been the advance of scientific knowledge. (...). [S]cientists

agreement between a Maryland employer and employee when the latter moved to work for a Californian firm thereby violating the non-compete. This case exemplifies that California's strong public policy in favor of the free movement of employees can even affect parties when a contract designates law of another state or country to govern interpretation of the contract. 
and engineers engaged in industrial R\&D employ science as a set of tools and stock of knowledge to be tapped in problem-solving" (Klevorick et al., 1995; p. 189). However, the above also creates appropriation concerns. Recent literature illustrates the difficulty of managing human assets (Coff, 1997), and scientists more in particular (Younge, 2012). Hiring away employees from other firms is a particularly effective method of acquiring knowledge (Levin, 1988). The above arguments point towards the proposition that scientifically oriented firms that engage in joint $R \& D$ will be concerned about losing scientific knowledge tied up in their employees to each other. Indeed, “...intense competition for (...) know how in biotechnology creates incentives for rival firms to appropriate scientific knowledge that is not already protected..." (Liebeskind et al., 1996; p. 429).

Recent research suggests a role for science, embedded in scientific publications, in attracting talented scientists and other research oriented employees (Cockburn and Henderson, 1998; Liu and Stuart, 2010; McMillan and Deeds, 1998; Younge, 2012). For instance, Cockburn and Henderson (1998) state that "[t]he highest quality scientists in a field are often reluctant to work for private firms if they will not be able to publish and thus maintain their personal scientific reputations" (Cockburn and Henderson, 1998; p. 163). A similar point is made by Liu and Stuart (2010) who, based on interviews, state that private sector firms often try to mimic university-like atmospheres to attract researchers, and McMillan and Deeds (1998) who state that "[a] ranking by our respondents of their top three prospective employers mirrored a ranking of those companies' publication records" (McMillan and Deeds, 1998; p. 299). If scientifically oriented firms attract skilled scientific labor (Mahroum, 2000), and two scientifically oriented firms collaborate in $R \& D$, it follows that these firms are likely to be concerned about unwanted employee mobility as a negative byproduct of their alliance. Empirical corroboration of this hypothesis would add credence to claims made by Liu and Stuart (2010) linking scientific publications to employee retention mechanisms.

Hypothesis 3. There is a positive association between the scientific orientation of partner firms, and the likelihood of observing a contractual restriction on employee mobility in an $R \& D$ alliance contract.

\subsubsection{Competitors}

Human assets can be a valuable resource for a firm, although managing human assets as a sustainable competitive advantage poses some significant challenges (Coff, 1997). For instance, employees can terminate their employment in response to an employment offer by a competitor. According to Kerstetter (2000), employees are often traded like commodities between rival high-technology companies, as illustrated by the phrase: "If you have trouble with the competition, simply raid its talent" (Kerstetter, 2000; p. 43). When key employees leave to competitors, the negative consequences for the firm losing the employees can be especially severe. In their study, Somaya, Williamson and Lorinkova (2008) find that, in terms of new business obtained, employee mobility has beneficial effects for a law firm when their patent attorneys leave to client organizations, but harmful effects when patent attorneys leave to competitors of that law firm. Phillips (2002) finds that the greater the overlap in activities between a parent firm and its progeny, i.e., the greater the degree to which firms can be labeled as direct competitors, the larger the likelihood of failure on the side of the parent firm. Similarly, Coff (1997) and Somaya, Williamson and Lorinkova (2008) mention the 
example of Kidder Peabody \& Co. which was devastated when key employees left to competitors, taking with them valuable knowledge. In terms of alliances, firms that are competitors, or that perceive loss of knowledge through an alliance to significantly impair their competitive position, will be more prone to protect their knowledge (Baughn et al., 1997; Norman, 2002). In light of these arguments, I expect that:

Hypothesis 4. There is a positive association between the level of competition between partner firms, and the likelihood of observing a contractual restriction on employee mobility in an $R \& D$ alliance contract.

\subsection{Data, methods, and sample description}

\subsubsection{Sample description}

The preliminary sample comprised 587 deals for the period 1996-2005 obtained from Pharmaventures, a UK-based information and consulting firm. Pharmaventures has identified thousands of alliances in the biopharmaceutical sector in their PharmaDeals database. The collected deals are grouped into a number of categories, such as collaborative $R \& D$, distribution/marketing, manufacturing/supply, and business acquisition. For each agreement, the PharmaDeals database provides information on the names of the partners, type of contractual relationship, date deal signed, equity investment, relevant product areas and technology fields, press releases and, where available, the actual contracts. Pharmaventures acquired these actual contracts from the U.S. Securities and Exchange Commission (SEC) filings and their clients. To avoid unnecessary heterogeneity, I excluded all agreements where:

- one of the parties is a government agency or university

- the alliance is, as stated in the contract, a renegotiation or restatement of a previous alliance between the firms

- there is no R\&D component to the alliance

- one firm has a controlling interest in the other firm (greater than 50\%)

- contracts involve more than two parties.

The final contract database contains a set of 304 contracts between unique partner sets which was reduced in the model specifications to 302 contracts due to missing values. The dataset covers R\&D alliance contracts and additional information for the period 1996 through 2005. In addition, all alliances fall within the biopharmaceutical industry. The biopharmaceutical industry is a particularly interesting arena to study the proposed theoretical associations as it is characterized by frequent collaborations between firms, an important role for science, and aggressive hiring tactics between firms (Audretsch, 2001; Hess and Rothaermel, 2011; Prevezer, 1997; Swann and Prevezer, 1996; Whittington, Owen-Smith and Powell, 2009). In addition, by specifically focusing on the biopharmaceutical industry, we can be assured that variation in contracting terms does not come from a variation in the underlying contracting setting.

The agreements include both U.S. (domestic) contracts, i.e., the contracting parties are both U.S.-based firms (176 alliances), and international contracts, i.e., a U.S.-based firm collaborates with a non-U.S. based firm (128 alliances). A total of 284 firms were involved in the 304 contracts and about $55 \%$ of the agreements were concluded between a biotechnology 
firm and a pharmaceutical or a chemical firm. The complete dataset combines information from PharmaDeals with data retrieved from firm annual reports, the Cooperative Agreements and Technology Indicators (CATI) database, Datastream, Compustat, LexisNexis, Corptech, USPTO, and PubMed.

\subsubsection{Dependent variable}

Employee mobility restriction. I measure restrictions on employee mobility by investigating each R\&D contract on the presence of non-solicitation clauses, also called non-poaching agreements. These non-solicitation clauses restrict employee mobility by prohibiting alliance parties to actively approach each other's employees for employment. For instance, consider the following excerpt from the R\&D alliance contract between Innogenetics and Cepheid (1998):

"NON-SOLICITATION. During the term of the R\&D Collaboration, each Party agrees not to induce any employee of the other Party participating in the R\&D Collaboration to discontinue its employment with that Party in order to become employed by or associated with any business, enterprise, or effort that is associated with its own business".

Recently, non-solicitation agreements caused quite an upheaval when the Department of Justice accused several large technology firms (e.g. Apple Inc. and Google Inc.) of agreeing not to cold call each other's employees outside of collaborative endeavors.

I include a dummy variable which takes on a value of 1 if an employee mobility restriction is present in an $\mathrm{R} \& \mathrm{D}$ alliance contract, and 0 otherwise.

\subsubsection{Independent variables}

Pro-mobility environment. Using information provided by PharmaDeals, I am able to determine whether or not a firm from California is involved in an alliance. California is a quintessential example of a pro-mobility environment because of its strong public policy towards promoting the free movement of employees. According to California's Business and Professions Code section 16600 "[E]very contract by which anyone is restrained from engaging in a lawful profession, trade, or business of any kind is to that extend void", with a few notable exceptions such as the sale of ownership interest in a business. Californian firms are situated in an environment where contractual limitations on employee mobility are under close scrutiny (Gilson, 1999), and where, at least in Silicon Valley, non-linear career paths are standard (Saxenian, 1994). I include a dummy variable which equals 1 if an alliance includes at least one firm from California, and 0 otherwise.

Geographical distance. Previous literature has measured the geographical distance between two regions or cities in various ways. Most common are driving time, driving distance, and geodetic distance (Breschi and Lenzi, 2010; Gittelman, 2007; Whittington, Owen-Smith and Powell, 2009). I here use the direct great circle distance ('as the crow flies'). Given the latitudes and longitudes of two cities, distance is calculated as:

Distance $=\varphi * \omega$, with;

$\varphi=$ earth radius 
$\omega=\arccos \left(\cos \left(90-l a t_{2}\right) \cos \left(90-l a t_{1}\right)+\sin \left(90-l a t_{2}\right) \sin \left(90-l a t_{1}\right) \cos \left(\operatorname{lon}_{2}-\right.\right.$ $\left.\left.\operatorname{lon}_{1}\right)\right)$

And geographical distance $=\log (1+$ Distance $)$

I add plus one to the distance to account for a few firms that are located in the same city.

Scientific orientation. Several recent contributions have focused on the scientific publishing behavior of firms, especially in the biopharmaceutical industry (e.g. Almeida, Hohberger and Parada, 2011; Decarolis and Deeds, 1999; Gittelman, 2007; Gittelman and Kogut, 2003; Henderson and Cockburn, 1994; Liebeskind, 1996). I use the PubMed database to retrieve scientific publications for each firm in my dataset (see Casper (2007), Casper and Murray (2005) and Furman et al. (2005) for similar approaches in retrieving scientific publications for biopharmaceutical firms). PubMed incorporates over 22 million citations to journal articles in the fields of biomedicine and the life sciences. It includes prestigious journals such as Nature and Cell. In addition, the PubMed database incorporates MEDLINE. As stated by MEDLINE, it includes a host of different subject areas such as life sciences (including biotechnology) and chemical sciences.

Similar to patent counts, I take the number of published scientific articles of each firm in a five year window prior to the starting date of an alliance. This approach resembles that of Gittelman and Kogut (2003) who look at the publication count of firms between the years 1988 and 1994. I linked scientific publications to firms by investigating firm affiliations of first authors. As previous literature indicates, the total number of scientific publications authored by employees of a firm is an adequate proxy for the scientific quality of that firm (Almeida, Hohberger and Parada, 2011). Given alliance parties A and B, I define scientific orientation as:

Scientific orientation $=\frac{\text { Number of publications }}{\mathrm{A}}=\frac{\text { Number of publications }_{\mathrm{B}}}{\text { Number of publications }}$

Competition. Defining whether or not two firms can be labeled as competitors is an inherently subjective exercise, especially with large diversified firms, and no full-proof method exists. Previous contributions have mainly used overlap in primary SIC codes as an indication of the level of competition between firms (e.g. Oxley and Sampson, 2004; Park and Russo, 1996). Park and Russo (1996) find that joint ventures established between direct competitors, i.e., firms operating in the same primary 4-digit SIC code, more often fail. Oxley and Sampson (2004) proxy product market competition by whether or not firms operate in the same primary 4-digit SIC code and find that competitors limit the scope of their joint alliance activities.

Inspired by these previous contributions, I construct a measure based on the SIC classification of alliance parties using data from Thomson ONE Banker. This variable equals 2 if both parties operate in the same primary 4-digit SIC code, 1 if both parties operate in the same primary 3-digit SIC code but not in the same primary 4-digit SIC-code, and 0 otherwise.

\subsubsection{Control variables}

Size asymmetry. Previous literature on alliances indicates that large size asymmetries between firms are suggestive for differences in risk perceptions (for instance Berg, Duncan and 
Friedman, 1982; Mytelka, 1991). This literature suggests that the smaller firm perceives more risk due to potential opportunistic behavior on the side of the larger partner. ${ }^{46}$ I control for the size asymmetry between alliance parties by taking the logarithmic value of the number of employees of the firm with the largest number of employees, minus the logarithmic value of the number of employees of the other firm.

Alliance experience asymmetry. Based on the CATI database (see Hagedoorn, 2002), I obtained data on the prior R\&D alliance experience of firms in a five year window prior to the start of an alliance. A five year window is widely accepted in the literature as adequately capturing alliance experience of firms (see Gulati, 1995). Previous literature suggests that alliance experience affects contract design (Argyres, Bercovitz and Mayer, 2007), and could therefore influence the variable of interest. For instance, firms with considerable alliance experience may have some familiarity with collaboration partners hiring away valuable employees, while inexperienced firms do not. As such, I include the absolute difference in alliance experience between firms.

Scientific orientation asymmetry. In support of hypothesis 3, I argue that partner firms that are more scientifically oriented are more likely to include a clause in their R\&D alliance contract to limit the unintended outflow of employees to each other. To assure that findings regarding the scientific orientation of firms can be attributed to their total scientific orientation, I control for scientific orientation asymmetry between firms. Assume X being the most scientifically oriented firm and $Y$ the other firm, this variable is defined as:

Scientific orientation $=\frac{\text { Number of publications }}{\mathrm{X}}=\frac{\text { Number of publications }_{\mathrm{Y}}}{\text { Number of publications }}$

$R \& D$ budget asymmetry. Especially for scientists, interfirm asymmetry in R\&D budgets might influence job mobility. Research oriented employees might favor employers that have a large R\&D budget which they can partly use to fund their future research and/or development endeavors. In addition, firms that spend copious amounts of funds on R\&D are most likely characterized by a learning attitude (Schoenmakers and Duysters, 2006), which might be reflected in their propensity to opt for contractual limitations on employee mobility. As such, I control for asymmetry in R\&D budgets, i.e., technological sizes (Stuart, Ozdemir and Ding, 2007), between two collaborating firms by taking the logarithmic value of the R\&D expenses of the firm that spends the most on $R \& D$, minus the logarithmic value of the $R \& D$ expenses of the other firm.

Prior ties. Previous research illustrates that firms which have previously collaborated choose different governance structures for future collaborations (e.g. Gulati, 1995). Prior ties could signal a certain level of trust between collaboration partners, lessening the need to stipulate restrictions on hiring behavior, or it could signal learning over time, whereby parties amend future contracts based on their previous collaboration(s). Therefore, based on the CATI database, I control for the number of previous collaborations between two firms in a 5year period before their current alliance.

\footnotetext{
${ }^{46}$ Size asymmetry is also indicative of the level of interfirm dependence between parties whereby the small firm is usually dependent on financial support from the larger firm. I considered a more direct measure for the level of interfirm dependence between parties based on their R\&D plan. This variable did not appear to have any significant influence on the variable of interest, and neither did it change any of the presented results. Due to the large number of control variables already incorporated in the regressions, I therefore omit this variable.
} 
Equity. For each alliance in the sample, PharmaDeals reports whether or not equity is involved. Equity generates control in an alliance (Oxley, 1997), that might allow partner firms to more closely observe each other's employees. Baughn et al. (1997) state that firm boundaries become more or less permeable dependent on the governance structure of an alliance. Oxley and Wada (2009) show that in joint ventures unlike contracts, knowledge transfers unrelated to alliance activities tend to be more constrained ex-post. In line with these arguments, we might observe contractual limitations on employee mobility more often when alliances involve equity investments. Therefore, I include a dummy variable which equals 1 if equity is involved, and 0 otherwise.

$R \& D$ plus. Many alliances in the sample include, besides $R \& D$, additional activities such as marketing and distribution. Although, a priori, I do not expect a specific association between inclusion of these additional activities in alliances and the likelihood of observing employee mobility restrictions in R\&D alliance contracts, I do wish to control for a possible effect as additional activities have been shown to influence the governance mode of alliances (Sampson, 2004b). Therefore, I include a dummy variable that equals 1 if any additional activities are included in an alliance besides R\&D and 0 otherwise.

Early stage research. For each alliance contract in the sample, PharmaDeals makes a distinction between an early collaborative research phase, and a later co-development phase. Parties involved in early stage research still have a wide variety of research directions available and their collaborative activities are characterized by their experimental nature (Freeman and Soete, 1997; Nelson, 1961; 1982). By comparison, alliance partners that focus on a later co-development stage usually start from a predefined set of technologies that will be developed further (Freeman and Soete, 1997). It is likely that knowledge embedded in employees plays a more prominent role in an earlier research stage compared to a later development stage. Therefore, I include a control variable that equals 1 if an alliance focuses on early stage research and 0 otherwise.

Time-bound. Literature suggests two possible and conflicting associations between whether or not an alliance is time-bound and the likelihood of observing clauses that limit employee mobility. First, Reuer and Arińo (2007) find that in time-bound alliances parties place less emphasis on interfirm coordination. This could hint at a negative association between the time-boundedness of an alliance and the likelihood of observing contractual employee mobility restrictions, as firms will have more difficulty gauging each other's competitive advantages in terms of skilled employees (Baughn et al., 1997). Second, alliances with a pre-defined ending date are 'meant to end'. In alliances that are 'meant to end', attention of partners shifts from attainment of collaborative goals to individual gain maximization (Ness and Haugland, 2005). This individual gain maximization could manifest itself in firms attempting to raid each other's human capital, especially when their alliance approaches its pre-defined ending date. I include a dummy variable that equals 1 if an alliance has a pre-defined ending date as stated in the contract, and 0 otherwise.

Value. Based on information provided by PharmaDeals and LexisNexis, I take into account the value of an alliance. Greater value indicates that parties will be more willing to incur additional contracting costs to safeguard their collaboration. Because this variable is 
highly skewed, I take the logarithmic value of the alliance in millions of dollars. In case I am unable to retrieve the value of an alliance, this variable takes on a value of zero. ${ }^{47}$

Value dummy. I include a dummy variable that equals 1 if information about the value of an alliance is missing, and 0 otherwise.

Focus area. In some focus areas, relevant knowledge is concentrated in a small number of firms or persons (Chesbrough, 1999; Pisano, 1990). Based on information provided by PharmaDeals and similar to Shan and Song (1997), I therefore include dummy variables for certain non-mutually exclusive focus areas in my sample. These focus areas are alimentary and metabolism, anti-infective, cardiovascular, drug delivery, genomics, inflammation/musculoskeletal, neurological, and oncology. A focus area was included in the regression analyses if it was present in more than $10 \%$ of the alliances in my sample. Possibly, firms operating in these focus areas are less concerned about unwanted employee mobility as relevant knowledge is spread out over many firms or persons.

Year fixed effects. I include dummy variables for the period 1996-2005 with the year 1996 as the reference year to control for temporal trends in alliances.

\subsubsection{Analysis}

In the following, I use Probit models with robust and clustered standard errors. In all models, the dependent variable indicates whether or not a contractual employee mobility restriction is stipulated by alliance parties. PharmaDeals makes a distinction between the primary technology supplying firm, which is the firm that is the main supplier of the technology used or developed further in an alliance, and the partner firm. Not accounting for error correlations within firms can lead to downward biased standard errors (see Wooldridge, 2003). Therefore, I cluster standard errors based on the ID numbers of partner firms, as these have the highest likelihood of repeat occurrence in the sample. Alternatively, clustering the standard errors by primary technology supplying firm leaves the results unaltered.

Additionally, in unreported analyses, I rank firms based on their frequency of occurrence in my sample, and include firm fixed effects for the most frequently occurring firms. Results are similar to those reported here. An additional benefit of this approach is that it, at least to some extent, controls for the effects of unobserved firm characteristics on the dependent variable (Lerner and Malmendier, 2010). I will further elaborate on this approach in the section on alternative explanations and robustness checks.

\subsection{Results}

Table 5.1 shows a detailed overview of how clauses aimed at preventing interfirm employee mobility are constructed. Three observations are apparent with regards to their duration,

\footnotetext{
47 Although frequently used (see, for instance, Bastos (2010), Griliches (1976), Khorana, Servaes and Tufano (2009), Singh (2008); Smith and Huang (1995)), this method of dealing with missing values has its drawbacks, as do alternative methods. In unreported analyses, I use four other methods to deal with missing values to investigate whether or not my results change depending on which method I use. First, I run a regression without controlling for value. Second, I run a regression in which I only control for whether or not information on value is missing. Third, I limit my sample to include only those observations for which I was able to retrieve information on the value of alliances. Fourth and last, based on a host of observable variables, I estimate the value of an alliance if this information is missing, and use these estimates in the full model. Results do not materially change from those presented here.
} 
scope, and definition. First, the duration of most clauses seem to be directly related to the term of the agreement or research period, with only few clauses still in effect more than two years after a specific collaboration term. Second, in terms of their scope, the applicability of clauses that aim to prevent interfirm employee mobility is only limited to specific employees in $50 \%$ of all cases. By extension, in the other $50 \%$, contractual limitations on interfirm employee mobility could affect employees that are not directly involved in a collaboration. Regarding their definition, general advertisements aimed at the general public are only excluded from the definition 'not to approach each other's employees' in 38\% of all clauses. 
Table 5.1 Design of contractual employee mobility restrictions

\begin{tabular}{|c|c|c|c|}
\hline Limitation & Primary subdivision & Secondary subdivision & Tertiary subdivision \\
\hline \multirow{10}{*}{ Duration } & \multirow{9}{*}{ Duration limits (98\%) } & \multirow{7}{*}{$\begin{array}{l}\text { Related to term agreement } \\
\text { or research term }(92 \%)\end{array}$} & Applies only during term $(26 \%)$ \\
\hline & & & Plus 6 months after term $(2 \%)$ \\
\hline & & & Plus 1 year after term $(37 \%)$ \\
\hline & & & Plus 2 years after term $(13 \%)$ \\
\hline & & & Plus 3 years after term $(2 \%)$ \\
\hline & & & Plus 5 years after term $(2 \%)$ \\
\hline & & & Plus $x$ years after term $(10 \%)$ \\
\hline & & \# Years from starting date $(4 \%)$ & \\
\hline & & Whole employment term $(2 \%)$ & \\
\hline & \multirow[t]{2}{*}{ No duration limits $(2 \%)$} & & \\
\hline & & \multicolumn{2}{|c|}{ Examples } \\
\hline \multirow{2}{*}{ Scope } & $\begin{array}{c}\text { Limited to employees that } \\
\text { are involved in the alliance, have } \\
\text { specific technical expertise areas, } \\
\text { or occupy specific hierarchical } \\
\text { positions }(50 \%)\end{array}$ & \multicolumn{2}{|c|}{$\begin{array}{l}\text { "This restriction shall be limited to those individuals who have been } \\
\text { actively and directly involved in the R\&D Program..." }\end{array}$} \\
\hline & Applicable to all employees $(50 \%)$ & & \\
\hline \multirow{2}{*}{ Definition } & $\begin{array}{l}\text { General advertisements aimed } \\
\text { at the general public specifically } \\
\text { exempted }(38 \%)\end{array}$ & \multicolumn{2}{|c|}{$\begin{array}{l}\text { "This provision shall not restrict either Party or its Affiliates from } \\
\text { advertising employment opportunities in any manner that does not } \\
\text { directly target the other Party or its Affiliates..."2 }\end{array}$} \\
\hline & $\begin{array}{l}\text { General advertisements aimed } \\
\text { at the general public not } \\
\text { specifically exempted }(62 \%)\end{array}$ & & \\
\hline
\end{tabular}

${ }^{1}$ Excerpt taken from alliance contract between Antex Biologics and Smithkline Beecham (1999)

${ }^{2}$ Excerpt taken from alliance contract between Genome Therapeutics and Amgen (2002) 
Table 5.2 shows the descriptive statistics of all the variables included in terms of their mean, standard deviation, and bivariate correlations. Not surprisingly, two sets of variables appear to be highly correlated. First, there is a -0.877 correlation between value and value dummy. I refer to footnote 47 for a further elaboration on this issue. Second, there is a 0.861 correlation between scientific orientation and scientific orientation asymmetry. Controlling for scientific orientation asymmetry is crucial, as I want to rule out that any findings for the scientific orientation variable can be attributed to asymmetry in scientific orientation. We can assess the severity of multicollinearity by investigating the VIF's which indicate how much of the variance is inflated because of collinearity between predictors. The VIF's for value, value dummy, scientific orientation, and scientific orientation asymmetry remain under the usual cut-off value of 10. The mean VIF equals around 3.5. Simply omitting the variable relating to scientific orientation asymmetry only strengthens the results for the scientific orientation variable. Table 5.3 shows the results of the probit estimations. Model 1 in Table 5.3 refers to the base model only including control variables. In models 2 to 5 , I individually add each hypothesis related variable to the base model. Finally, in model 6, I include all independent variables and control variables. 


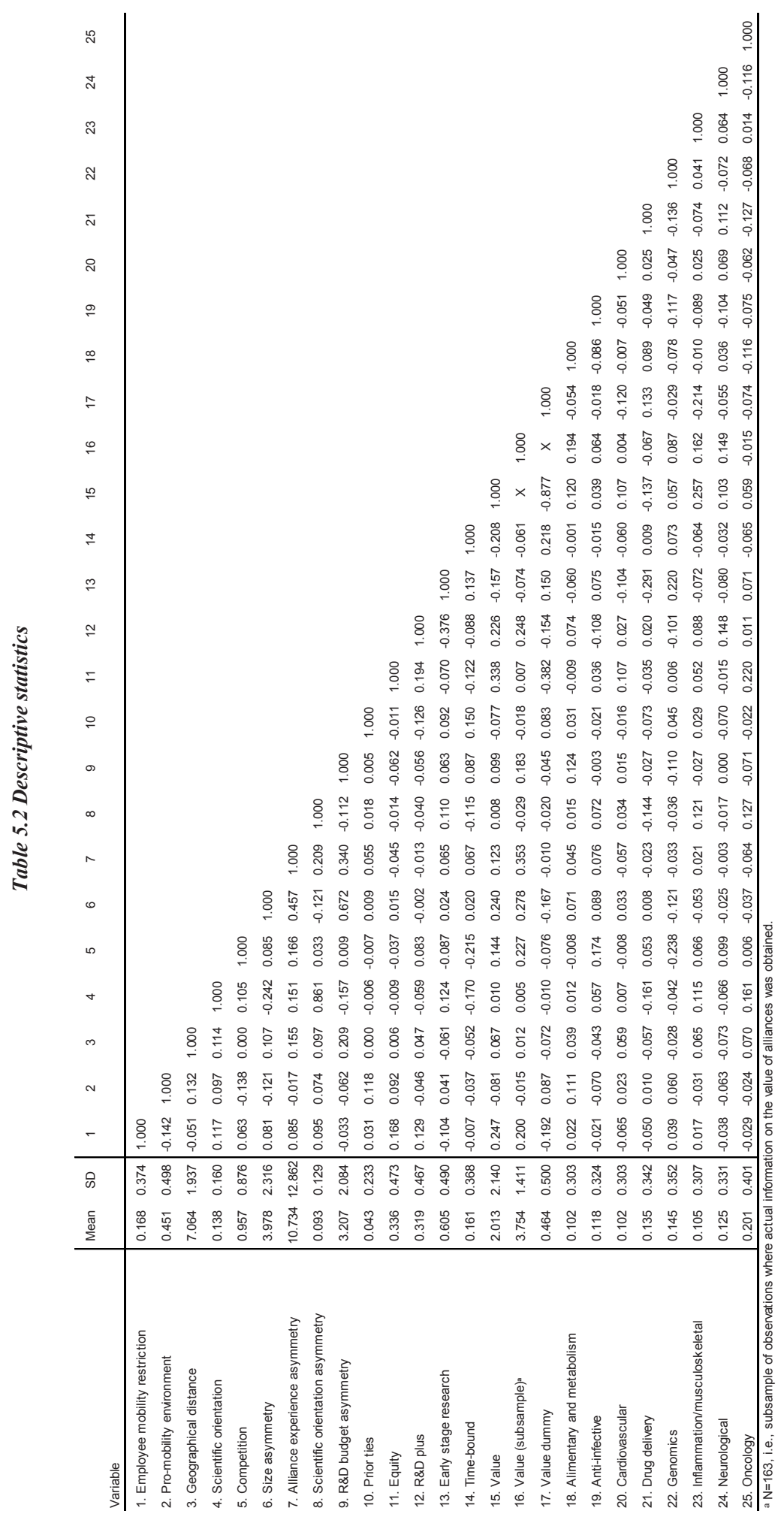


Hypothesis 1 states that when at least one alliance party is located in a pro-mobility environment, one is less likely to observe restrictions on employee mobility in alliance contracts. Models 2 and 6 show the expected negative and significant sign. Of the 51 alliances that include restrictions on employee mobility, 15 alliances include Californian firms (about $29 \%$ ). Of the 251 alliances that do not include restrictions on employee mobility, 122 alliances include Californian firms (about 49\%). Hypothesis 2 predicts that with increasing geographical distance between firms, the propensity to include employee mobility restrictions in R\&D alliance contracts will decline. Models 3 and 6 show the expected sign, but the effect of geographical distance is not significant at conventional significance levels. Hypothesis 3 poses that more scientifically oriented alliance parties are more likely to stipulate contractual restrictions on employee mobility. Models 4 and 6 show the expected positive and significant sign. Last, hypothesis 4 predicts that direct competitors are more likely to include clauses in their R\&D alliance contracts that restrict interfirm employee mobility. I find no support for this claim in models 5 and 6 . 
Table 5.3 Probit model estimation results of employee mobility restrictions

\begin{tabular}{|c|c|c|c|c|c|c|c|c|c|c|c|c|}
\hline \multirow{2}{*}{$\frac{\text { Variable }}{\text { Pro-mobility environment }}$} & \multicolumn{2}{|l|}{ Model 1} & \multicolumn{2}{|l|}{ Model 2} & \multicolumn{2}{|l|}{ Model 3} & \multicolumn{2}{|l|}{ Model 4} & \multicolumn{2}{|l|}{ Model 5} & \multicolumn{2}{|l|}{ Model 6} \\
\hline & & & $\begin{array}{l}-0.635 \\
(0.208)\end{array}$ & & & & & & & & $\begin{array}{l}-0.648 \\
(0.219)\end{array}$ & *** \\
\hline Geographical distance & & & & & $\begin{array}{l}-0.040 \\
(0.043)\end{array}$ & & & & & & $\begin{array}{l}-0.023 \\
(0.051)\end{array}$ & \\
\hline Scientific orientation & & & & & & & $\begin{array}{c}2.782 \\
(1.270)\end{array}$ & ** & & & $\begin{array}{c}2.968 \\
(1.160)\end{array}$ & ** \\
\hline Competition & & & & & & & & & $\begin{array}{c}0.117 \\
(0.138)\end{array}$ & & $\begin{array}{l}-0.009 \\
(0.125)\end{array}$ & \\
\hline Size asymmetry & $\begin{array}{c}0.099 \\
(0.063)\end{array}$ & & $\begin{array}{c}0.084 \\
(0.063)\end{array}$ & & $\begin{array}{c}0.094 \\
(0.062)\end{array}$ & & $\begin{array}{c}0.151 \\
(0.069)\end{array}$ & ** & $\begin{array}{c}0.099 \\
(0.064)\end{array}$ & & $\begin{array}{c}0.134 \\
(0.066)\end{array}$ & ** \\
\hline Alliance experience asymmetry & $\begin{array}{l}-0.001 \\
(0.009)\end{array}$ & & $\begin{array}{l}-0.002 \\
(0.010)\end{array}$ & & $\begin{array}{c}0.001 \\
(0.009)\end{array}$ & & $\begin{array}{l}-0.003 \\
(0.010)\end{array}$ & & $\begin{array}{l}-0.002 \\
(0.010)\end{array}$ & & $\begin{array}{l}-0.004 \\
(0.010)\end{array}$ & \\
\hline Scientific orientation asymmetry & $\begin{array}{c}2.049 \\
(0.752)\end{array}$ & $* * *$ & $\begin{array}{c}2.369 \\
(0.774)\end{array}$ & $* * *$ & $\begin{array}{c}2.099 \\
(0.759)\end{array}$ & $* * *$ & $\begin{array}{l}-0.544 \\
(1.431)\end{array}$ & & $\begin{array}{c}2.099 \\
(0.788)\end{array}$ & $* * *$ & $\begin{array}{c}-0.340 \\
(1.374)\end{array}$ & \\
\hline R\&D budget asymmetry & $\begin{array}{l}-0.120 \\
(0.062)\end{array}$ & * & $\begin{array}{l}-0.115 \\
(0.062)\end{array}$ & * & $\begin{array}{l}-0.110 \\
(0.063)\end{array}$ & * & $\begin{array}{l}-0.140 \\
(0.062)\end{array}$ & ** & $\begin{array}{l}-0.117 \\
(0.062)\end{array}$ & * & $\begin{array}{c}-0.127 \\
(0.061)\end{array}$ & ** \\
\hline Prior ties & $\begin{array}{c}0.288 \\
(0.350)\end{array}$ & & $\begin{array}{c}0.463 \\
(0.357)\end{array}$ & & $\begin{array}{c}0.289 \\
(0.355)\end{array}$ & & $\begin{array}{c}0.312 \\
(0.355)\end{array}$ & & $\begin{array}{c}0.246 \\
(0.344)\end{array}$ & & $\begin{array}{c}0.503 \\
(0.367)\end{array}$ & \\
\hline Equity & $\begin{array}{c}0.489 \\
(0.225)\end{array}$ & ** & $\begin{array}{c}0.590 \\
(0.235)\end{array}$ & ** & $\begin{array}{c}0.492 \\
(0.225)\end{array}$ & ** & $\begin{array}{c}0.527 \\
(0.230)\end{array}$ & ** & $\begin{array}{c}0.512 \\
(0.229)\end{array}$ & ** & $\begin{array}{c}0.633 \\
(0.241)\end{array}$ & $* * *$ \\
\hline R\&D plus & $\begin{array}{c}0.065 \\
(0.252)\end{array}$ & & $\begin{array}{c}0.066 \\
(0.256)\end{array}$ & & $\begin{array}{c}0.078 \\
(0.254)\end{array}$ & & $\begin{array}{c}0.080 \\
(0.245)\end{array}$ & & $\begin{array}{c}0.059 \\
(0.252)\end{array}$ & & $\begin{array}{c}0.094 \\
(0.254)\end{array}$ & \\
\hline Early stage research & $\begin{array}{l}-0.299 \\
(0.231)\end{array}$ & & $\begin{array}{l}-0.323 \\
(0.243)\end{array}$ & & $\begin{array}{c}-0.306 \\
(0.231)\end{array}$ & & $\begin{array}{l}-0.335 \\
(0.224)\end{array}$ & & $\begin{array}{c}-0.310 \\
(0.233)\end{array}$ & & $\begin{array}{c}-0.373 \\
(0.241)\end{array}$ & \\
\hline Time-bound & $\begin{array}{c}0.336 \\
(0.286)\end{array}$ & & $\begin{array}{c}0.358 \\
(0.286)\end{array}$ & & $\begin{array}{c}0.327 \\
(0.287)\end{array}$ & & $\begin{array}{c}0.478 \\
(0.300)\end{array}$ & & $\begin{array}{c}0.387 \\
(0.301)\end{array}$ & & $\begin{array}{c}0.509 \\
(0.316)\end{array}$ & \\
\hline Value & $\begin{array}{c}0.257 \\
(0.093)\end{array}$ & $* * *$ & $\begin{array}{c}0.259 \\
(0.095)\end{array}$ & $* * *$ & $\begin{array}{c}0.248 \\
(0.090)\end{array}$ & $* * *$ & $\begin{array}{c}0.245 \\
(0.095)\end{array}$ & ** & $\begin{array}{c}0.253 \\
(0.092)\end{array}$ & $* * *$ & $\begin{array}{c}0.242 \\
(0.096)\end{array}$ & ** \\
\hline Value dummy & $\begin{array}{c}0.383 \\
(0.445)\end{array}$ & & $\begin{array}{c}0.439 \\
(0.441)\end{array}$ & & $\begin{array}{c}0.348 \\
(0.442)\end{array}$ & & $\begin{array}{c}0.331 \\
(0.457)\end{array}$ & & $\begin{array}{c}0.374 \\
(0.440)\end{array}$ & & $\begin{array}{c}0.373 \\
(0.451)\end{array}$ & \\
\hline Alimentary and metabolism & $\begin{array}{l}-0.095 \\
(0.298)\end{array}$ & & $\begin{array}{l}-0.037 \\
(0.316)\end{array}$ & & $\begin{array}{c}-0.077 \\
(0.296)\end{array}$ & & $\begin{array}{c}-0.114 \\
(0.301)\end{array}$ & & $\begin{array}{c}-0.090 \\
(0.293)\end{array}$ & & $\begin{array}{l}-0.050 \\
(0.319)\end{array}$ & \\
\hline Anti-infective & $\begin{array}{l}-0.537 \\
(0.308)\end{array}$ & * & $\begin{array}{c}-0.664 \\
(0.323)\end{array}$ & ** & $\begin{array}{c}-0.542 \\
(0.309)\end{array}$ & * & $\begin{array}{l}-0.570 \\
(0.307)\end{array}$ & * & $\begin{array}{l}-0.617 \\
(0.310)\end{array}$ & ** & $\begin{array}{c}-0.699 \\
(0.323)\end{array}$ & ** \\
\hline Cardiovascular & $\begin{array}{l}-0.865 \\
(0.381)\end{array}$ & ** & $\begin{array}{c}-0.852 \\
(0.388)\end{array}$ & ** & $\begin{array}{c}-0.843 \\
(0.380)\end{array}$ & ** & $\begin{array}{c}-0.874 \\
(0.384)\end{array}$ & ** & $\begin{array}{c}-0.852 \\
(0.378)\end{array}$ & ** & $\begin{array}{c}-0.843 \\
(0.380)\end{array}$ & ** \\
\hline Drug delivery & $\begin{array}{l}-0.317 \\
(0.322)\end{array}$ & & $\begin{array}{l}-0.281 \\
(0.328)\end{array}$ & & $\begin{array}{l}-0.331 \\
(0.319)\end{array}$ & & $\begin{array}{l}-0.321 \\
(0.318)\end{array}$ & & $\begin{array}{l}-0.348 \\
(0.322)\end{array}$ & & $\begin{array}{l}-0.295 \\
(0.316)\end{array}$ & \\
\hline Genomics & $\begin{array}{c}0.134 \\
(0.303)\end{array}$ & & $\begin{array}{c}0.221 \\
(0.298)\end{array}$ & & $\begin{array}{c}0.147 \\
(0.303)\end{array}$ & & $\begin{array}{c}0.207 \\
(0.304)\end{array}$ & & $\begin{array}{c}0.196 \\
(0.305)\end{array}$ & & $\begin{array}{c}0.308 \\
(0.310)\end{array}$ & \\
\hline Inflammation/musculoskeletal & $\begin{array}{l}-0.497 \\
(0.270)\end{array}$ & * & $\begin{array}{l}-0.586 \\
(0.275)\end{array}$ & ** & $\begin{array}{l}-0.485 \\
(0.269)\end{array}$ & * & $\begin{array}{c}-0.496 \\
(0.266)\end{array}$ & * & $\begin{array}{l}-0.530 \\
(0.262)\end{array}$ & ** & $\begin{array}{c}-0.579 \\
(0.258)\end{array}$ & ** \\
\hline Neurological & $\begin{array}{l}-0.443 \\
(0.272)\end{array}$ & & $\begin{array}{l}-0.507 \\
(0.271)\end{array}$ & * & $\begin{array}{l}-0.451 \\
(0.277)\end{array}$ & & $\begin{array}{c}-0.388 \\
(0.285)\end{array}$ & & $\begin{array}{l}-0.458 \\
(0.275)\end{array}$ & * & $\begin{array}{l}-0.458 \\
(0.287)\end{array}$ & \\
\hline Oncology & $\begin{array}{l}-0.449 \\
(0.214)\end{array}$ & ** & $\begin{array}{l}-0.515 \\
(0.213)\end{array}$ & ** & $\begin{array}{c}-0.424 \\
(0.213)\end{array}$ & ** & $\begin{array}{l}-0.560 \\
(0.203)\end{array}$ & $* * *$ & $\begin{array}{l}-0.461 \\
(0.207)\end{array}$ & ** & $\begin{array}{c}-0.618 \\
(0.205)\end{array}$ & *** \\
\hline Year fixed effects & $\mathrm{X}$ & & $\mathrm{X}$ & & $\mathrm{x}$ & & $\mathrm{x}$ & & $\mathrm{X}$ & & $\mathrm{X}$ & \\
\hline Constant & $\begin{array}{l}-1.249 \\
(0.499) \\
\end{array}$ & ** & $\begin{array}{l}-1.040 \\
(0.522)\end{array}$ & ** & $\begin{array}{c}-0.967 \\
(0.560)\end{array}$ & * & $\begin{array}{l}-1.445 \\
(0.542)\end{array}$ & *** & $\begin{array}{l}-1.313 \\
(0.504)\end{array}$ & $\star * *$ & $\begin{array}{l}-1.085 \\
(0.645)\end{array}$ & * \\
\hline $\begin{array}{l}\text { Log Pseudolikelihood } \\
\text { Observations }\end{array}$ & $\begin{array}{c}-110.5 \\
302\end{array}$ & & $\begin{array}{c}-106.3 \\
302\end{array}$ & & $\begin{array}{c}-110.2 \\
302\end{array}$ & & $\begin{array}{c}-107.8 \\
302\end{array}$ & & $\begin{array}{c}-110.1 \\
302\end{array}$ & & $\begin{array}{c}-103.4 \\
302\end{array}$ & \\
\hline
\end{tabular}

Notes: Probit regressions with dependent variable contractual clause limiting employee mobility

Robust standard errors, clustered by firm, in parentheses.

* significance at the $10 \%$ level; ${ }^{* *}$ significance at the $5 \%$ level; ${ }^{* \star *}$ significance at the $1 \%$ level. 
I find consistent results for a small number of control variables. First, I find a significant and negative association between asymmetry in R\&D budgets and the propensity of firms to stipulate contractual limitations on employee mobility. Second, there is a positive and significant association between the presence of equity in an alliance and the likelihood of observing contractual employee mobility restrictions. Third, there is a positive correlation between the value of alliances and the propensity of parties to implement contractual employee mobility restrictions. Fourth, controlling for different focus areas seems to be important as anti-infective, cardiovascular, inflammation/musculoskeletal, and oncology are all negatively related to the presence of clauses intended to hinder interfirm employee mobility.

\subsection{Alternative explanations and robustness checks}

In this section I explore a number of plausible alternative explanations for the findings reported in this study and perform some additional robustness checks.

Pro-mobility environment. Given the prevalence of Californian firms in my sample, I investigated how many dyads are between two Californian firms. This is an important question because for CA-CA dyads the theory supporting Hypothesis 1 contradicts the theory supporting Hypothesis 2. As such, a CA-CA dummy variable may be necessary to tease out these contradicting effects. Additional analyses reveal that 22 firm pairs are between two Californian firms. I create two new dummy variables. The first dummy variable equals 1 if both alliance firms are located in California, and 0 otherwise. The second dummy variable equals 1 if one of the alliance firms is headquartered in California but not both, and 0 otherwise. Both dummy variables are significantly and negatively related to the inclusion of employee mobility restrictions in alliance contracts, while the insignificant result for geographical distance remains.

I also investigated how the results for pro-mobility environment hold up in the subsample of domestic deals. Although significance levels vary depending on the specification, results seem to generally agree with those presented here. Additionally, simply including a dummy variable that indicates whether or not firms are headquartered in different countries in the main regressions leaves the presented results unaltered.

Geographical distance. There are strong reasons to believe that representing geographical distance as a dichotomous variable rather than a continuous variable might be more suitable (Gittelman, 2007). Indeed, firms may be particularly concerned about unwanted employee mobility to geographically proximate partner firms. Using different dummy variables with cut-off values of $25,50,100$, and 200 miles respectively, does not materially change the presented results. Alternatively, I include a quadratic distance term in the final model to investigate the presence of a non-linear association between distance and the likelihood of observing a contractual limitation on employee mobility. However, no such association was found.

I also considered the possibility that specific national effects interfere with my geographical distance measure. I include dummy variables for the most frequently occurring countries. These country dummy variables are in general not significant, and the presented results remain unaltered.

Scientific orientation. Although the PubMed database has previously been used in the context of the biopharmaceutical industry (Casper, 2007; Casper and Murray, 2005; Furman 
et al., 2005), one concern is that firms with no publications drive the results. These firms may not see scientific publications as a serious research outlet, or publish in journals not captured by PubMed. In unreported regressions I therefore include a dummy variable which equals 1 if I was able to find at least one scientific publication for both alliance firms in the relevant timeframe, and 0 otherwise. Results remain similar to those presented here.

The PubMed database includes many journals, and its coverage can slightly change over time. For instance, new journals can be added to the database. Therefore I also investigated whether there is any significant time trend in the scientific orientation and scientific orientation asymmetry variables. First, I regress both scientific orientation and scientific orientation asymmetry variables on a linear time trend. Only the scientific orientation variable seems to slightly increase over time. Second, I regress both variables on individual year dummies with the year 1996 as the base category. Except for the year 2001, there is little evidence to support the claim that in time, irrespective of the specific cause, the variables scientific orientation and scientific orientation asymmetry have steadily increased.

As argued for in the third hypothesis, science stands at the base of the biopharmaceutical industry and firms rely on scientific knowledge to help them advance through drug development (Gittelman and Kogut, 2003). As such, scientifically oriented firms may perform better, and better performing firms may choose to limit the outflow of human capital. Therefore in unreported regressions I control for asymmetry in financial constraints by taking the absolute difference between firms' (Net Income/Total Assets) ratio. It turns out that this variable is negatively associated with the propensity of firms to opt for contractual restrictions on employee mobility, while leaving the presented results unaltered.

Competition. As previously indicated, measuring the level of competition between highly diversified firms is problematic (Oxley and Sampson, 2004). Although I have no direct measure on the level of diversification of firms in my sample, and thus no formal way of limiting the sample on rather focused firms, larger firms can be assumed to be more diversified on average. Therefore, I rerun the final model on the subsample of firms excluding 'Global' firms as indicated by PharmaDeals. Results remain similar to those presented here.

Also, in unreported regressions, I use cruder measures for my competition variable by investigating whether or not firms are active in the same primary 3-digit, 2-digit, or 1-digit SIC codes. Results remain similar to those presented here.

Unobserved firm effects. It is possible that unobserved firm characteristics interfere with the presented results. For instance, Coff (1997) discusses several firm strategies to aid a firm in retaining its most valued employees, such as a specific corporate culture or compensation schemes. To try and remedy any effect this may have on the variable of interest, I include dummy variables for the most frequently occurring firms in my sample (see Lerner and Malmendier (2010) for a similar approach). I indeed find that a small number of firms are significantly more or less likely to opt for clauses that limit interfirm employee mobility. Nevertheless, the presented results remain unaltered.

\subsection{Discussion and conclusions}

This paper sought to align literature on alliances (Gulati, 1995; Hagedoorn, 1993; Hamel, 1991) with research on employee mobility (Almeida and Kogut, 1999; Somaya, Williamson and Lorinkova, 2008; Wezel, Cattani and Pennings, 2006) by focusing on contractual clauses in alliance contracts aimed at discouraging interfirm employee mobility. In doing so, I aimed 
to shed a light on both the design of these clauses, and on their antecedents. The findings reported in this paper add to the literature on the design of contracts. For instance, Reuer and Ariño (2007) indicate that contracts sometimes include specific clauses intended to limit employee mobility between collaborating firms, but leave a more careful examination of these clauses to future research. De Rond and Bouchikhi (2004) sketch a real-life example where a pharmaceutical company actively approached and recruited a promising chemist that was employed by its collaboration partner, a biotechnology firm. The particular chemist had taken the lead in several joint projects and as such the pharmaceutical company was quite familiar with his or her knowledge and skills (de Rond and Bouchikhi, 2004). However, de Rond and Bouchikhi (2004) remain silent on contractual mechanisms that would have prevented the employee poaching from occurring. The results of this paper identify how and where contractual restrictions on interfirm employee mobility are used. Firms are often concerned with the possibility that their collaboration partners appropriate knowledge outside the scope of their initial agreements (Hamel, 1991). Contractual limitations on hiring practices can help soften this concern. However, descriptive statistics seem to indicate that such contractual limitations on hiring practices are probably used in less than $20 \%$ of all alliance contracts. Results hint at the proposition that firms located in a pro-mobility environment, or partner with a firm located in a pro-mobility environment, need to find alternative ways of limiting employee mobility besides relying on formal contracts.

In terms of the design of clauses that impair free movement of employees between collaborating firms, I made a distinction based on their duration, scope, and definition. In nearly all cases, the duration of clauses limiting interfirm employee mobility is spelled out in the contract. This duration rarely exceeds two years after the term of an alliance. In terms of their scope, many clauses seem to be open for substantial interpretation. Firms appear to limit the scope of these clauses to employees that actually perform work under an agreement, possess specific technical expertise areas, or occupy specific hierarchical positions within a firm, in only $50 \%$ of all cases. By extension, in $50 \%$ of all cases, no specific limitation regarding scope is specified. This could indicate that in $50 \%$ of the cases in which a contractual limitation on hiring practices is stipulated, employees that are not directly involved in a collaboration are still affected by receiving less offers for employment by partner firms of their current employer. It is exactly this broadness which is often critized. ${ }^{48}$ Firms explicitly exclude general advertisements aimed at the general public from the prohibition on approaching each other's employees in about $38 \%$ of all cases.

In terms of explaining the occurrence of clauses that hinder firms in approaching each other's employees for employment, two conditions appear to be of crucial importance. The first condition refers to the institutional environment in which firms reside (Davis and North, 1971; Roberts and Greenwood, 1997; Williamson, 1991; 1992; 1993). Institutional environments are sets of social and legal ground rules (Davis and North, 1971), which influence alliance parties, and can act as restraints on their behavior (Williamson, 1991; 1992; 1993). In the current context, I find that when at least one firm participating in a collaboration is located in a pro-mobility environment, the chance of observing a contractual limitation on

\footnotetext{
48 See United States vs. Adobe Systems Inc., Apple Inc., Google Inc., Intel Corporation, Intuit Inc., and Pixar. Case No: 1:10-cv-01629. (DOJ Sept 24, 2010), (competitive impact statement). In this statement, the defendants were criticized on the fact that their agreements not to approach each other's employees did not only involve employees that were actively involved in collaborative projects, but also extended to employees that were barely involved in any collaboration.
} 
employee movement between partners decreases. This association is already evident from simple descriptive statistics. In the subset of alliances involving no firms located in a promobility environment, employee mobility restrictions occur on average in around $22 \%$ of all R\&D contracts. In the subset of alliances involving one, but not two, firms located in a promobility environment the average occurrence of employee mobility impairing clauses equals around $12 \%$. Last, in the subset of alliances involving two firms located in a pro-mobility environment, about $5 \%$ of all contracts include limitations on the hiring behavior of partner firms. This finding highlights that when studying the design of contracts, the institutional environment of firms is often of crucial importance. In the past, TCE has been criticized for not explicitly taking into consideration the institutional environment of firms (see Oxley (1999) for a similar observation). Here, inspired by recent TCE literature (Oxley, 1999; Williamson, 1991; 1992; 1993), I show that when explaining the occurrence of contractual limitations on interfirm employee mobility, the institutional environment of firms, i.e., whether or not a firm from a pro-mobility environment is involved in an alliance, is of paramount importance. This finding aligns with recent literature on employee poaching (see Horn, 2011), which recognizes the importance of taking the institutional environment of firms into account. The presented results extrapolate observations made in the employee poaching literature to the realm of alliances.

The second condition found crucial in explaining the occurrence of contractual limitations on interfirm employee mobility refers to the scientific orientation of partner firms. From a TCE viewpoint, alliance parties can be expected to supplement their contract with additional contractual safeguards regarding unwanted employee mobility, when they perceive the risks and consequences of unwanted employee mobility to be especially great. Here, I find that partner firms are more likely to include contractual limitations on employee mobility, when they are more scientifically oriented. Previous research indicates that, especially in high technology industries, a strong scientific orientation is important for firms (Almeida, Hohberger and Parada, 2011; Deeds, Decarolis and Coombs, 1997; Decarolis and Deeds, 1999; Gittelman and Kogut, 2003; Henderson and Cockburn, 1994; Kaplan, Murray and Henderson, 2003; Koenig, 1983). Firms that are characterized by their high scientific quality and a significant possession of know-how, are wary of unwanted employee mobility as it would erode at least some of their knowledge stock (Younge, 2012). Many firms actively encourage their scientists to publish in scientific journals, as illustrated by a quote from a manager working in the biopharmaceutical industry: "[W]e need for our scientists to have great reputations in order to bring others like them to the firm" (Zucker and Darby, 1997; p. 438). A firm's policy regarding scientific publications can attract scientists (Cockburn and Henderson, 1998; Liu and Stuart, 2010; McMillan and Deeds, 1998; Younge, 2012; Zucker and Darby, 1997). When two firms are strongly scientifically oriented, each party will perceive the risk of unwanted employee mobility to be substantial, and thus favor contractual safeguards effectively limiting interfirm employee mobility (Williamson, 1993). This finding lends support to claims made by Liu and Stuart (2010) who conjectured that there might be a positive association between scientific publications and employee retention strategies.

However, the above finding comes with two caveats. First, in unreported analyses, I am unable to distinguish between the number of patents and the number of scientific publications of firms. In hindsight this is not surprising as "[i]n the case of biotechnology (...) basic scientific discoveries and commercially viable products are typically indistinguishable" (Liesbeskind et al., 1996; p. 438). In that sense, the positive association between the scientific 
orientation of partner firms and their propensity to include contractual limitations on employee mobility may be interpreted in terms of joint innovativeness. Indeed, hiring employees of innovating firms can be a particularly effective method of learning about new products and processes (Levin, 1988). The findings of this paper might be interpreted as such, i.e., innovating firm pairs are inclined to limit the outflow of human capital to each other. Second, I control for the difference in scientific orientation between partner firms while investigating the association between the total scientific orientation of partner firms and their propensity to include contractual limitations on employee mobility. Descriptive statistics in table 5.2 indicate that the correlation between the difference in scientific orientation between partner firms and their total scientific orientation equals around 0.86 . This indicates that many firm pairs with a jointly high scientific orientation are actually comprised of highly asymmetric firms in terms of scientific orientation. Although joint scientific orientation remains positive and significant when controlling for the difference in scientific orientation between firms, I note that the former variable adds little explanatory power to the second variable as they are nearly econometrically equivalent.

Surprisingly, I find no significant association between the geographical distance between firms and the likelihood of observing contractual employee mobility restrictions. Also, there appears to be no significant association between the level of competition between firms and their propensity to include contractual limitations on hiring practices. I expected that collaborating firms located in close geographical proximity to each other would be more concerned with the unintended outflow of employees to each other, and thus, would try to limit this outflow via their contract. Also, I anticipated that firms which are direct competitors in their primary market would try to limit interfirm employee mobility by contract. For both suggested effects I find no direct empirical support. One explanation is that these factors work in tandem. Wezel, Cattani and Pennings (2006) find that the dissolution risk of a firm experiencing the departure of key employees is highest when these employees start a new competing business in close geographical proximity to the existing firm. Similarly, for Silicon Valley law firms, Phillips (2002) finds that the failure rate of the parent company is highest when the progeny firm is a direct competitor, i.e., when the progeny firm and the parent company have a large overlap in business activities. As a corollary to these findings, it is possible that geographical distance between parties only has a negative effect on their propensity to stipulate an employee mobility restriction in their contract when these firms are direct competitors. However empirically, I find no support for such claim.

Another explanation for why both geographical distance and the level of competition between alliance partners appear to have no significant associations with the inclusion of contractual limitations on employee mobility can be found in the literature on employee poaching. Firms located in close geographical proximity to each other might be reluctant to approach each other's employees because of mutual forbearance, i.e., they might have agreed to some sort of gentlemen's agreement not to aggressively recruit each other's employees (Horn, 2011, de Rond and Bouchikhi, 2004). As such, and opposed to the second hypothesis, alliance firms located in close geographical proximity to each other might not be particularly concerned about unwanted interfirm employee mobility during or after their collaboration. The fourth hypothesis predicted that direct competitors would be more inclined to restrain each other's hiring behavior by contract. The empirical results provide no support for this claim. A possible explanation for the lack of empirical support for hypothesis four is that many firms already include non-compete clauses in their employment contracts which 
prohibit key employees from departing to direct competitors (Horn, 2011), rendering additional contractual safeguards in collaboration contracts superfluous. As such, the findings in this paper do not negate the possibility that direct competitors are especially concerned about unwanted employee mobility (see Somaya, Williamson and Lorinkova, 2008).

Initially a byproduct of my four hypotheses, analyses show that controlling for the focus area of an alliance is of crucial importance in explaining the likelihood that alliance parties will opt for an employee mobility restriction in their contract. I included dummy variables for those focus areas that occurred in more than $10 \%$ of all alliances in my sample. Model 6 in Table 5.3 shows that parties to an alliance that involve the focus areas 'Anti-infective', 'Cardiovascular', 'Inflammation/Musculoskeletal', or 'Oncology' are significantly less likely to include limitations on interfirm employee mobility. One explanation for this finding relates to the small-number-bargaining situation highlighted in TCE literature (e.g. Pisano, 1990). In a nutshell, small-numbers-bargaining hazards occur when a firm partners with another firm that possesses knowledge in a particular technological field for which limited alternative partners exist. In such a setting, the collaboration partner could behave opportunistically in contract renegotiation phases. In the context of this study, each party could fear opportunistic hiring practices when operating in a biopharmaceutical area where knowledge resides in a limited number of individuals or firms. Previous research indicates that relevant R\&D capabilities and knowledge are rather concentrated in some therapeutic areas (Pisano, 1990), while being more dispersed in other areas. Chiaroni, Chiesa and Frattini (2009) highlight the therapeutic areas oncology, cardiovascular diseases, and central nervous system diseases, as the three major technological fields in which many biotechnology and pharmaceutical firms are active. These results are corroborated by Dorsey et al. (2009) who look at the funding for biomedical research by different therapeutic areas. By and large, in the period between 1995 and 2005, most funding was directed to biomedical research in the areas of neuroscience, oncology, and cardiovascular diseases (Dorsey et al., 2009). In light of these arguments, the concentration of knowledge workers in particular therapeutic areas could be of crucial importance in explaining the occurrence of clauses in alliance contracts that limit employee mobility.

\subsection{Limitations and future research directions}

This study is not without its limitations. Each limitation however, points to interesting avenues for further research. First, this study focuses on the design and occurrence of clauses that aim to limit employee mobility between alliance partners, and thus sheds no light on the consequences of these clauses for collaborating parties. Future research could try to examine the effects of these clauses on employee mobility between former collaboration partners. Another option would be to relate the broadness of employee mobility restrictions drafted by collaboration partners to their hiring behavior in markets unrelated to the focal collaboration. Second, I proxy pro-mobility environment by investigating whether or not a firm from California is involved. The state of California is well known for its antipathy towards restrictions on employee mobility. However, due to the cross-sectional nature of my analysis, I can never fully rule out the possibility that unobserved (state) effects actually drive the results. In line with the explorative nature of this paper, the findings regarding California should therefore be interpreted carefully in the sense that other explanations as those presented here are possible. It is for instance difficult to disentangle the effects of California's 
legal environment from its regional local culture (Gilson, 1999; Saxenian, 1994). Similarly, California could be characterized by a more loose 'contracting style' (Bengtsson and Ravid, 2009; Kaplan and Strömberg, 2003), having an impact on the variable of interest. Although I maintain that labeling California as a pro-mobility environment offers the most fertile ground for explaining the proclivity of Californian firms to shunt contractual limitations on employee mobility, I urge future research to more carefully disentangle different explanations. Third, due to the strong reliance on science in the biopharmaceutical industry, the findings for scientific orientation might be an industry-specific effect. Future research might investigate the use of clauses that limit interfirm employee mobility in different industrial contexts. Fourth and last, as discussed in the section on alternative explanations and robustness checks, a firm's number of scientific publications and number of patents are highly correlated. As such, in the current contribution I am unable to reliably distinguish between measures for scientific orientation based on scientific publications, or on patents. Nevertheless, it could be argued that while scientific publications are a more adequate proxy for basic science, patents are a better proxy for more applied science. As such, we need more research to understand the precise relationship between the scientific orientation of partner firms and their propensity to limit employee mobility via their collaboration contract. 



\section{Conclusions}

\subsection{Introduction}

This dissertation sought to answer the question what factors influence, or are associated with, the design of $R \& D$ alliance contracts in the biopharmaceutical industry. Most previous research on the governance of alliances has differentiated between alternative governance arrangements along relatively crude scales (Reuer and Ariño, 2007), such as an equity/nonequity divide (e.g. Gulati, 1995). Such classifications are only accurate to the extent to which the contracts accompanying these alliances are fairly homogeneous within groups (e.g. nonequity alliances), and fairly heterogeneous between groups (e.g. non-equity versus equity alliances). Discriminating between alternative governance arrangements based on relatively crude scales is unlikely to adequately represent the plethora of different contractual supports, i.e., contractual clauses, available to alliance partners (Reuer and Ariño, 2007), and we thus need a more in-depth investigation of contracting between companies in a 'real-world setting' (Coase, 1992; Hagedoorn and Hesen, 2007). Moreover, an answer to this broader research question is relevant as the contractual design of $\mathrm{R} \& \mathrm{D}$ alliances is associated with many of the core constructs studied in alliance research such as alliance adaptation, knowledge transfer, alliance failure, and more (Reuer and Ariño, 2007).

In this dissertation I (perhaps implicitly) move away from a classical contracting perspective towards a more neoclassical contracting perspective which signals my conviction that $R \& D$ alliance contracts in the biopharmaceutical industry are not discrete transactions, are not mere risk allocation mechanisms, are not complete, and are, from the perspective of contract parties, not preferably enforced by the courts. The inherent uncertainty and complexity of many real world exchanges coupled with transaction costs makes the drafting of complete contracts prohibitively costly (Williamson, 1985; 1996). Recognizing that many contracts are inevitably incomplete (Williamson, 1985), recent contributions to the field of alliance contract design sought to explain the complexity of contracts (Mellewigt, Decker and Eckhard, 2012). Referring back to figure 1.2, many previous contributions that study the design of alliance contracts focus on contractual complexity which encompasses a myriad of different provisions (Parkhe, 1993), and contractual functions. I deliberately side-step such an approach in this dissertation, and seek to provide an overall picture of alliance contract design by answering four more specific sub research questions that, in my opinion, highlight different functions of (neoclassical) alliance contracts, such as, dividing 'control' and facilitating 'coordination'. To answer my four sub research questions, I relied on several 
theoretical perspectives and literatures including, but not limited to, a bargaining power perspective on R\&D alliances in Chapter 2, literature on coordination within firms in Chapter 3, transactions costs economics theory in Chapter 4, and literature on employee poaching in Chapter 5. As the study of contractual provisions in alliance agreements is important, but has thus far received only scant attention in the literature (Kale and Singh, 2009), I expect that answering my four sub research questions has the potential to significantly contribute to our knowledge about the contract design of R\&D alliances, and alliances more in general.

In this concluding chapter, I first elaborate on the major findings of my four empirical studies, then provide some theoretical and managerial implications, and finally discuss the limitations of this dissertation and some potential avenues for future research.

\subsection{Major findings}

Here I will elaborate on the major findings of my four empirical studies.

\subsubsection{Study 1}

My first sub research question is formulated as follows:

How is the bargaining power of initial, primary technology supplying firms associated with the number of intellectual property control rights allocated to these firms in $R \& D$ alliance contracts?

Chapter 2 formed expectations regarding the number of intellectual property control rights allocated to the initial, primary technology supplying firm based on a bargaining power perspective of $R \& D$ alliances. In that sense, inspired by the Aghion and Tirole (1994) qualification of the classical Grossman-Hart-Moore (GHM) approach to property rights (Grossman and Hart, 1986; Hart and Moore, 1990), I take the bargaining power of the initial, primary technology supplying firm as a strong indication of the number of intellectual property control rights it retains (Adegbesan and Higgins, 2011). I pose that the bargaining power of the initial, primary technology supplying firm depends on both firm level attributes as on transaction attributes. I find moderate support for such an extended bargaining power perspective.

At the firm level, results indicate that asymmetry in innovative capabilities, from the perspective of the initial, primary technology supplying firm, is positively associated with the number of intellectual property control rights this firm retains. I expected that a large asymmetry in innovative capabilities is indicative of the extent to which the primary technology supplying firm is instrumental to the success of an alliance. As also recently suggested by Bosse and Alvarez (2010), asymmetry in innovative capabilities appears to be more relevant in explaining retention of intellectual property control rights compared to the more traditional notion of size asymmetry. At the transaction (alliance) level, results indicate that the technological breadth of an R\&D alliance, based on the initial technology input from the primary technology supplying firm, is positively associated with the number of intellectual property control rights this firm retains. Considerable technological breadth can signal latent demand for a technology and put the technology provider in a stronger bargaining position. Interestingly, auxiliary regressions reveal that the above results do not 
hold when considering a set of non-intellectual property control rights, providing merit to the treatment of IPR control rights as a subset of control rights sui generis.

In short, the bargaining power of the initial, primary technology supplying firm, and in particular when based on interfirm asymmetries in innovative capabilities or relating to the breadth of the technology scope, appears to be of importance in explaining the number of intellectual property control rights allocated to this firm.

\subsubsection{Study 2}

My second sub research question is formulated as follows:

What factors are associated with the stipulation of more or less interfirm coordination provisions in $R \& D$ alliance contracts?

Chapter 3 formed expectations regarding the degree to which alliance parties stipulate contractual governance mechanisms that serve to facilitate interfirm coordination during execution of their agreement. Drawing on extant work I suggested that contracts, besides their legal role in setting out contractual promises of which the law gives a remedy (Goldberg, 1976; Macneil, 1974), also serve as a framework to guide collaboration between firms and promote adaptability to unforeseen events (Williamson, 1979). Inspired by organizational economics, strategy, and organization literatures on the design on contracts, I suggested that the nature of the alliance activities undertaken within an R\&D alliance, the geographical distance between partners, and the alliance experience of firms can serve as predictors of the level of interfirm contractual coordination. I find that transactional complexity, the task interdependence between alliance parties, and the alliance experience of firms are positively related to the level of interfirm contractual coordination.

Yet, auxiliary regressions add nuance to relationship between transactional complexity, i.e., whether or not additional activities are included in an R\&D alliance, and the degree to which alliance parties stipulate mechanisms to facilitate coordination in their contracts, i.e., some additional activities seem to be unrelated to the number of coordination committees. The positive relationship between the level of task interdependence and the number of coordination committees stipulated in an alliance contract adds to studies on the intrafirm level that suggest a similar relationship (e.g. van de Ven, Delbecq and Koenig, 1976), and confirms recent predictions in the literature on the design of alliance contracts that postulated the existence of the aforementioned relationship (Mellewigt, Decker and Eckhard, 2012). Results also indicate that (the minimum) previous alliance experience of partners is positively related to their propensity to stipulate a larger number of coordination committees in their current contract. Over time, through alliances with other parties, firms learn about best practices, attain a more complete overview of their internal resources and how to use these resources to support alliance objectives (Kale, Dyer and Singh, 2002; Kotabe, Martin and Domoto, 2003), and make available more personnel dedicated to supporting alliance endeavors (Kale, Dyer and Singh, 2002; Schilke and Goerzen, 2010). This finding extends a burgeoning stream of literature on firm learning in the context of interfirm contracts (e.g. Argyres, Bercovitz and Mayer, 2007; Argyres and Mayer, 2007; Luo, 2002; Reuer, Ariño and Mellewigt, 2006; Ryall and Sampson, 2009). Implicit in many of the arguments underlying Chapter 3 is that more interfirm coordination is better. I challenge this assumption in auxiliary 
regressions where I find that in the subset of non-equity alliances, i.e., those alliances in which the level of interfirm control is relatively low (Pisano, 1989), firms that can be labeled as direct competitors, compared to firms that cannot, stipulate fewer coordination committees in their contract. These additional results hint at the proposition that competitors in alliances, that lack control and incentive alignment through equity participation, consciously try to limit the number of interaction points during execution of their agreement to avoid the unintended loss of knowledge.

In short, I find that inclusion of certain additional activities besides $R \& D$, increasing the transactional complexity of an alliance, task interdependence, and alliance experience are positively related to the number of coordination committees that firms stipulate in their alliance contracts.

\subsubsection{Study 3}

My third sub research question is formulated as follows:

What factors are associated with the stipulation of particular dispute resolution clauses in $R \& D$ alliance contracts?

Chapter 4 formed expectations regarding the relationships between exchange complexity, environmental uncertainty, and the presence of a high growth firm on the one hand, and internal dispute resolution via hierarchy and arbitration, both stipulated in the R\&D alliance contract, on the other hand. Parties to an alliance characterized by substantial complexity and uncertainty inevitably have to deal with disputes emerging during their collaboration (Mayer and Teece, 2008), and on average two thirds of all alliances run into serious disputes within the first two years of collaboration (Das and Teng; 2000a; Koza and Lewin, 2000). I therefore expected that parties would foresee the possibility of their alliance ending in a dispute and design, based on certain factors, their contracts accordingly. Because parties to an alliance characterized by substantial exchange complexity often possess idiosyncratic knowledge about their collaboration and dispute, which often resolves around initial unmet interests and expectations that are difficult to transfer to a neutral third-party (Edelman, Erlanger and Lande, 1993; Sampson, 2004a; Williamson, 1991; 1994), I suggested that there is a positive association between exchange complexity and the propensity of firms to promote internal dispute resolution via hierarchy in their contracts. The results suggest that elements of exchange complexity, i.e., the inclusion of a relatively complex technology (e.g. Klitgaard and Mussman, 1992) or an open-ended alliance (e.g. Phene and Tallman, 2012), are positively related to the stipulation of clauses that promote internal dispute resolution via hierarchy. This finding adds to previous literature which has already stated that "in many instances the participants can devise more satisfactory solutions to their disputes than can professionals constrained to apply general rules on the basis of limited knowledge of the dispute" (Galanter, 1981; p. 4; Williamson, 2002). Arbitration is defined as a voluntary arrangement between parties to refer disputes to a neutral third party and to be bound by the decision of that third party (Bonn, 1972; Mattli, 2001). Because arbitration allows custom rather than law to guide resolution of disputes (Bonn, 1972), and arbitration awards are confidential (Allison, 1990; Mattli, 2001), Chapter 4 argues that we are more likely to observe arbitration clauses in alliance contracts if parties experience substantial environmental uncertainty, or if a high- 
growth firm is involved. Environmental uncertainty, i.e., whether or not firms participating in an alliance are headquartered in the same country, is positively associated with the presence of arbitration clauses in alliance contracts. This indicates that parties are wary of having their disputes interpreted by a foreign and usually unknown legal system (Redfern, 1976). I also expected that in the subset of international alliances, firms from more similar legal regimes would be less inclined to opt for arbitration in their contracts compared to firms from more different legal regimes. I find no empirical support for such a claim. However, additional analyses reveal the presence of a strong 'Japan effect', i.e., contracts between U.S. and Japanese firms are significantly more likely to contain arbitration clauses compared to other international alliance contracts. The Japanese legal system differs considerably from both common and civil law traditions which might be reflected in the propensity of U.S.-Japan firm pairs to opt for arbitration in their contracts. Results also indicate that in the subset of domestic alliances, the presence of a high-growth firm in an interfirm collaboration is positively related to the chance of observing an arbitration clause in the alliance contract. This could indicate that firms which have experienced recent and rapid growth are especially concerned about valuable business information leaking out to the general public when their alliance runs into a dispute, and design contractual safeguards accordingly.

In short, I find a positive relationship between certain elements of exchange complexity and the propensity of alliance parties to promote internal dispute resolution via hierarchy in their contract. Also, results indicate that both environmental uncertainty and the presence of a high-growth firm in an alliance are positively related to the proclivity of parties to opt for arbitration in their alliance contract.

\subsubsection{Study 4}

My fourth sub research question is formulated as follows:

What factors are associated with the stipulation of employee mobility restrictions in $R \& D$ alliance contracts?

Chapter 5 formed expectations regarding the use of contractual restrictions on the hiring behavior of firms participating in an R\&D alliance. Furthermore, Chapter 5 gives an overview of how contractual limitations with regards to employee mobility are constructed in terms of duration, scope, and definition. I started from the baseline prediction that contractual safeguards are a reflection of underlying exchange hazards (Shelanski and Klein, 1995), while acknowledging the role of the institutional environment in which firms reside (Oxley, 1999; Roberts and Greenwood, 1997; Williamson, 1991; 1992). As such, I anticipated that firms are more likely to implement contractual limitations on employee mobility when they perceive the risks and consequences of employee mobility to be great, but less likely when located in an environment not supportive of contractual limitations on employee mobility. Results indicate that the presence of an alliance firm located in a 'pro-mobility environment' substantially decreases the likelihood of observing a contractual restriction on employee mobility in an R\&D alliance contract. Additionally, scientifically oriented firm pairs, that undoubtedly possess considerable knowhow crucial for survival in the biopharmaceutical industry (Almeida, Hohberger and Parada, 2011; Deeds, Decarolis and Coombs, 1997; Decarolis and Deeds, 1999; Gittelman and Kogut, 2003; Henderson and Cockburn, 1994; 
Kaplan, Murray and Henderson, 2003; Koenig, 1983; Younge, 2012), are more likely to include contractual restrictions on the mobility of employees between each other. In terms of the design of contractual clauses that seek to limit interfirm employee mobility, results indicate that only in $50 \%$ of all cases these clauses are limited to employees that actually perform work under an agreement, possess specific technical expertise areas, or occupy specific hierarchical positions within a firm. Additional inspection of the results also reveal that certain frequently occurring focus areas are significantly and negatively related to the propensity of parties to limit interfirm employee mobility. This could indicate that firms are less protective of their human capital when operating in a focus area where knowledge is spread out over a relatively large number of firms or persons.

In short, I find that the presence of a firm located in a 'pro-mobility environment' and more scientific partner firms decrease and increase, respectively, the likelihood of observing contractual limitations on interfirm employee mobility in R\&D alliance contracts.

\subsection{Implications}

Here, I will elaborate on the theoretical and managerial implications of my four empirical studies. First, recent contributions by Kale and Singh (2009) and Mellewigt, Decker and Eckhard (2012) highlight the scant attention previous research has paid to contractual provisions in alliance agreements, and call for more research on the content of alliance contracts. In this dissertation I worked towards addressing this call by carefully selecting four elements of alliance contracts that individually represent little researched areas of contract design, while together constituting a comprehensive overview of contractual functions. In that sense and as suggested by Poppo and Zenger (2002), I purposely sidestep previous approaches in the field of alliance contract design that have mainly focused on contractual complexity (Anderson and Dekker, 2005; Barthélemy and Quélin, 2006; Luo, 2002; Poppo and Zenger, 2002; Reuer and Ariño, 2007; Ryall and Sampson, 2009; Sobrero and Roberts, 2002). Indeed, there appears to be room for moving away from a focus on more general aggregate measures of contractual complexity towards more targeted investigations regarding specific, sets of, clauses.

Second, and related to the first, "the possibility exists that established empirical relationships between the what (e.g. resources being exchanged, scope of collaboration, etc.), the how (e.g. governance), and the who (e.g. partner selection) of strategic alliances, as well as their effects on performance, might be subject to misattributes without accounting for the various contractual provisions that firms can put into collaborative agreements" (Reuer and Ariño, 2007; p. 326). As such, a closer examination of the contractual provisions firms implement in their collaborative agreements has the potential to significantly add nuance to previous empirical findings in the field of alliances. Indeed, interesting questions emerge. For instance, does previous general alliance experience really directly increase the performance of R\&D alliances (Hoang and Rothaermel, 2005), or does previous general alliance experience indirectly increase performance by first affecting the degree of interfirm coordination (Chapter 3), and then performance (Doz, 1996, Park and Ungson, 2001; Sarkar et al., 2001)? Also, do equity arrangements, i.e., JV's, unlike contracts, directly constrain unintended knowledge transfer ex-post (Oxley and Wada, 2009), or does equity participation indirectly limit unintended knowledge transfer ex-post by first affecting the propensity of firms to include clauses that limit their hiring behavior (Chapter 5), which then in turn limits the 
(unwanted) spread of information between firms (Arrow, 1962). The theory implication is this: without a proper understanding of the various contractual provisions firms can implement in their alliance contracts, established empirical findings in the field of alliances might misrepresent actual relationships (Reuer and Ariño, 2007). I believe there is ample room for further research that seeks to investigate the plethora of contractual options available to collaborating firms (see the shaded area in figure 1.2), and their antecedents and effects.

Third, the results of this dissertation strongly suggest that R\&D alliance contracts are not to be seen as mere legal devices, but instead seem to adhere to the 'contract as a framework' notion proposed by Llewellyn (1931). In that sense, R\&D alliance contracts are characterized by their high degree of adjustability, their informative nature on how the relationship between contract parties should work and develop, and their private ordering geared towards problem solving. To illustrate the foregoing, and in line with Williamson (2001) who points out the benefits of arbitration, Chapter 4 indicates that the majority of parties to interfirm arrangements elect to have their disputes settled by arbitration and thus voluntarily avoid (parts of) the traditional legal system. This finding agrees with other contributions that illustrate the prominent usage of non-traditional dispute resolution mechanisms in a variety of contexts, such as, the diamond industry (Bernstein, 1992). Such findings may have implications for legislators. For instance, the prevalence of alternative dispute resolution mechanisms in R\&D alliance contracts may point towards the sub-optimality of the traditional legal system in enforcing contracts in the current business environment (Hesen, 2010). There is considerable room left for more research that seeks to unravel the how, why, and where of alternative dispute resolution mechanisms.

Fourth, contract design is unequivocally complicated, as suggested by many studies documenting strong experience effects in the drafting of contracts (e.g. Argyres, Bercovitz and Mayer, 2007; Argyres and Mayer, 2007). Managers with none or little experience in the interfirm contracting process are likely to benefit from a minimum awareness of relevant clauses in alliance contracts. Although some of that knowledge can be provided by employing (external) lawyers to aid in the drafting process of alliance contracts, many contract terms require specific input from managers and engineers (Argyres and Mayer, 2007). Absent some basic knowledge regarding contract design, managers and engineers might either (1) not be aware of the existence of certain kinds of contract terms, or (2) be aware of the existence of certain kinds of contract terms but not willing to aid in the actual drafting of contracts thereby leaving contract design solely to lawyers, or (3) be aware of the existence of certain kinds of contract terms and also willing to participate in the drafting of the actual contract(s), but not able to link certain kinds of contract terms to specific circumstances. I believe this dissertation provides some guidance for managers in all three categories. For managers in the first category, I believe this dissertation provides a comprehensive overview of contract terms that seek to control (mainly Chapters 2 and 5), coordinate (Chapter 3), and guide dispute resolution (Chapter 4). For managers in the second category, this dissertation might suggest that input from managers in the drafting process of contracts can be beneficial for firms when these firms, for instance, decide on how much interfirm coordination (Chapter 2) is needed to support alliance activities. For managers in the third category, this dissertation establishes some basic relationships that help managers to decide when certain contractual supports are appropriate. 


\subsection{Limitations and suggestions for further research}

Some general limitations emerge from individual chapters. I chose to highlight five. First, all studies in this dissertation are susceptible to the criticism that unobserved heterogeneity and/or omitted variables influence the relationships of interest, i.e., affect both dependent and independent variables simultaneously. For instance in chapter 5, it is possible that unobserved firm characteristics idiosyncratic to Californian firms - such as specific technological expertise areas - influence the negative relationship between the presence of a Californian firm in an alliance and the likelihood of observing a contractual limitation on employee mobility. According to Stinchcombe (1987), one condition necessary for establishing causal relationships is temporal precedence of the causal variable to the dependent variable. In this dissertation, this condition is often not met. For instance in Chapter 3, the number of coordination committees - the dependent variable - and the level of interfirm dependence the independent variable - are part of the same contract. It is conceivable that other unobserved transaction attributes might influence this relationship, or that the dependent variable also influences the independent variable. I sought to minimize the risk of unobserved factors tampering with the proposed relationships by (1) employing a host of control variables that can potentially affect both independent and dependent variables (2) testing for the robustness of the results proposed in each chapter, similar to Lerner and Malmendier (2010), by including 'firm fixed effects' for the most frequently occurring firms in my sample and (3) employing a careful sample selection strategy that produces a sample free of undesirable unobserved heterogeneity (Lerner and Merges, 1998). Despite these conscious efforts to decrease the risk of unobserved heterogeneity and/or omitted variables affecting my results, I am ultimately conservative in the empirical inferences I draw similar to other recent contributions in the field of (alliance) contract design (Bengtsson, 2011). ${ }^{49}$ I believe establishing conditional correlations between my variables of interest is a logical first step towards the ultimate goal of establishing causal relationships.

Second, we have little understanding on how certain contractual provisions are used expost by alliance parties. In Chapter 3, I investigated the number of coordination committees that alliance parties stipulate in their contract. It is yet unknown how intensively parties use these committees ex-post to communicate and adjust to unforeseen contingencies. In Chapter 4, I investigated specific dispute resolution clauses in R\&D alliance contracts. When a dispute arises, parties can deviate from the contract and opt for a more satisfactory solution based on information that was not yet available at the contract signing date, i.e., firms that initially opted for arbitration can jointly decide to have their dispute settled in court. As such, it would be worthwhile to investigate the ex-post usage of certain contractual clauses.

Third, it would be worthwhile to replicate this study in a different industrial contracting environment. The biopharmaceutical industry is an interesting high-technology industry as it accounts for a large share of the total alliance activity. Furthermore, the inherent uncertainty and complexity, coupled with substantial potential pay-offs, of biopharmaceutical projects assures us that contract design is unlikely to be characterized by a haphazard collection of clauses. Nevertheless, it would be interesting to see how the results presented in this dissertation hold up in different industrial contexts.

\footnotetext{
${ }^{49}$ As stated by Bengtsson (2011), firm level instruments are generally not convincing because one could argue that they affect the whole contract, including individual provisions.
} 
Fourth, the empirical results in this dissertation are based on U.S.-U.S. and U.S.-International firm pairs. It would be interesting to see whether or not the results of my analyses would be generalizable to International-International dyads. For instance, it could be that U.S. firms are systematically different from other firms in terms of their contract design behavior. Also, contracts that include at least one firm from the U.S. are typically relevant in the U.S. context as they fall under, or are affected by, the U.S. legal regime. Given the current international context of many alliances, an interesting topic for future research is to be found in the comparison of alliance contracts executed between U.S.-U.S., U.S.-International, and International-International firm pairs.

Five, I believe there is substantial room for improving construct validity in the field of alliance contract design. Constructs are abstractions from reality created by researchers to conceptualize a latent variable and are thus necessarily subject to different interpretations in different contexts. For instance, researchers in other disciplines have used firm age as a proxy for reputation (Gompers, 1996), flexibility and management efficiency (Fok, Chang and Lee, 2004), innovation inertia (Zona, Zattoni and Minichilli, 2012), resource scarcity (Castrogiovanni, Combs and Justis, 2006), and more. The constructs used in this dissertation can, to some extent, also be interpreted differently in different contexts. For instance, based on relevant literature, I interpret the number of technological interest areas as the number of potential technology applications in Chapter 2, but also as technological complexity in Chapter 4. These interpretations can offer different explanations for the presented results in this dissertation. Parties might not be more inclined to supplement their contract with additional mechanisms supporting internal dispute resolution in reaction to technological complexity (Chapter 4), but rather prefer to solve disputes internally when the benefits, i.e., number of potential technology applications (Chapter 2), are great. I encourage future research to further refine proxies used in the literature on alliance contract design.

Despite these limitations, I expect this dissertation to significantly add to our understanding of the design of $R \& D$ alliance contracts. 



\section{Literature}

Adegbesan, J.A., Higgins, M.J. 2011. The intra-alliance division of value created through collaboration. Strategic Management Journal, 32(2): 187-211.

Adler, P.S. 1995. Interdepartmental interdependence and coordination: the case of the design/manufacturing interface. Organization Science, 6(2): 147-167.

Aghion, P., Tirole, J. 1994. The management of innovation. Quarterly Journal of Economics, 109(4): 11851209.

Allison, J.R. 1990. Five ways to keep disputes out of court. Harvard Business Review: 166-177.

Almeida, P., Dokko, G., Rosenkopf, L. 2003. Startup size and the mechanisms of external learning: increasing opportunity and decreasing ability? Research Policy, 32(2): 301-315.

Almeida, P., Hohberger, J., Parada, P. 2011. Individual scientific collaboration and firm-level innovation. Industrial and Corporate Change, 20(6): 1571-1599.

Almeida, P., Kogut, B. 1999. Localization of knowledge and the mobility of engineers in regional networks. Management Science, 45(7): 905-917.

Anand, B.N., Khanna, T. 2000. The structure of licensing contracts. Journal of Industrial Economics, 48(1): 103-135.

Andersen, P.H. 1999. Organizing international technological collaboration in subcontractor relationships: an investigation of the knowledge-stickiness problem. Research Policy, 28(6): 625-642.

Anderson, S.W., Dekker, H.C. 2005. Management control for market transactions: the relation between transaction characteristics, incomplete contract design and subsequent performance. Management Science, 51(12): 1734-1752.

Argyres, N.S., Bercovitz, J., Mayer, K.J. 2007. Complementarity and evolution of contractual provisions: An empirical study of IT services contracts. Organization Science, 18(1): 3-19.

Argyres, N.S., Mayer, K.J. 2007. Contract design as a firm capability: An integration of learning and transaction cost perspectives. Academy of Management Review, 32(4): 1060-1077.

Ariño, A., Ragozzino, R., Reuer, J.J. 2008. Alliance dynamics for entrepreneurial firms. Journal of Management Studies, 45(1): 147-168.

Ariño, A., Reuer, J.J. 2004. Designing and renegotiating strategic alliance contracts. Academy of Management Executive, 18(3): 37-48.

Ariño, A., de la Torre, J. 1998. Learning from failure: Towards an evolutionary model of collaborative ventures. Organization Science, 9(3): 306-325.

Arita, T., McCann, P. 2000. Industrial alliances and firm location behavior: Some evidence from the U.S. semiconductor industry. Applied Economics, 32(11): 1391-1403.

Arrow, K.J. 1962. Economic welfare and the allocation of resources for invention. In R.R. Nelson (Ed.), The Rate and Direction of Inventive Activity: Economic and Social Factors: 609-626. Princeton, NJ: Princeton University Press.

Audretsch, D.B. 2001. The role of small firms in U.S. biotechnology clusters. Small Business Economics, 17(12): 3-15.

Bastos, J.A. 2010. Forecasting bank loans loss-given-default. Journal of Banking and Finance, 34(10): 25102517.

Baughn, C.C., Denekamp, J.G., Stevens, J.H., Osborn, R.N. 1997. Protecting intellectual capital in international alliances. Journal of World Business, 32(2): 103-117.

Baum, J.A.C., Calabrese, T., Silverman, B.S. 2000. Don't go it alone: Alliance network composition and startups' performance in Canadian biotechnology. Strategic Management Journal, 21: 267-294.

Barthélemy, J., Quélin, B.V. 2006. Complexity of outsourcing contracts and ex post transaction costs: An empirical investigation. Journal of Management Studies, 43(8): 1775-1797.

Bengtsson, O. 2011. Covenants in venture capital contracts. Management Science, 57(11): 1926-1943.

Bengtsson, O., Ravid, S.A. 2009. The importance of geographical location and distance on venture capital contracts. Working Paper.

Berg, S.V., Duncan, J., Friedman, P. 1982. Joint venture strategies and corporate innovation: Oelgeschlager, Gunn \& Hain. 
Bernstein, L. 1992. Opting out of the legal system: Extralegal contractual relations in the diamond industry. Journal of Legal Studies, 21(1): 115-157.

Bessy, C., Brousseau, E. 1998. Technology licensing contracts features and diversity. International Review of Law and Economics, 18(4): 451-490.

Bonn, R.L. 1972. Arbitration: An alternative system for handling contract related disputes. Administrative Science Quarterly, 17(2): 254-264.

Bosse, D.A., Alvarez, S.A. 2010. Bargaining power in alliance governance negotiations: Evidence from the biotechnology industry. Technovation, 30(5-6): 367-375.

Brenowitz, S. 2004. Deadly secrecy: The erosion of public information under private justice. Ohio State Journal on Dispute Resolution, 19(2): 679-708.

Breschi, S., Lenzi, C. 2010. Spatial patterns of inventors' mobility: Evidence on U.S. urban areas. Papers in Regional Science, 89(2): 235-250.

Brousseau, E., Coeurderoy, R., Chaserant, C. 2007. The governance of contracts: Empirical evidence on technology licensing agreements. Journal of Institutional and Theoretical Economics, 163(2): 205-235.

Brousseau, E., Glachant, J-M. 2002. Contract economics and the renewal of economics. In E. Brousseau and J-M Glachant (Eds.), The Economics of Contracts: Theories and Applications: 3-30. Cambridge, MA: Cambridge University Press.

Casper, S. 2007. How do technology clusters emerge and become sustainable? Social network formation and inter-firm mobility within the San Diego biotechnology cluster. Research Policy, 36(4): 438-455.

Casper, S., Murray, F. 2005. Careers and clusters: Analyzing the career network dynamic of biotechnology clusters. Journal of Engineering and Technology Management, 22(1- 2): 51-74.

Castrogiovanni, G.J., Combs, J.G., Justis, R.T. 2006. Resource scarcity and agency theory predictions concerning the continued use of franchising in multi-outlet networks. Journal of Small Business Management, 44(1): 27-44.

CATI. 2012. The cooperative agreements and technology indicators database: Maastricht.

Caves, R.E., Crookell, H., Killing, J.P. 1983. The imperfect market for technology licenses. Oxford Bulletin of Economics and Statistics, 45(3): 249-267.

Chesbrough, H.W. 1999. The organizational impact of technological change: A comparative theory of national institutional factors. Industrial and Corporate Change, 8(3): 447- 485.

Chiaroni, D., Chiesa, V., Frattini, F. 2008. Patterns of collaboration along the bio-pharmaceutical innovation process. Journal of Business Chemistry, 5(1): 7-22.

Chiaroni, D., Chiesa, V., Frattini, F. 2009. Investigating the adoption of open innovation in the biopharmaceutical industry. European Journal of Innovation Management, 12(3): 285-305.

Coase, R.H. 1937. The nature of the firm. Economica, 4(16): 386-405.

Coase, R.H. 1992. The institutional structure of production. American Economic Review, 82(4): 713-719.

Cockburn, I.M., Henderson, R.M. 1998. Absorptive capacity, coauthoring behavior, and the organization of research in drug discovery. Journal of Industrial Economics, 46(2): 157-182.

Coff, R.W. 1997. Human assets and management dilemmas: Coping with hazards on the road to resource-based theory. Academy of Management Review, 22(2): 374-402.

Cohen, W.M., Levinthal, D.A. 1990. Absorptive capacity: A new perspective on learning and innovation. Administrative Science Quarterly, 35: 128-152.

Cohen, W.M., Nelson, R.R., Walsh, J.P. 2000. Protecting their intellectual assets: Appropriability conditions and why U.S. manufacturing firms patent (or not). Working Paper.

Contractor, F.J., Woodley, J.A., Piepenbrink, A. 2011. How tight an embrace? Choosing the optimal degree of partner interaction in alliances based on risk, technology characteristics, and agreement provisions. Global Strategy Journal, 1(1-2): 67-85.

Cooper, T. 2007. Change and disruption in the pharmaceutical industry, Deloitte Consulting LLP.

Cooper, R.W., Ross, T.W. 2007. Sustaining cooperation with joint ventures. Journal of Law, Economics, and Organization, 25(1): 31-54.

Corredoira, R.A., Rosenkopf, L. 2010. Should auld acquaintance be forgot? The reverse transfer of knowledge through mobility ties. Strategic Management Journal, 31(2): 159-181.

Crocker, K.J., Reynolds, K.J. 1993. The efficiency of incomplete contracts: An empirical analysis of air force engine procurement. RAND Journal of Economics, 24(1): 126-146. 
Das, T.K., Kumar, R. 2007. Learning dynamics in the alliance development process. Management Decision, 45(4): 684-707.

Das, T.K., Teng, B. 2000a. Instabilities of strategic alliances: An internal tensions perspective. Organization Science, 11(1): 77-101.

Das, T.K., Teng, B. 2000b. A resource-based theory of strategic alliances. Journal of Management, 26(1): 31-61.

Davidson, R., MacKinnon, J.G. 1993. Estimation and inference in econometrics. New York, NY: Oxford University Press.

Davis, L.E., North, D.C. 1971. Institutional change and American economic growth. Cambridge, MA: Cambridge University Press.

Decarolis, D.M., Deeds, D.L. 1999. The impact of stocks and flows of organizational knowledge on firm performance: An empirical investigation of the biotechnology industry. Strategic Management Journal, 20(10): 953-968.

Deeds, D.L., DeCarolis, D., Coombs, J.E. 1997. The impact of firm-specific capabilities on the amount of capital raised in an initial public offering: Evidence from the biotechnology industry. Journal of Business Venturing, 12(1): 31-46.

Deloitte Technology Fast 500. Retrieved from http://www.deloitte.com/us/fast500/. March 13, 2012.

Djankov, S., La Porta, R., Lopez-De-Silanes, F., Schleifer, A. 2003. Courts. Quarterly Journal of Economics, 118(2): 453-517.

Dorsey, E.R., Thompson, J.P., Carrasco, M., de Roulet, J., Vitticore, P., Nicholson, S., Johnston, S.C., Holloway, R.G., Moses III, H. 2009. Financing of U.S. biomedical research and new drug approvals across therapeutic areas. PLOS ONE, 4(9): 1-9.

Dow, J.K., Endersby, J.W. 2004. Multinomial probit and multinomial logit: A comparison of choice models for voting research. Electoral Studies, 23(1): 107-122.

Doz, Y.L. 1996. The evolution of cooperation in strategic alliances: Initial conditions or learning processes? Strategic Management Journal, 17(S1): 55-83.

Edelman, L.B., Erlanger, H.S., Lande, J. 1993. Internal dispute resolution: The transformation of civil rights in the workplace. Law and Society Review, 27(3): 497-534.

Eisenberg, T., Miller, G.P. 2007. Flight from arbitration: An empirical study of ex ante arbitration clauses in the contracts of publicly held companies. DePaul L. Review, 56: 335-374.

Eisenhardt, K.M., Schoonhoven, C.B. 1996. Resource-based view of strategic alliance formation: Strategic and social effects in entrepreneurial firms. Organization Science, 7(2): 136-150.

Elangovan, A.R. 1995. Managerial third-party dispute intervention: A prescriptive model of strategy selection. Academy of Management Review, 20(4): 800-830.

Elfenbein, D.W., Lerner, J. 2012. Exclusivity, contingent control rights, and the design of internet portal alliances. Journal of Law, Economics, and Organization, 28(1): 45-74.

Elsing, S.H., Townsend, J.M. 2002. Bridging the common law civil law divide in arbitration. Arbitration International, 18(1): 1-7.

Faems, D., Janssens, M., Madhok, A., van Looy, B. 2008. Toward an integrative perspective on alliance governance: Connecting contract design, trust dynamics, and contract application. Academy of Management Journal, 51(6): 1053-1078.

Fallick, B., Fleischman, C.A., Rebitzer, J.B. 2006. Job-hopping in silicon valley: Some evidence concerning the microfoundations of a high-technology cluster. Review of Economics and Statistics, 88(3): 472-481.

Farnsworth, 1969. The past of promise: an historical introduction to contract. Columbia Law Review: 69(4), 576607.

Fok, R.C.W., Chang, Y., Lee, W. 2004. Bank relationships and their effects on firm performance around the Asian financial crisis: Evidence from Taiwan. Financial Management, 33(2): 89-112.

Fombrun, C.J., Wally, S. 1989. Structuring small firms for rapid growth. Journal of Business Venturing, 4(2): 107-122.

Frankort, H.T.W. 2010. R\&D alliances, knowledge flows, and innovation. Three studies on the value of collaborative R\&D. Dissertation.

Frankort, H.T.W., Hagedoorn, J., Letterie, W. 2012. R\&D partnership portfolios and the inflow of technological knowledge. Industrial and Corporate Change, 21(2): 507-537.

Freeman, C., Soete, L. 1997. The economics of industrial innovation. London: Pinter. 
Furlotti, M. 2007. There is more to contracts than incompleteness: A review and assessment of empirical research on inter-firm contract design. Journal of Management and Governance, 11(1): 61-99.

Furman, J.L., Kyle, M.K., Cockburn, I., Henderson, R.M. 2005. Public \& private spillovers. Location and the productivity of pharmaceutical research. Annales d'Économie et de Statistique, 79/80: 165-188.

Galanter, M. 1981. Justice in many rooms: Courts, private ordering, and indigenous law. Journal of Legal Pluralism, 19(1): 1-47.

Garcia-Canal, E. 1996. Contractual form in domestic and international strategic alliances. Organization Studies, 17(5): 773-794.

Gerwin, D. 2004. Coordinating new product development in strategic alliances. Academy of Management Review, 29(2): 241-257.

Gilson, R.J. 1999. The legal infrastructure of high technology industrial districts: Silicon Valley, Route 128, and covenants not to compete. New York University Law Review, 74(3): 575-629.

Gittelman, M. 2007. Does geography matter for science-based firms? Epistemic communities and the geography of research and patenting in biotechnology. Organization Science, 18(4): 724-741.

Gittelman, M., Kogut, B. 2003. Does good science lead to valuable knowledge? Biotechnology firms and the evolutionary logic of citation patterns. Management Science, 49(4): 366-382.

Gompers, P.A. 1996. Grandstanding in the venture capital industry. Journal of Financial Economics, 42(1): 133156.

Goldberg, V.P. 1976. Toward an expanded economic theory of contract. Journal of Economic Issues, 10(1): 4561.

Goldman, L. 2003. Contractually expanded review of arbitration awards. Harvard Negotiation Law Review, 8: 171-200.

Gooroochurn, N., Hanley, A. 2007. A tale of two literatures: Transaction costs and property rights in innovation outsourcing. Research Policy, 36(10): 1483-1495.

Grandori, A. 1997. An organizational assessment of interfirm coordination modes. Organization Studies, 18(6): 897-925.

Grandori, A., Soda, G. 1995. Inter-firm networks: Antecedents, mechanisms and forms. Organization Studies, 16(2): 183-214.

Griliches, Z. 1976. Wages of very young men. Journal of Political Economy, 84(4): S69-S86.

Grinter, R.E., Herbsleb, J.D., Perry, D.E. 1999. The geography of coordination: dealing with distance in R\&D work. Paper presented at the 1999 SIGGROUP conference, Phoenix, AZ.

Grossman, S.J., Hart, O.D. 1986. The costs and benefits of ownership: A theory of vertical and lateral integration. Journal of Political Economy, 94(4): 691-719.

Gulati, R. 1995. Does familiarity breed trust? The implications of repeated ties for contractual choice in alliances. Academy of Management Journal, 38(1): 85-112.

Gulati, R., Singh, H. 1998. The architecture of cooperation: Managing coordination costs and appropriation concerns in strategic alliances. Administrative Science Quarterly, 43(4): 781-814.

Haeussler, C., Higgins, M.J. 2009. Control rights and the performance of strategic alliances. Working paper.

Hagedoorn, J. 1989. The dynamic analysis of innovation and diffusion: A study in process control. Dissertation.

Hagedoorn, J. 1993. Understanding the rationale of strategic technology partnering: Interorganizational modes of cooperation and sectoral differences. Strategic Management Journal, 14(5): 371-385.

Hagedoorn, J. 2002. Inter-firm R\&D partnerships: An overview of major trends and patterns since 1960. Research policy, 31(4): 477-492.

Hagedoorn, J., Cloodt, D.,Van Kranenburg, H. 2005. Intellectual property rights and the governance of international R\&D partnerships. Journal of International Business Studies, 36(2): 175-186.

Hagedoorn, J., Hesen, G. 2007. Contract law and the governance of inter-firm technology partnerships. An analysis of different modes of partnering and their contractual implications. Journal of Management Studies, 44(3): 342-366.

Hagedoorn, J., Hesen, G. 2009. Contractual complexity and the cognitive load of R\&D alliance contracts. Journal of Empirical Legal Studies, 6(4): 818-847.

Hagedoorn, J., Schakenraad, J. 1994. The effect of strategic technology alliances on company performance. Strategic Management Journal, 15(4): 291-309. 
Haley, J.O. 1991. Dispute resolution in Japan: Lessons in autonomy. Canada-United States Law Journal, 17: 443-447.

Hall, B., Jaffe, A., Trajtenberg, M. 2005. Market value and patent citations. RAND Journal of Economics, 36(1): 16-38.

Hambrick, D.C., Crozier, L.M. 1985. Stumblers and stars in the management of rapid growth. Journal of Business Venturing, 1(1): 31-45.

Hamel, G. 1991. Competition for competence and inter-partner learning within international strategic alliances. Strategic Management Journal, 12(S1): 83-103.

Hansen, Z.K., Higgins, M.J. 2008. A multi-dimensional view of alliance complexity and value division in technology sourcing agreements. Working paper.

Hart, O. 1989. An economist's perspective on the Theory of the Firm. Columbia Law Review, 89(7): 1757-1774.

Hart, O., Moore, J. 1988. Incomplete contracts and renegotiation. Econometrica, 56(4): 755- 785.

Hart, O., Moore, J. 1990. Property rights and the nature of the firm. Journal of Political Economy, 98(6): 11191158 .

Hart, O., Moore, J. 2008. Contracts as reference points. Quarterly Journal of Economics, 123(1): 1-48.

Hausman, J., McFadden, D. 1984. Specification tests for the multinomial logit model. Econometrica, 52(5): 1219-1240.

Helm, R., Kloyer, M. 2004. Controlling contractual exchange risks in R\&D interfirm cooperation: An empirical study. Research Policy, 33(8): 1103-1122.

Henderson, R., Cockburn, I. 1994. Measuring competence? Exploring firm effects in pharmaceutical research. Strategic Management Journal, 15(S1): 63-84.

Hesen, G. 2009. The empirics of contracts. Theoretical and empirical observations on contract design. Dissertation.

Hess, A.M., Rothaermel, F.T. 2011. When are assets complementary? Star scientists, strategic alliances, and innovation in the pharmaceutical industry. Strategic Management Journal, 32(8): 895-909.

Higgins, M.J. 2007. The allocation of control rights in pharmaceutical alliances. Journal of Corporate Finance, 13(1): 58-75

Hill, C.W.L. 1992. Strategies for exploiting technological innovations: When and when not to license. Organization Science, 3(3): 428-441.

Hoang, H., Rothaermel, F.T. 2005. The effect of general and partner-specific alliance experience on joint R\&D project performance. Academy of Management Journal, 48(2): 332-345.

Hoegl, M., Proserpio, L. 2004. Team member proximity and teamwork in innovative projects. Research Policy, 33(8): 1153-1165.

Hofstede, G.H. 1980. Culture's consequences: International differences in work-related values. Beverly Hills, CA: Sage.

Horn, S. 2011. Competitor recruitment. Theory and practice-based explorations. Dissertation.

Hyde, A. 1998. Silicon Valley's high-velocity labor market. Journal of Applied Corporate Finance, 11(2): 2837.

Hyde, A. 2012. Intellectual property justifications for restricting employee mobility: A critical appraisal in light of the economic evidence. In C.L. Estlund and M.L. Wachter (Eds.), Research Handbook on the Economics of Labor and Employment Law: 357-385. Edward Elgar Publishing.

Inkpen, A.C., Beamish, P.W. 1997. Bargaining power, and the instability of international joint ventures. Academy of Management Review, 22(1): 177-202.

Johnson, S., McMillan, J., Woodruff, C. 2002. Courts and relational contracts. Journal of Law, Economics, and Organization, 18(1): 221-277.

Joireman, S.F. 2001. Inherited legal systems and effective rule of law: Africa and the Colonial Legacy. The Journal of Modern African Studies, 39(4): 571-596.

Kalaignanam, K., Shankar, V., Varadarajan, R. 2007. Asymmetric new product development alliances: Win-win or win-lose partnerships. Management Science, 53(3): 357-374.

Kale, P., Singh, H. 2009. Managing strategic alliances: What do we know now, and where do we go from here? Academy of Management Perspectives, 23(3): 45-62. 
Kale, P., Dyer, J.H., Singh, H. 2002. Alliance capability, stock market response, and long-term alliance success: The role of the alliance function. Strategic Management Journal, 23(8): 747-767.

Kalnins, A., Mayer, K. 2004. Relationships and hybrid contracts: An analysis of contract choice in information technology. Journal of Law, Economics, and Organization, 20(1): 207-229.

Kaplan, S., Murray, F., Henderson, R. 2003. Discontinuities and senior management: Assessing the role of recognition in pharmaceutical firm response to biotechnology. Industrial and Corporate Change, 12(4): 203-233.

Kaplan, S.N., Strömberg, P. 2003. Financial contracting theory meets the real world: An empirical analysis of venture capital contracts. Review of Economic Studies, 70(2): 281-315.

Karambayya, R., Brett, J.M. 1989. Managers handling disputes: Third-party roles and perceptions of fairness. Academy of Management Journal, 32(4): 687-704.

Kaufmann, D., Kraay, A., Mastruzzi, M. 2010. The worldwide governance indicators: Methodology and analytical issues. Working paper.

Kerstetter, J. 2000. The dark side of the valley: In techdom's win-at-all-costs culture, hardball tactics and dirty tricks are just part of doing business. Businessweek, 17 July 2000.

Khorana, A., Servaes, H., Tufano, P. 2009. Mutual fund fees around the World. Review of Financial Studies, 22(3): 1279-1310.

Killing, J.P. 1988. Understanding alliances: The role of task and organizational complexity. In F.J. Contractor and P. Lorange (Eds.), Co-operative Strategies and International Business: 55-67. Lexington, MA: Lexington Books.

Klevorick, A.K., Levin, R.C., Nelson, R.R., Winter, S.G. 1995. On the sources and significance of interindustry differences in technological opportunities. Research Policy, 24(2): 185-205.

Klitgaard, T.J., Mussman, W.E. 1992. High technology disputes: The minitrial as the emerging solution. Computer and High Technology Law Journal, 8: 1-18.

Koenig, M.E.D. 1983. A bibliometric analysis of pharmaceutical research. Research Policy, 12(1): 15-36.

Kogut, B., Zander, U. 1993. Knowledge of the firm and the evolutionary theory of the multinational corporation. Journal of International Business Studies, 24(4): 625-645.

Kotabe, M., Martin, X., Domoto, H. 2003. Gaining from vertical partnerships: Knowledge transfer, relationship duration, and supplier performance improvement in the U.S. and Japanese automotive industries. Strategic Management Journal, 24(4): 293-316.

Koza, M., Lewin, A. 1998. The co-evolution of strategic alliances. Organization Science, 9(3): 255-264.

Koza, M., Lewin, A. 2000. Managing partnerships and strategic alliances: Raising the odds of success. European Management Journal, 18(2): 146-151.

La Porta, R., Lopez-de-Silanes, F., Schleifer, A., Vishny, R.W. 1998. Law and finance. Journal of Political Economy, 106(6): 1113-1155.

La Porta, R., Lopez-de-Silanes, F., Schleifer, A. 2008. The economic consequences of legal origins. Journal of Economic Literature, 46(2): 285-332.

Legrand, P. 1997. Against a European Civil Code. The Modern Law Review, 60(1): 44-63.

Leiponen, A. 2008. Control of intellectual assets in client relationships: Implications for innovation. Strategic Management Journal, 29(13): 1371-1394.

Lerner, J., Merges, R.P. 1998. The control of technology alliances: An empirical analysis of the biotechnology industry. Journal of Industrial Economics, 46(2): 125-156.

Lerner, J., Malmendier, U. 2010. Contractibility and the design of research agreements. American Economic Review, 100(1): 214-246.

Lerner, J., Shane, H.,Tsai, A. 2003. Do equity financing cycles matter? Evidence from biotechnology alliances. Journal of Financial Economics, 67(3): 411-446.

Levin, R.C. 1988. Appropriability, R\&D spending, and technological performance. American Economic Review, 78(2): 424-428

Levitt, B., March, J.G. 1988. Organizational learning. Annual Review of Sociology, 14: 319-340.

Lhuillery, S., Pfister, E. 2009. R\&D cooperation and failures in innovation projects: Empirical evidence from French CIS data. Research Policy, 38(1): 45-57.

Liebeskind, J.P., Oliver, A.L., Zucker, L., Brewer, M. 1996. Social networks, learning, and flexibility: Sourcing scientific knowledge in new biotechnology firms. Organization Science, 7(4): 428-443. 
Liu, C.C., Stuart, T.E. 2010. Boundary spanning in a for-profit research lab: An exploration of the interface between commerce and academe. Working paper.

Llewellyn, K.N. 1931. What price contract? An essay in perspective. Yale Law Journal, 40(5): 704-751.

Lumineau, F., Malhotra, D. 2011. Shadow of the contract: How contract structure shapes interfirm dispute resolution. Strategic Management Journal, 32(5): 532-555.

Lumineau, F., Oxley, J.E. 2012. Let's work it out (or we'll see you in court...): Litigation and private dispute resolution in vertical exchange relationships. Organization Science, 23(3): 820-834.

Lumineau, F., Quélin, B.V. 2012. An empirical investigation of interorganizational opportunism and contracting mechanisms. Strategic Organization, 10(1): 55-84.

Luo, Y. 2002. Contract, cooperation, and performance in international joint ventures. Strategic Management Journal, 23(10): 903-919.

Luo, Y. 2007. Are joint venture partners more opportunistic in a more volatile environment? Strategic Management Journal, 28(1): 39-60.

Macaulay, S. 1963. Non-contractual relations in business: A preliminary study. American Sociological Review, 28(1): 55-67.

Macher, J.T. 2006. Technological development and the boundaries of the firm: A knowledge- based examination in semiconductor manufacturing. Management Science, 52(6): 826-843.

Macneil, I.R. 1974. The many futures of contracts. Southern California Law Review, 47: 691-816.

Macneil, I.R. 1978. Contracts: Adjustment of long-term economic relations under classical, neoclassical and relational contract law. Northwestern University Law Review, 72: 854-905.

Macneil, I.R. 2000. Relational contract theory: Challenges and queries. Northwestern University Law Review, 94: 877-907.

Mahroum, S. 2000. Highly skilled globetrotters: Mapping the international migration of human capital. $R \& D$ Management, 30(1): 23-31.

Malone, T.W. 1987. Modeling coordination in organizations and markets. Management Science, 33(10): 13171332.

Mansfield, E. 1962. Gibrat's Law, innovation, and the growth of firms. American Economic Review, 52(5): 1023-1051.

Marx, M., Strumsky, D., Fleming, L. 2009. Mobility, skills, and the Michigan non-compete experiment. Management Science, 55(6): 875-889.

Mattli, W. 2001. Private justice in a global economy: From litigation to arbitration. International Organization, 55(4): 919-947.

Mayer, K.J., Teece, D. 2008. Unpacking strategic alliances: The structure and purpose of alliance versus supplier relationships. Journal of Economic Behavior and Organization, 66(1): 106-127.

McCulloch, R., Rossi, P.E. 1994. An exact likelihood analysis of the multinomial probit model. Journal of Econometrics, 64(1-2): 207-240.

McGrath, R.G. 1997. A real options logic for initiating technology positioning investments. Academy of Management Review, 22(4): 974-996.

McMillan, G.S., Deeds, D.L. 1998. The role of reputation in the recruitment of scientists. R\&D Management, 28(4): 299-304.

Mellewigt, T., Decker, C., Eckhard, B. 2012. What drives contract design in alliances? Taking stock and how to proceed. Zeitschrift für Betriebswirtschaft, 82: 839-864.

Mowery, D.C., Oxley, J.E., Silverman, B.S. 1996. Strategic alliances and interfirm knowledge transfer. Strategic Management Journal, 17: 77-91.

Mytelka, L.K. 1991. Strategic partnerships and the world economy. London, UK: Pinter Publishers.

Nelson, R.R. 1961. Uncertainty, learning, and the economics of parallel research and development efforts. Review of Economics and Statistics, 43(4): 351-364.

Nelson, R.R. 1982. The role of knowledge in R\&D efficiency. Quarterly Journal of Economics, 97(3): 453-470.

Ness, H., Haugland, S.A. 2005. The evolution of governance mechanisms and negotiation strategies in fixedduration interfirm relationships. Journal of Business Research, 58(9): 1226-1239.

Nickerson, J.A., Zenger, T.R. 2004. A knowledge-based theory of the firm - The problem-solving perspective. Organization Science, 15(6): 617-632. 
Norman, P.M. 2002. Protecting knowledge in strategic alliances. Resource and relational characteristics. Journal of High Technology Management Research, 13: 177-202.

Ohba, M. and Figueiredo, P.N. 2007. Innovative capabilities and strategic alliances: Who is gaining what in the pharmaceutical industry? Journal of Commercial Biotechnology, 13(4): 273-282.

Olsen, G.M., Olsen, J.S. 2000. Distance matters. Human-Computer Interaction, 15(2): 139-178.

Oxley, J.E. 1997. Appropriability hazards and governance in strategic alliances: A transaction cost approach. Journal of Law, Economics, and Organization, 13(2): 387-409.

Oxley, J.E. 1999. Institutional environment and the mechanisms of governance: The impact of intellectual property protection on the structure of inter-firm alliances. Journal of Economic Behavior and Organization, 38(3): 283-309.

Oxley, J.E., Sampson, R. 2004. The scope and governance of international R\&D alliances. Strategic Management Journal, 25(8-9): 723-749.

Oxley, J.E., Wada, T. 2009. Alliance structure and the scope of knowledge transfer: Evidence from U.S.-Japan agreements. Management Science, 55(4): 635-649.

Pakes, A., Nitzan, S. 1983. Optimum contracts for research personnel, research employment, and the establishment of "rival" enterprises. Journal of Labor Economics, 1(4): 345- 365.

Panico, C. 2011. On the contractual governance of research collaborations: Allocating control and intellectual property rights in the shadow of potential termination. Research Policy, 40(11): 1403-1411.

Papke, L.E., Wooldridge, J.M. 1996. Econometric methods for fractional response variables with an application to 401 (k) plan participation rates. Journal of Applied Econometrics, 11(6): 619-632.

Park, S.H., Russo, M.V. 1996. When competition eclipses cooperation: An event history analysis of joint venture failure. Management Science, 42(6): 875-890.

Park, S.H., Ungson, G.R. 2001. Interfirm rivalry and managerial complexity: A conceptual framework of alliance failure. Organization Science, 12(1): 37-53.

Parkhe, A. 1993. Strategic alliance structuring: A game theoretic and transaction cost examination of interfirm cooperation. Academy of Management Journal, 36(4): 794-829.

Phene, A., Tallman, S. 2012. Complexity, context and governance in biotechnology alliances. Journal of International Business Studies, 43: 61-83.

Phillips, D.J. 2002. A genealogical approach to organizational life chances: The parent-progeny transfer among Silicon Valley law firms, 1946-1996. Administrative Science Quarterly, 47(3): 474-506.

Pinkley, R.L., Brittain, J., Naele, M.A., Northcraft, G.B. 1995. Managerial third-party dispute intervention: An inductive analysis of intervenor strategy selection. Journal of Applied Psychology, 80(3): 386-402.

Pisano, G.P. 1989. Using equity participation to support exchange: Evidence from the biotechnology industry. Journal of Law, Economics and Organization, 5(1): 109-126.

Pisano, G.P. 1990. The R\&D boundaries of the firm: An empirical analysis. Administrative Science Quarterly, 35(1): 153-176.

Polzer, J.T., Crisp, C.B., Jarvenpaa, S.L., Kim, J.W. Extending the faultline model to geographically dispersed teams: How collocated subgroups can impair group functioning. Academy of Management Journal, 49(4): 679-692.

Poppo, L., Zenger, T. 2002. Do formal contracts and relational governance function as substitutes or complements? Strategic Management Journal, 23(8): 707-725.

Prevezer, M. 1997. The dynamics of industrial clustering in biotechnology. Small Business Economics, 9: 255271.

Redfern, A. 1976. Arbitration: Myth and reality. International Business Lawyer, 4: 450-453.

Reuer, J.J., Ariño, A. 2007. Strategic alliance contracts: Dimensions and determinants of contractual complexity. Strategic Management Journal, 28(3): 313-330.

Reuer, J.J., Ariño, A., Mellewigt, T. 2006. Entrepreneurial alliances as contractual forms. Journal of Business Venturing, 21(3): 306-325.

Ring, P.S., van de Ven, A.H. 1992. Structuring cooperative relationships between organizations. Strategic Management Journal, 13(7): 483-498. 
Roberts, P.W., Greenwood, R. 1997. Integrating transaction cost and institutional theories: Towards a constrained-efficiency framework for understanding organizational design adoption. Academy of Management Review, 22(2): 346-373.

Robson, M.J., Katsikeas, C.S., Bello, D.C. 2008. Drivers and performance outcomes of trust in international strategic alliances: The role of organizational complexity. Organization Science, 19(4): 647-665.

Roijakkers, N., Hagedoorn, J. 2006. Inter-firm R\&D partnering in pharmaceutical biotechnology since 1975: Trends, patterns, and networks. Research Policy, 35(3): 431-446.

Rond de, M., Bouchikhi, H. 2004. On the dialectics of strategic alliances. Organization Science, 15(1): 56-69.

Rosenkopf, L., Almeida, P. 2003. Overcoming local search through alliances and mobility. Management Science, 49(6): 751-766.

Rothaermel, F.T., Hess, A.M. 2007. Building dynamic capabilities: Innovation driven by individual-, firm-, and network-level effects. Organization Science, 18(6): 898-921.

Rubinstein, J.H. 2004. International commercial arbitration: Reflections at the crossroads of the common law and civil law traditions. Chicago Journal of International Law, 5(1): 303-310.

Ryall, M.D., Sampson, R.C. 2006. Do prior alliances influence alliance contract structure? In A. Arino and J.J. Reuer (Eds.), Strategic alliances: Governance and Contracts: 206-216. Palgrave MacMillan.

Ryall, M.D., Sampson, R.C. 2009. Formal contracts in the presence of relational enforcement mechanisms: Evidence from technology development projects. Management Science, 55(6): 906-925.

Salbu, S.R. 1997. Evolving contract as a device for flexible coordination and control. American Business Law Journal, 34(3): 329-384.

Sampson, R. 2004a. Organizational choice in R\&D alliances: Knowledge-based and transaction cost perspectives. Managerial and Decision Economics, 25(6-7): 421-436.

Sampson, R. 2004b. The cost of misaligned governance in R\&D alliances. The Journal of Law, Economics and Organization, 20(2): 484-526.

Sarkar, M.B., Echambadi, R., Tamer Cavusgil, S., Aulakh, P.S. 2001. The influence of complementarity, compatibility, and relationship capital on alliance performance. Journal of the Academy of Marketing Science, 29(4): 358-373.

Saxenian, A. 1994. Regional advantage: Culture and competition in Silicon Valley and Route 128. Cambridge, MA, and London: Harvard University Press.

Schilke, O., Goerzen, A. 2010. Alliance management capability: An investigation of the construct and its measurement. Journal of Management, 36(5): 1192-1219.

Schoenmakers, W., Duysters, G. 2006. Learning in strategic technology alliances. Technology Analysis and Strategic Management, 18(2): 245-264.

Schreiner, M., Kale, P., Corsten, D. 2009. What really is alliance management capability and how does it impact alliance outcomes and success? Strategic Management Journal, 30(13): 1395-1419.

Shan, W., Song, J. 1997. Foreign direct investment and the sourcing of technological advantage: Evidence from the biotechnology industry. Journal of International Business Studies, 28(2): 267-284.

Shan, W., Walker, G., Kogut, B. 1994. Interfirm cooperation and startup innovation in the biotechnology industry. Strategic Management Journal, 15(5): 387-394.

Shelanski, H.A., Klein, P.G. 1995. Empirical research in transaction cost economics: A review and assessment. The Journal of Law, Economics and Organization, 11(2): 335- 361.

Sheppard, B.H. 1983. Managers as inquisitors: Some lessons from the law. In M.H. Bazerman and R.J. Lewicki (Eds.), Negotiating in Organizations: 193-213. Beverly Hills: Sage Publications.

Sheppard, B.H. 1984. Third party conflict intervention: A procedural framework. In B.M. Staw and L.L. Cummings (Eds.), Research in Organizational Behavior: 141-190. Greenwich, CT: JAI Press.

Simon, H.A. 1976. Administrative behavior. New York, NY: The Free Press.

Singh, J. 2008. Distributed R\&D, cross-regional knowledge integration and quality of innovative output. Research Policy, 37(1): 77-96.

Sirmon, D.G., Lane, P.J. 2004. A model of cultural differences and international alliance performance. Journal of International Business Studies, 35(4): 306-319.

Slaby, D.W., Chapman, J.C., O’Hara, G.P. 1989. Trade secret protection: An analysis of the concept "efforts reasonable under the circumstances to maintain secrecy". Computer and High Technology Law Journal, 5: 321-348. 
Slater, G., Spencer, D.A. 2000. The uncertain foundations of transaction cost economics. Journal of Economic Issues, 34(1): 61-87.

Smith, A. (1776) 1979. The wealth of nations. Edited by Andrew Skinner. Baltimore: Penguin.

Smith, K., Huang, J. 1995. Can markets value air quality? A meta-analysis of hedonic property value models. Journal of Political Economy, 103(1): 209-227.

Sobrero, M., Roberts, E.B. 2002. Strategic management of supplier-manufacturer relations in new product development. Research Policy, 31(1): 159-182.

Somaya, D., Williamson, I.O., Lorinkova, N. 2008. Gone but not lost: The different performance impacts of employee mobility between cooperators versus competitors. Academy of Management Journal, 51(5): 936-953.

Stinchcombe, A.L. 1987. Constructing social theories. Chicago, IL: University of Chicago Press.

Stuart, T.E. 2000. Interorganizational alliances and the performance of firms: A study of growth and innovation rates in a high-tech industry. Strategic Management Journal, 21(8): 791-811.

Stuart, T.E., Ozdemir, S.Z., Ding, W.W. 2007. Vertical alliance networks: The case of university-biotechnologypharmaceutical alliance chains. Research Policy, 36(4): 477- 498.

Swann, P., Prevezer, M. 1996. A comparison of the dynamics of industrial clustering in computing and biotechnology. Research Policy, 25(7): 1139-1157.

Teece, D.J. 1977. Technology transfer by multinational firms: The resource cost of transferring. The Economic Journal, 87: 242-261.

Torre, A., Rallet, A. 2005. Proximity and localization. Regional Studies, 39(1): 47-59.

Tushman, M.L. 1977. Special boundary roles in the innovation process. Administrative Science Quarterly, 22(4): 587-605.

Ven van de, A.H., Delbecq, A.L., Koenig, R. 1976. Determinants of coordination modes within organizations. American Sociological Review, 41(2): 322-338.

Wang, Q., von Tunzelmann, N. 2000. Complexity and the functions of the firm: Breadth and depth. Research Policy, 29(7-8): 805-818.

Ware, S. 2001. Paying the price of process: Judicial regulation of consumer arbitration agreements. Journal of Dispute Resolution, 1: 89-101.

Weber, L., Mayer, K.J., Macher, J.T. 2011. An analysis of extendibility and early termination provisions: The importance of framing duration safeguards. Academy of Management Journal, 54(1): 182-202.

Wezel, F.C., Cattani, G., Pennings, J.M. 2006. Competitive implications of interfirm mobility. Organization Science, 17(6): 691-709.

Whittington, K.B., Owen-Smith, J., Powell, W.W. 2009. Networks, propinquity, and innovation in knowledgeintensive industries. Administrative Science Quarterly, 54(1): 90-122.

Williamson, O.E. 1979. Transaction-cost economics: The governance of contractual relations. Journal of Law and Economics, 22(2): 233-261.

Williamson, O.E. 1981. The economics of organization: The transaction cost approach. American Journal of Sociology, 87(3): 548-577.

Williamson, O.E. 1985. The economic institutions of capitalism. New York, NY: The Free Press.

Williamson, O.E. 1991. Comparative economic organization: The analysis of discrete structural alternatives. Administrative Science Quarterly, 36(2): 269-296.

Williamson, O.E. 1992. Markets, hierarchies, and the modern corporation. Journal of Economic Behavior and Organization, 17: 335-352.

Williamson, O.E. 1993. Calculativeness, trust, and economic organization. Journal of Law and Economics, 36(1): 453-486.

Williamson, O.E. 1994. Visible and invisible governance. American Economic Review, 84(2): 323-326.

Williamson, O.E. 1996. Revisiting legal realism: The law, economics, and organization perspective. Industrial and Corporate Change, 5(2): 383-420.

Williamson, O.E. 1999. Strategy research: Governance and competence perspectives. Strategic Management Journal, 20: 1087-1108.

Wooldridge, J.M. 2003. Cluster-sample methods in applied econometrics. American Economic Review, 93(2): 133-138. 
Younge, K.A. 2012. Science and the mobility discount: Evidence from initial public offerings. Working paper.

Zona, F., Zattoni, A., Minichilli, A. 2012. A contingency model of boards of directors and firm innovation: The moderating role of firm size. British Journal of Management: 1-17.

Zucker, L.G. 1986. Production of trust: Institutional sources of economic structure, 1840-1920. Research in Organizational Behavior, 8: 53-111.

Zucker, L.G., Darby, M.R. 1997. Present at the biotechnological revolution: Transformation of technological identity for a large incumbent pharmaceutical firm. Research Policy, 26(4-5): 429-446. 



\section{Samenvatting}

Deze dissertatie bevat vier empirische studies op het gebied van onderzoeks- en ontwikkelingsallianties (R\&D-allianties) en bijbehorende contracten in de biotechnische en farmaceutische industrie. In elk van de vier empirische studies hier beschreven, behandel ik een specifiek aspect van R\&D-alliantiecontracten. Mijn algemene onderzoeksvraag luidt als volgt: welke factoren bepalen, of zijn geassocieerd met, de manier waarop R\&Dalliantiecontracten tussen bedrijven worden vormgegeven? Om deze onderzoeksvraag te beantwoorden tracht ik vier, meer specifieke, vragen te beantwoorden, namelijk:

Hoe beïnvloedt de onderhandelingspositie van het bedrijf, dat initieel de bulk van de technologie aanlevert voor een verdere coöperatie, het aantal controlerechten met betrekking tot intellectueel eigendom (IP), zoals bepaald in het R\&D-alliantiecontract, dat dit bedrijf uiteindelijk verkrijgt?

Welke factoren beïnloeden de mate waarin contractpartijen de nadruk leggen op coördinatie in een $R \& D$-alliantiecontract?

Welke factoren beïnvloeden de beslissing van partijen om bepaalde dispuut resolutie clausules op nemen in een $R \& D$-alliantiecontract?

Welke factoren beïnvloeden de beslissing van contractpartijen om elkaars rekruteringsbeleid via een $R \& D$-alliantiecontract tijdens, en vaak na, een samenwerking te beperken?

Om deze vier vragen te beantwoorden maak ik gebruik van een deelverzameling van bedrijven die tussen 1996 en 2005 een samenwerkingsverband op het gebied van R\&D afsloten in de biotechnische en/of farmaceutische industrie en hiervoor een contract opstelde. Zoals reeds eerder genoemd, onderzoekt de eerste studie in essentie hoe de onderhandelingspositie van een bedrijf van invloed is op het aantal controlerechten dat dit bedrijf verkrijgt, zoals bepaald in een R\&D-alliantiecontract. Controlerechten geven een bedrijf bepaalde rechten met betrekking tot eigendom en/of het maken van beslissingen. De studie is gebaseerd op het idee dat bedrijven in een sterkere onderhandelingspositie gunstigere contractvoorwaarden kunnen uitonderhandelen. Vergeleken met voorgaande studies onderzoek ik (1) een meer specifieke set van controlerechten, id est, IP-controlerechten, en (2) een breder scala aan factoren die bijdragen aan een sterkere onderhandelingspositie voor een bedrijf, (3) welke ik bekijk vanuit het perspectief van het bedrijf dat initieel de bulk van de technologie aanlevert als basis voor een verdere samenwerking. De empirische resultaten in hoofdstuk 2 lijken te bevestigen dat bedrijven in een sterkere onderhandelingspositie gunstigere contractvoorwaarden kunnen bedingen. Ten eerste behouden meer innovatieve bedrijven meer IP-controlerechten. Innovatieve bedrijven zijn vaak cruciaal voor het succes van R\&D-allianties en staan dus in een sterkere positie om meer IP-controlerechten te eisen. Ten tweede behouden de bedrijven die initieel de bulk van de technologie inbrengen, meer IPcontrolerechten als de technologie meer toepassingsgebieden kent. De implicatie is dat de onderhandelingspositie van bedrijven niet alleen bepaald wordt door hun grootte, maar ook door de innovatieve kracht en de technologie die ze inbrengen. 
De tweede studie onderzoekt welke factoren bijdragen aan het bepalen van meer of minder contractuele mechanismen, id est, coördinatiecommissies, die de coördinatie tussen partijen gedurende hun samenwerking zou moeten bevorderen. Ik karakteriseer allianties daarbij op een meer coöperatieve manier vergeleken met voorgaande studies. Enkele wetenschappers suggereren dat een tekort aan coördinatie tussen partijen kan leiden tot het uiteindelijke falen van een alliantie. Omdat contracten nooit compleet zijn, is het van belang dat alliantiepartijen bepaalde contractuele mechanismen bepalen die het mogelijk maken om in een later stadium - als nieuwe informatie beschikbaar komt - bepaalde veranderingen te implementeren. Voorgaande impliceert dat hoofdstuk 3 afstand neemt van klassieke contracttheorieën waarin contracten worden beschreven als alomvattende documenten welke naadloos huidige en toekomstige omstandigheden beschrijven. Voorspellingen met betrekking tot het aantal coördinatie commissies welke partijen bepalen zijn gebaseerd op relevante literaturen op het gebied van coördinatie binnen bedrijven, geografische afstand en alliantie management leerprocessen. Hoofdstuk 3 presenteert drie bevindingen. Ten eerste, bepalen partijen meer coördinatie commissies in contracten wanneer de complexiteit van de alliantie groter is, id est, wanneer partijen behalve R\&D nog andere activiteiten uitvoeren. Echter, additionele analyses suggereren dat dit mogelijk niet geldt voor alle additionele activiteiten. Ten tweede, extrapoleer ik bevindingen op het gebied van coördinatie binnen bedrijven naar coördinatie tussen bedrijven door empirisch te bevestigen dat partijen geneigd zijn meer coördinatie commissies vast te leggen in hun contract als ze voor de uitvoering van hun activiteiten meer afhankelijk van elkaar zijn. Ten derde wijzen de empirische resultaten uit dat partijen met meer alliantie-ervaring meer coördinatie commissies bepalen. Additionele analyses laten bovendien een interessante nevenbevinding zien: directe concurrenten die samenwerken in R\&D en waar bovendien geen van beide partijen een minderheidsbelang in de andere partij heeft, bepalen minder coördinatie commissies. Dit zou erop kunnen duiden dat concurrenten bewust het aantal contactpunten minimaliseren om zo het risico op ongewenste kennisstromen te verlagen.

De derde studie onderzoekt welke factoren ten grondslag liggen aan de keuze van alliantiepartijen om specifieke dispuut resolutie clausules te implementeren in een R\&Dalliantieovereenkomst. Veel wetenschappers suggereren dat, en beschrijven hoe, contract partijen vaak zelf in staat zijn disputen op te lossen door middel van idiosyncratische dispuut resolutie mechanismen. Partijen kunnen er bijvoorbeeld voor kiezen om disputen intern op te lossen via hiërarchie en/of via arbitrage. Beide methoden hebben voor- en nadelen. Een voordeel van interne dispuut resolutie via hiërarchie is dat partijen facetten kunnen laten meewegen in hun beslissing die normaal gesproken ontoelaatbaar als bewijs zouden zijn. Bovendien is interne dispuut resolutie vaak amicaal van karakter. Als partijen voor arbitrage kiezen, betekent dit dat toekomstige disputen beslist worden door particuliere rechters. Twee voordelen van arbitrage zijn dat (1) de partijen minder afhankelijk zijn van een specifiek rechtssysteem en (2) dat arbitrage zittingen en uitspraken in principe confidentieel zijn. Hoofdstuk 4 toetst in essentie twee ideeën. Ten eerste, de voordelen van interne dispuut resolutie via hiërarchie doen vermoeden dat partijen vaker voor dit soort dispuut resolutie zullen kiezen in een R\&D-contract wanneer de technologische complexiteit van een alliantie hoog is, of wanneer er vooraf geen specifieke einddatum van de samenwerking is afgesproken. De empirische resultaten bevestigen deze vermoedens. Ten tweede, gezien de voordelen van arbitrage, lijkt het aannemelijk dat partijen kiezen voor arbitrage wanneer ze gesitueerd zijn in verschillende landen, id est, internationale allianties, wanneer beide 
rechtssystemen minder op elkaar lijken en wanneer tenminste één van de deelnemende bedrijven in een alliantie recentelijk een spectaculaire groei heeft doorgemaakt. De empirische resultaten bevestigen de eerste en derde verwachting. Aangezien disputen tussen alliantiepartijen frequent voorkomen in complexe en onzekere omgevingen, kunnen bovengenoemde resultaten een belangrijke bijdrage leveren aan bestaande kennis met betrekking tot alternatieve dispuut resolutie mechanismen in de context van R\&D-allianties in de biofarmaceutische industrie.

De vierde en laatste empirische studie onderzoekt welke factoren bijdragen aan de beslissing van contractpartijen om elkaars rekruteringsbeleid via een R\&D-alliantiecontract tijdens, en vaak na, een samenwerking te beperken. Een alliantie wordt gekenschetst door zowel competitieve als coöperatieve elementen. Een voorbeeld van een competitief element is opportunistisch rekruteringsbeleid waarbij partijen elkaars medewerkers actief benaderen en aanzetten tot het verlaten van hun huidige werkgever. Dit risico is groot, omdat een alliantie de informatieasymmetrie tussen partijen verkleint en het derhalve eenvoudig maakt elkaars waardevolle medewerkers te identificeren. De studie neemt daarom aan dat bedrijven contractuele beperkingen ten aanzien van elkaars rekruteringsbeleid implementeren wanneer de risico's en kosten met betrekking tot ongewenste mobiliteit van medewerkers substantieel zijn. Echter, de studie stelt ook dat partijen beperkt worden door de omgeving waarin zij opereren. De resultaten geven aan dat de waarschijnlijkheid waarmee alliantiepartijen contractuele restricties ten aanzien van hun rekruteringsbeleid implementeren een functie is van (1) de omgeving waarin partijen zich bevinden en (2) de wetenschappelijke oriëntatie van deelnemende bedrijven aan een R\&D-alliantie. Bovendien geven de resultaten aan dat contractuele restricties met betrekking tot rekruteringsbeleid vaak verrassend breed geconstrueerd zijn, id est, ook medewerkers die niet direct betrokken zijn bij een R\&Dalliantie kunnen mogelijk (negatieve) effecten ondervinden van contractuele restricties met betrekking tot de mobiliteit van medewerkers tussen alliantiepartijen.

De vier empirische studies illustreren dat bedrijven die participeren in een R\&Dsamenwerkingsverband verscheidene contractuele opties hebben om hun collaboratie vorm te geven. Een eenzijdige focus op contractuele complexiteit van R\&D-allianties mist veel (contractuele) nuances die ik heb getracht in deze dissertatie (deels) te extraheren. 



\section{Biographical Sketch}

Bart (Leonardus Elisabeth) Dormans was born on July $26^{\text {th }}$, 1985 in Geleen, the Netherlands. He holds a master's degree in Innovation Management (Cum Laude) and a bachelor's degree in Industrial Engineering and Management Science from Eindhoven University of Technology. In September 2009 he joined the department of Organization and Strategy as a $\mathrm{PhD}$ Candidate in the field of alliances and contracts. Bart was a visiting doctoral researcher at the Graduate School of Arts and Sciences at Harvard University in Cambridge, Massachusetts. Parts of this dissertation have been presented at various occasions, including seminars at the Copenhagen Business School (Denmark), Grenoble Graduate School of Business (France), Imperial College London (UK), KU Leuven (Belgium), Sorbonne Graduate Business School (France), Tilburg University (the Netherlands), and the 2011 American Law and Economics Association conference at Columbia University (US), the 2011 Society for Empirical Legal Studies conference at Yale University (US), the 2012 Academy of Management conference in Boston (US), the 2012 Canadian Law and Economics conference at the University of Toronto (Canada), and the 2011 workshop of the European School on New Institutional Economics (France). Bart will be working as a consultant in financial risk management at Capgemini Consulting as of December 2013. 